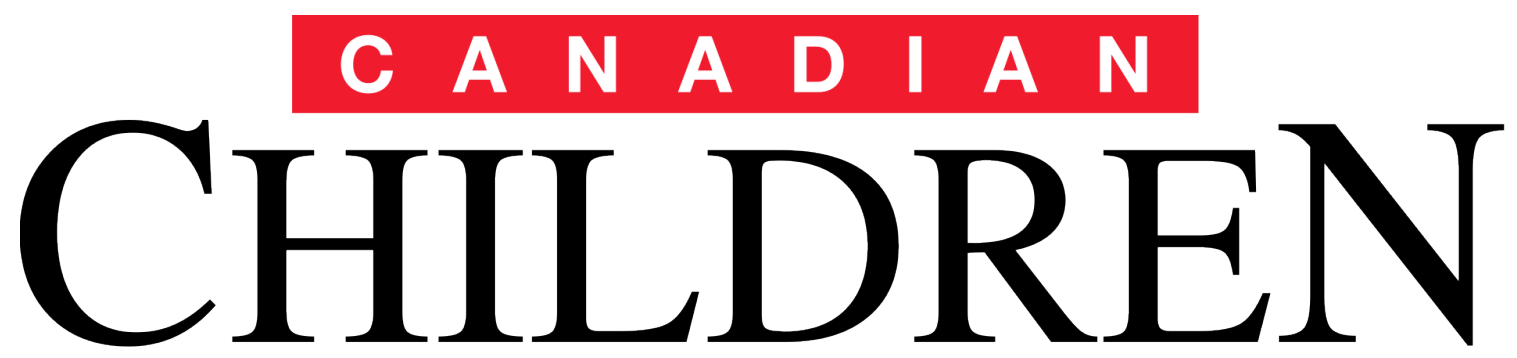

JOURNAL OF THE CANADIAN ASSOCIATION FOR YOUNG CHILDREN

Spring 2015/Printemps 2015

Vol. 40 No. 2

Special Issue:

Learning How to Inherit Colonized and Ecologically Challenged Lifeworlds

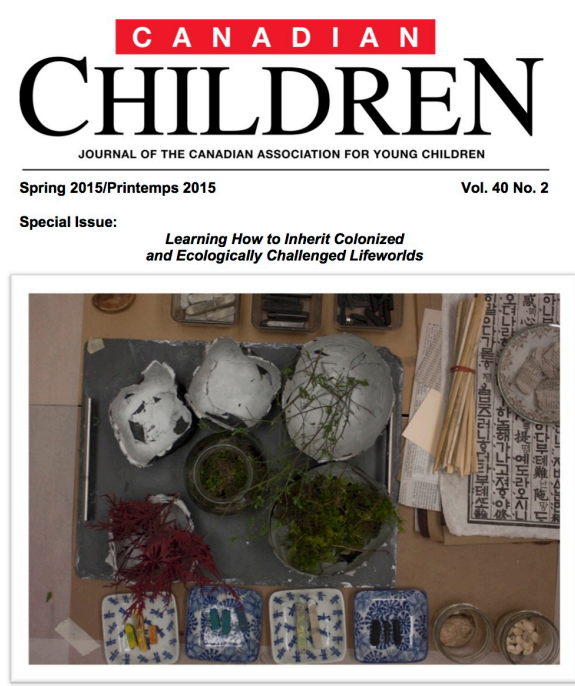

Editors:

Dr. Laurie Kocher, Douglas College,

Coquitlam, British Columbia and

Dr. Veronica Pacini-Ketchabaw, University of Victoria,

Victoria, British Columbia

Guest Editors, Special Issue: Learning How to Inherit Colonized and Ecologically Challenged Lifeworlds

Dr. Veronica Pacini-Ketchabaw

Dr. Affrica Taylor

Dr. Mindy Blaise

Dr. Sandrina de Finney

Publications Chairperson:

Dr. Iris Berger, University of British Columbia, Vancouver, British Columbia

Cover Photo: Dr. Sylvia Kind

(C) 1996: The Canadian Association for Young Children ISSN: 0833-7519

Author Guidelines: visit www.cayc.ca

Published with support from the

Social Sciences and Humanities Research Council of Canada

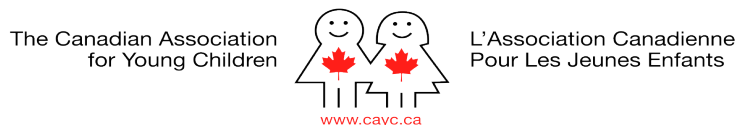




\section{In this issue:}

From the Editors' Desk:

Learning how to inherit (in) colonized and ecologically challenged lifeworlds in early childhood education: An introduction

Guest Editors: Dr. Veronica Pacini-Ketchabaw, Dr. Affrica Taylor, Dr. Mindy Blaise, and Dr.

Sandrina de Finney page 3

Possibilities for Geontological Learning in Common Worlds

by Emily Ashton

page 9

Entangled Frictions with Place as Assemblage

by Sherri-Lynn Yazbeck and Ildikó Danis

page 22

The Colour of Country

by Adam Duncan

page 32

Engaging With the Messiness of Place: Exploring Animal Relations, Traditional Hide, and Drum

by Narda Nelson, Emily Coon, and Anna Chadwick

page 42

Walking with Place

by Catherine Hamm

page 56

Wasps-bees-mushrooms-children

by Kim Atkinson

page 67

Entangled Dialogues on Learning How to Inherit

by Fikile Nxumalo, Sera Oh, Jacky Hughes, \& Saaiqa Bhanji

page 80

Wanderings with Waste

by B. Denise Hodgins

page 88 


\section{From the Editors' Desk}

\section{Learning How to Inherit in Colonized and Ecologically Challenged Life Worlds in Early Childhood Education: An Introduction}

\section{By Veronica Pacini-Ketchabaw, Affrica Taylor, Mindy Blaise, and Sandrina de Finney}

The complex and intensifying ecological challenges of the $21^{\text {st }}$ century call for new ways of thinking, being, and doing in all sectors of our society, including early childhood education, and the Aboriginal environmental humanities offer alternative ways of being present and acting in the world. Accordingly, in September 2014 we gathered for three days in Victoria, British Columbia, with leading Indigenous and environmental humanities scholars and a group of 40 early childhood scholars, educators, and students to mobilize these perspectives in the early education of young children. This special issue presents eight articles inspired by the conversations that took place at the "Learning How to Inherit in Colonized and Ecologically Challenged Life Worlds" symposium. ${ }^{1}$

Like the articles in this special issue, the symposium covered topics such as place and agency in Indigenous cosmologies, Canada's waste legacies, cohabiting with other species in a time of mass extinctions, and Indigenous modes of inheritance, from new to old in a time of immateriality and precarity. ${ }^{2}$ Early childhood scholars and educators (including the authors in this special issue) considered how they might respond to these issues in their work with young children within their local "common world" environments by addressing:

- the responsibility of early childhood education to address intergenerational ecological justice in the Anthropocene (see Ashton; Duncan; Nelson, Coon, \& Chadwick; Hamm; and Nxumalo Oh, Hughes, \& Bhanji)

- the pedagogical significance of Aboriginal and non-Aboriginal children's relations with place, plants, and animals (see Duncan; Hamm; and Nxumalo Oh, Hughes, \& Bhanji)

- the pedagogical significance of place and belonging in early childhood education (see Ashton; Yazbeck \& Danis; Duncan; Hamm; and Atkinson)

- pedagogical strategies for dealing with waste in early childhood settings (see Hodgins)

- the ethics of young children's relationships with animals that are threatened and/or not easy to live with (see Atkinson; and Nxumalo Oh, Hughes, \& Bhanji)

\footnotetext{
${ }^{1}$ This symposium, organized by the Common World Childhoods Research Collective, was funded by the Canadian Social Science and Humanities Research Council, the Centre for Global Studies (University of Victoria, $\mathrm{BC}$ ), and the Centre for Asian and Pacific Research Initiatives (University of Victoria, BC).

${ }^{2}$ Keynotes are available on our Common World Childhoods Research Collective website at http://commonworlds.net/
} 
The discussions in the symposium were inspired by the collaborations that the authors and we (editors) are engaged in through the Common World Childhoods Research Collective, a network of practitioners concerned with children's relations with the more-than-human world. In the rest of this introduction, we introduce the framing ideas that the authors deploy from these collaborations.

Exciting new dialogues and synergies have recently emerged among the Aboriginal and environmental humanities, motivated by the intensifying ecological challenges we all now face. Scholars in the Aboriginal and environmental humanities (Battiste, 2002; Haraway, 2008; Hird, 2012, 2013; Povinelli, 2012a, 2012b; Rose, 2013; Watts, 2013) increasingly refer to the Anthropocene, a new geological era in which human activities have fundamentally changed the earth's systems (Steffen et al., 2007). The premise of these dialogues is that we cannot carry on as we have in the past - we need to find new ways of thinking, acting, and relating to the rest of the world as human beings. Scholars in the Aboriginal and environmental humanities, often in consultation with Aboriginal communities, are leading the way in theorizing the social, cultural, and ethical implications of the interdependencies and mutual vulnerabilities of humans, other life forms, and the earth's geo-ecological systems. They challenge us to learn "how to inherit" (Haraway, 2012) these entangled legacies. They also call for rethinking the human as an integral part of geo-ecological systems, and repositioning geo-ecological systems within the domain of ethics and responsibility (Rose et al., 2012).

The challenges of the Anthropocene have clear implications for the field of early childhood education. Children in contemporary early childhood settings are inheriting increasingly complex and challenging common worlds, but mainstream Euro-Western pedagogies seldom support children to engage meaningfully with them. Primarily informed by Piaget's (1928) early $20^{\text {th }}$-century child developmental theories, $21^{\text {st }}$-century Western early childhood education is resolutely committed to individually focused child-centred learning (Blaise, 2010; Pacini-Ketchabaw, 2011). Such understandings are incommensurable with Indigenous notions of the inseparable connectedness of children and the world (Martin, 2007; Ritchie \& Rau, 2010), and conflict with contemporary ecological understandings of human embeddedness in the environment that we addressed above.

Because these developmental theories stem from the same "progress and development" thinking that drove European colonization and precipitated the human-caused ecological crisis we now face, they cannot accommodate the paradigm shift we seek for $21^{\text {st }}$-century children (Pacini-Ketchabaw \& Taylor, forthcoming; Taylor, Blaise, \& Giugni, 2013; Taylor, PaciniKetchabaw, \& Blaise, 2012). This is not to say that child development theory is oblivious to contemporary environmental concerns. Within the overarching field of developmental psychology, exponents of direct nature experiences in early childhood (Dau, 2005; Davis, 2010; Elliott, 2008; Wilson, 2011) argue that environmental education promotes children's physical and emotional development and encourages young children to form the emotional attachments with nature that are necessary for environmental stewardship (Chawla, 2006; Sobel, 2008).

Boosted by rising concerns about the threat of "nature-deficit disorder" in the digital age (Louv, 2008), many Canadian early childhood educators look to northern Europe's "all- 
weather outside" or nature kindergartens (Änggård, 2010; Warden, 2010) as models of naturebased education. Replica forest and nature kindergartens are increasingly popular in Canada (Pelo, 2013). However, these programs are seldom attuned to the post- and neocolonial complexities of Canadian "natures" or to the interrelated Indigenous, ecological, and justice perspectives we wish to pursue. While playing an important role in promoting children's embodied learning "in nature," most nature kindergartens remain firmly rooted in Western developmental psychology and dualistic, romantic, and idealized Euro-Western notions of nature as separate from culture (Pacini-Ketchabaw, 2013; Taylor, 2013). The time is ripe to develop early childhood pedagogies that are situated within, and respond to, children's lifeworlds.

The articles in this special issue build on the common worlds conceptual framework that we have extrapolated elsewhere (Common World Childhoods Research Collective, 2015; PaciniKetchabaw, 2012; Taylor, 2013; Taylor \& Giugni, 2012). Children's common worlds consist of the full gamut of complex relationships, traditions, and legacies that they inherit in the places in which they grow up. These include children's relationships with their immediate natural and built environments, with the other human and nonhuman beings that share these same environments, and, in settler societies such as Canada, with complex cultural, colonial, and environmental historical traditions and legacies. This inclusive framework resists the nature/culture divide and situates childhoods within entangled human and nonhuman, Indigenous and non-Indigenous, social and environmental issues and concerns. Common worlds differ from the idealized natural worlds usually associated with Romantic Euro-Western traditions of nature and childhood (Taylor, 2013). They are the actual, messy, unequal, and imperfect worlds real children inherit and co-inhabit along with other human and nonhuman beings and entities.

The articles draw particular inspiration from Donna Haraway's $(2008,2011)$ modest and grounded eco-philosophies, which entreat us to learn how to inherit and co-inhabit our entangled multispecies worlds and to respond and act in these worlds in ways that allow all to flourish. In working to make the world more sustainable and liveable for all, Haraway (2013) urges us to resist the heroic human rescue and salvation responses to the ecological challenges we face. Instead of seeking techno-fixes and grand solutions to the problems we have created, she urges us to attend to the small, mundane, seemingly insignificant everyday relations in our immediate worlds. Haraway (2008) proposes that by attending to our on-ground everyday small encounters with others (including animals, plants, and places), we can learn to become "more worldly with" these others. She highlights our need to recognize how the world affects us and acts on us - even as we act on it. The authors enact such paradigm-shifting approaches and learnings.

We hope that the articles in this special issue mobilize these interdisciplinary, cross-sector conversations to explore how to rethink early childhood education in response to the new synergies across the Aboriginal and environmental humanities. We also hope that the articles assist early childhood educators to engage meaningfully with the social and ecological challenges that are the legacies of colonialism, so that they can help children to learn how to inherit these challenges 


\section{References}

Änggård, E. (2010). Making use of "nature" in an outdoor preschool: Classroom, home, and fairyland. Children, Youth, and Environments, 20(1), 4-25.

Battiste, M. (2002). Reclaiming indigenous voice and vision. Vancouver, BC: UBC Press.

Blaise, M. (2010). Creating a postdevelopmental logic for mapping gender and sexuality in early childhood. In S. Edwards \& L. Brooker (Eds.), Engaging play (pp. 80-95). Buckingham, UK: Open University Press.

Chawla, L. (2006). Learning to love the environment enough to protect it. Barn, 2, 57-78.

Common World Childhoods Research Collective. (2015). Common world childhoods and pedagogies. Retrieved from: http://www.commonworlds.net/

Dau, E. (Ed.). (2005). Taking early childhood education outdoors. Croydon, Australia: Tertiary Press.

Davis, J. (Ed.). (2010). Young children and the environment: Early education for sustainability. Port Melbourne, Australia: Cambridge University Press.

Elliott, S. (Ed.). (2008). The outdoor playspace-naturally-for children birth to five years. Castle Hill, Australia: Pademelon Press.

Haraway, D. (2008). When species meet. Minneapolis, MN: University of Minnesota Press.

Haraway, D. (2011). Speculative fabulations for technoculture's generations: Taking care of unexpected country. Australian Humanities Review, 50, 95-118.

Haraway, D. 2013. Distinguished lecture. Arizona State University, Institute for Humanities Research [video]. Retrieved from: http://ihr.asu.edu/news-events/news/2013distinguished-lecturer-donna-haraway-reading-group

Hird, M. J. (2012). Animal, all too animal: Toward an ethic of vulnerability. In A. Gross \& A. Vallely (Eds.), Animal others and the human imagination (pp. 331-348). New York, NY: Columbia University Press.

Hird, M. J. (2013). Waste, landfills, and an environmental ethics of vulnerability. Ethics and the Environment, 18(1), 105-124.

Louv, R. (2008). Last child in the woods: Saving our children from nature-deficit disorder (2 ${ }^{\text {nd }}$ ed.). Chapel Hill, NC: Algonquin.

Martin, K. (2007). Ma(r)king tracks and reconceptualising Aboriginal early childhood education: An Aboriginal Australian perspective. Childrenz Issues, 11(1), 15-20. 
Pacini-Ketchabaw, V. (2011). Developmental theories and child and youth care. In A. Pence \& J. White (Eds.), New perspectives in child and youth care (pp. 19-32). Vancouver, BC: UBC Press.

Pacini-Ketchabaw, V. (2012). Postcolonial entanglements: Unruling stories. Child \& Youth Services, 33, 313-316.

Pacini-Ketchabaw, V. (2013). Frictions in forest pedagogies: Common worlds in settler colonial spaces. Global Studies of Childhood, 3(4), 355-365.

Pacini-Ketchabaw, V., \& Taylor, A. (forthcoming), Unsettling pedagogies: Grappling with (post)colonial legacies in Canadian forests and Australian bushlands. In V. PaciniKetchabaw \& A. Taylor (Eds.), Unsettling the colonialist places and spaces of early childhood education. New York, NY: Routledge.

Pelo, A. (2013). The goodness of rain: Developing an ecological identity in young children. Redmond, WA: Exchange Press.

Piaget, J. (1928). The child's conception of the world. London, UK: Routledge \& Kegan Paul.

Povinelli, E. A. (2012a). The will to be otherwise/The effort of endurance. South Atlantic Quarterly, 111(3), 453-475.

Povinelli, E. A. (2012b). After the last man: Images and ethics of becoming otherwise. $e-f l u x$, $35,1-9$.

Ritchie, J., \& Rau, C. (2010). Kia mauki te wairuatanga: Countercolonial narratives of early childhood education in Aotearoa. In G. S. Cannella \& L. Diaz Soto (Eds.), Childhoods: A handbook (pp. 355-374). New York, NY: Peter Lang.

Ritchie, J., \& Skerrett, M. (2014). Early childhood education in Aotearoa New Zealand: History, pedagogy, and liberation. New York, NY: Palgrave Macmillan.

Rose, D. B. (2000). Dingo makes us human. Cambridge, UK: University of Cambridge Press.

Rose, D. B. (2004). Reports from a wild country: Ethics for decolonization. Sydney, Australia: University of New South Wales Press.

Rose, D. B. (2011). Wild dog dreaming: Love and extinction. Charlottesville, VA: University of Virginia Press.

Rose, D. B. (2013). Multispecies belonging in the time of extinctions. Public lecture, Australian Studies Research Network 2013 Seminar Series, History House, Sydney, Australia, May 10, 2013.

Sobel, D. (2008). Children and nature: Design principles for educators. Portland, ME: Stenhouse. 
Steffen, W., Crutzen, P. J., \& McNeill, J. R. (2007). The Anthropocene: Are humans now overwhelming the great forces of nature? Ambio, 36, 614-621.

Taylor, A. (2013). Reconfiguring the natures of childhood. London, UK: Routledge.

Taylor, A., Blaise, M., \& Giugni, M. (2013). Haraway’s “bag lady story-telling”: Relocating childhood and learning within a 'post-human landscape.' Discourse: Studies in the Cultural Politics of Education, 34(1), 48-62.

Taylor, A., \& Giugni, M. (2012). Common worlds: Reconceptualising inclusion in early childhood communities. Contemporary Issues in Early Childhood Education, 13(2), $108-120$.

Taylor, A., Pacini-Ketchabaw, V., \& Blaise, M. (2012). Children's relations with the morethan-human world. Contemporary Issues in Early Childhood, 13(2), 81-85.

Warden, C. (2010). Nature kindergartens: An exploration on naturalistic learning within nature kindergartens and forest schools. Perthshire, UK: Mindstretchers.

Watts, V. (2013). Indigenous place-thought and agency amongst humans and non humans (First Woman and Sky Woman go on a European world tour!). Decolonization, 2(1). Retrieved from: http://decolonization.org/index.php/des/article/view/19145

Wilson, R. A. (2011, May/June). Becoming whole: Developing an ecological identity. Wonder. Retrieved from: http://ccie-media.s3.amazonaws.com/nacc/wonder_may11.pdf 


\title{
Possibilities for Geontological Learning in Common Worlds
}

\section{By Emily Ashton}

\begin{abstract}
Author's Bio
Emily Ashton is pursuing a doctoral degree in child and youth care at the University of Victoria. She is interested in how child-figures, figurations of childhood, and early childhood imaginaries entangle to create particular worlds. She is a graduate of the Critical Studies in Education master's program at the University of New Brunswick, where she completed a thesis titled Governing New Brunswick Early Learning and Child Care: Ethical and Political Tensions. Email: eashton@uvic.ca
\end{abstract}

\begin{abstract}
In this article I examine the productive relations between Elizabeth Povinelli's notion of learning-how and the pedagogical provocations proposed by the Common World Childhoods Research Collective. First, I encourage a move from thinking about the child as subject-object-other of early childhood education to thinking about relational becomings in common worlds. Second, I draw on Povinelli's work to propose a form of geontological learning that shifts from learning-about to learning-with a range of existents. Geontological learning attends to the thick enmeshment of nonhuman geographies, more-than-human existents, and human lives in the quirky, messy, complex common worlds we co-inhabit.
\end{abstract}

In her presentation at the "Learning How to Inherit in Colonized and Ecologically Challenged Lifeworlds" symposium (University of Victoria, September 26-28, 2014), Elizabeth Povinelli (2014) asked us to pay particular attention to the learning-how component of the event title. ${ }^{3}$ In contemplating the possibilities of learning-how for early childhood education, this article makes two related moves. In the first section, I think through the shifts that might be necessary to engage with the pedagogies proposed by the Common World Childhoods Research Collective (http://commonworlds.net/; Taylor, Pacini-Ketchabaw, \& Blaise, 2012), including a move from thinking about the child as subject-object-other to "thinking about the ongoing ethics and politics of living in heterogeneous (human and more-than-human) common worlds" (Taylor, 2013c, p. 78). In the second half of the article, I revisit aspects of Povinelli's presentation to consider how learning-how might inspire a transition from learning-about to learning-with a range of existents in a range of common worlds. Overall, this article gestures toward a form of geontological learning orientated toward human and more-than-human

\footnotetext{
${ }^{3}$ Povinelli's (2014) presentation can be viewed in full at https://www.youtube.com/watch?v=CyLWmSDfkv4\&feature=youtu.be

Canadian Children JOURNAL OF THE CANADIAN ASSOCIATION FOR YOUNG CHILDREN 
relational becomings, toward grappling with challenging ecological and colonial inheritances, and toward an appreciation and possibility of the otherwise.

\section{Subject, Object, Other}

I do not think it too controversial to suggest that the very existence of early childhood education as we know it has depended on the child. Taken at a surface level, such a statement seems rather unnecessary, but what I am interested in are the more subtle ways that the child and early childhood education are entwined. In other words, I am concerned with the child as object of knowledge, the child as subject to be made, and the child as other to be grasped. Take, for example, the sizable body of academic knowledge generated about the autonomous, individualized child. How many articles, books, and textbooks are filled with key words like physical growth, emotional competence, and developmental potential? How many of us have taken a child development course as a core module in our tertiary programs? I am also curious about how pedagogies of child-centred learning, perhaps most familiar today in the form of "following the child's lead," pivot around the child as learning subject. So, despite some profound differences, I wonder if there are convergences between ways of knowing the child and ways of doing early childhood education that invite further, careful analysis. How might we think and do otherwise than theories and pedagogies that take the child-object-subject as centre?

Additionally, whether childhood is understood as a biologically delimited periodization of life or a historical and cultural construction, dominant beliefs of childhood have turned on the separation of adult and child. The child as the adult's other - as the not yet and the somedayhas for too long been taken as definitional fact (Cannella, 1997; Castañeda, 2002). I agree with Marg Sellers (2013) that "disrupting the modernist adult|child binary is significant to the project of (re)conceiving children and their childhood(s)" (p. 69), and I think that such a reconceptualization requires an implosion of the subject-object-other tripartition. To be clear, I am not advocating throwing out the concepts altogether. Even if such a move were possible, I am not sure it would be advisable. I wager these are the sort of stalwarts that Gayatri Spivak (1996) says are "that which we cannot not want" (p. 28). What I do want, however, is to consider how these ideas might overorganize thought and practice, and to ask what limits are noticeable and what possibilities are made feasible if we do some disrupting and decentring. Arguably, what the child-centred theories and pedagogies gestured to above have in common is an anthropocentric inclination, a pedagogical habit to "see the child, but also ourselves as humans, as the centre of attention and the origin of all knowing" (Hultman \& Lenz-Taguchi, 2010, p. 525).

With this in mind, this section goes on to consider how we might dislodge the dependence relation of child and early childhood education from a humancentric orientation. How can we alter the equation to include "an inevitable and positive dependence on other bodies and matter in the child's ongoing and specific style of becoming human" (Hultman \& Lenz-Taguchi, 2010 , p. 531)? Or, in a related framing, how might dependence become "interdependence in multispecies common worlds" (Taylor, 2013b, p. 10)? What counts as subjects, objects, and others will undoubtedly shift when we understand the child (and ourselves) as marked by relationships with rather than distinctiveness from the rest of the world. But I may be getting 
ahead of myself here. To be honest, when I began to think about the child's enmeshment with subject-object-other, the borders were a bit murky from the start. But I do think first teasing them apart with an ordinary early childhood moment and then later on in the article with a story from Povinelli's symposium presentation might move us down a different path. The disposition recommended for this path-setting is one of curious questioning and of continuously asking "what else is going on here?" (Taylor, 2013c, p. 109).

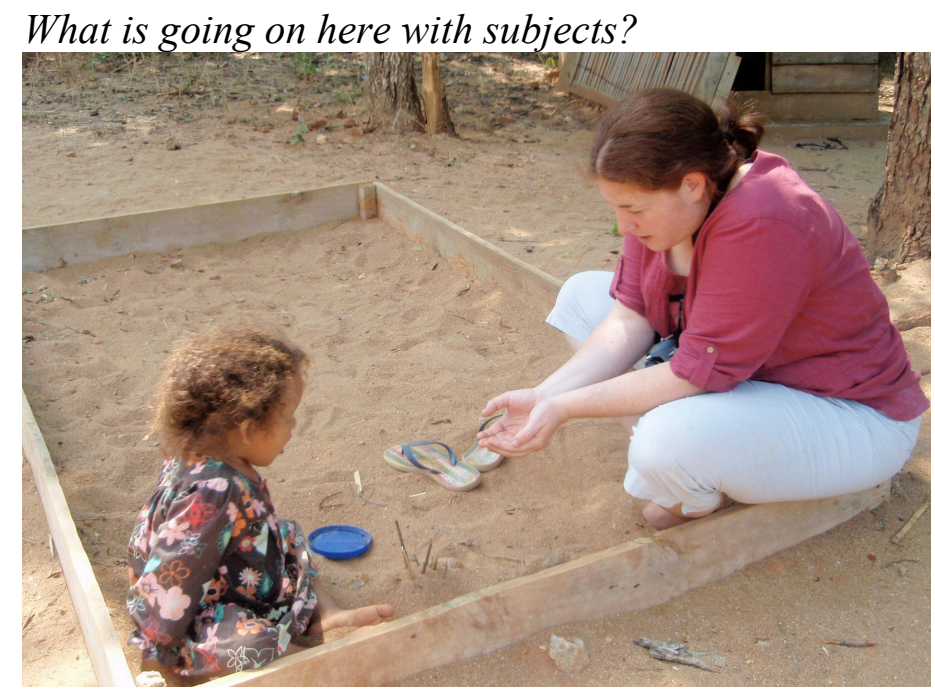

There is nothing extraordinary about this image. Such a scene can be captured most days at most early childhood centres. A narrative remembering of the event goes something like this: My friend invited me to a birthday party so I joined her in the sandbox for the festivities. She made a cake, regaled me with tales of birthdays past, and invented all sorts of new birthday games for us to play. Aware that she should not use matches (even when pretend), she asked me to light the stick-candles and then to sing "Happy Birthday" with her. I probably asked her questions like how many people were invited to the party and at what time it started, suggested to her that we could write invitations to hand out to friends, wondered with her if we could draw a map to the party so her guests could easily find their way. Phrased in the language of contemporary early childhood curricula, she "explore[d] ideas and theories using imagination, creativity, and play" (Australian Government Department of Education, Employment, and Workplace Relations, 2009, p. 37), "negotiated the meaning of symbols with others" (University of New Brunswick Early Childhood Centre, 2008, p. 102), and used open-ended and "natural materials ... in the child's environment" (Government of British Columbia, 2008, p. 27). My friend is a rich child, an agentic child, a competent child-subject (Rinaldi, 2006). And what sort of teacher-subject was I? My actions were in line with what many curricula suggest. Reflecting on Aotearoa/New Zealand educators' practices using the curriculum Te Whāriki, Sellers (2013) writes:

In these generative play spaces of the setting, programme and games the children played, the way the teachers operated was also significant; as with many teachers operating in these kinds of settings their approach afforded open play(ing) learning spaces; while they interacted with the children, it was on the 
children's terms. But, most significantly, these teachers were with the children in their learning spaces, ever vigilant against assuming control and adept at not interacting needlessly. (p. xix)

I entered the sandbox when invited; I followed the child's dramatic lead; I made attempts to extend her play. My hope is that this restorying does not come across as an insincere caricature, because that is far from my intention. There is nothing markedly wrong here. This is not an example of bad practice; it is just not all that is going on (Taylor, 2013c).

What is going on here with subjects and objects?

In an article outlining their "relational materialist approach" to early childhood pedagogy, Karin Hultman and Hillevi Lenz-Taguchi (2010) begin with an image much like that above, only there is no adult present in their frame. Representative of an "anthropocentric style of seeing," they describe a close-up shot of a young girl in a sandbox sprinkling a handful of sand into a waiting bucket below (p. 526). The child as subject of the photo is separated out from what surrounds her; the sandbox is scenic staging for the main act and the bucket is an inconsequential, inanimate play prop. Such a "way of looking ... relies on a subject/object binary divide" (p. 527), which comprises

a foundational division between subjects understood as humans (subjecthumans) and objects understood as part of nature (objects-nature). This division is asymmetrical in terms of value, that is, the girl playing with sand is given a far greater value and is seen as superior to the sand, the bucket and the sandbox. She is active and the sand is passive. As a subject she acts out her intentions and competences. (p. 527)

Hultman and Lenz-Taguchi start with this reading in order to disrupt it. Their goal is to open possibilities for a pedagogy that takes materiality seriously, an approach where we understand the girl as acting on the sand and the sand as acting on the girl. The girl-sand assemblage is grounded theoretically by Karen Barad's (2007) notion of intra-action. Interaction is emblematic of my first story, where adult and child, teacher and student, she and I, came together in play but retained our individuality as separate agents-subjects. Unlike interaction, which centres on such interpersonal relationships, “'intra-action' signifies the mutual constitution of entangled agencies ... intra-action recognizes that distinct agencies do not precede, but rather emerge through, their intra-action" (Barad, 2007, p. 33; emphasis in original). Here boundaries between object and subject mix and tangle. Neither precedes their coming together, but while borders blur, I do not think they quite get messed up enough ... yet.

In wondering about the ethical possibilities of deer-child encounters, Veronica PaciniKetchabaw (2012) remarks: "We cannot innocently ignore the ways in which the deer's livesand our own - are shaped by our intra-actions. We are in the middle of who the deer are and the deer are in the midst of who we become" (p. 304). Attending to this middle, PaciniKetchabaw foregrounds the entangled, messy relatings of common world pedagogies: neither

\footnotetext{
${ }^{4}$ To semicomplicate things, we can also read the girl-child as object of knowledge and the photograph as object of analysis for both Hultman and Taguchi as subject-researcher and me as analyst-subject.
} 
child nor deer are readily reducible to autonomous subject, object, or other-they are a childdeer figure. This sort of figuration connects to Donna Haraway's (1992) idea of "otherworldly conversations," which Stacy Alaimo and Susan Hekman (2008) understand as a practice "in which various nonhuman entities participate as subjects rather than objects" (p. 13) and one that "provides one model for ethical relations that respect difference and allow for mutual transformation" (p. 13). While I agree in large part with their interpretation, I am not so sure that the achievement of subject status is a necessary step. Does the sand or bucket have to be/come a subject to count, to affect, to relate? In other words, how might we "refuse the idea that matter needs to be granted meaning by thought" (Colebrook, 2008, p. 56)? And, in that refusal, what might a deer-child figure do differently? Insomuch as Hultman and Lenz-Taguchi do much to counter the historic early childhood education blind spot of failing to consider the materiality of learning, by privileging the intra-agency of the sand and girl-child almost exclusively, they leave me inspired but not quite satisfied. ${ }^{5}$ For me, the world still remains at large.

What else is going on here?

"Bringing the world back into the mix," Affrica Taylor (2013c) writes, is imperative to "reconstituting the nature of childhood 'elsewhere' - an 'elsewhere' where children's lives are inseparably bound up with all manner of other lives, other forces and other things" (p. 79). This elsewhere is otherwhere than an early childhood education that privileges human agency above all else. These "common worlds" have their share of "wonders (unknown until sought out), but they are also messy worlds of co-implicated histories, uneven power relations and ethical challenges" (p. 79). Neither innocence nor isolation has a place in worlds confronted by settler colonialism and environmental degradation. In a complementary theorization, Iris Duhn (2012) holds that taking place seriously can provoke a pedagogical shift "from the individual child to the child's entanglement with forces and forms of all sorts, both human and more-than-human" (p. 104). In the middle of such place and worlding pedagogies are all sorts of "what elses" and goings-on that matter in excess of easy delineations of subjects, objects, and others.

Returning to the image that opened this section, there are many forces that warrant articulation and others that, although deserving, defy description because they were not "sought out" in the first place. To start, place matters. While the sandbox may be a familiar landmark to most readers, its specific physical location probably is not. The photo was taken at a communitybased nursery in a rural village in Malawi. Understanding place as more than a point on a map means that "place-constellating geo-historic specificities" make a difference here (Taylor, 2013a, p. 368). For instance, there are many postcolonial concerns embodied by me as a white settler Canadian accepting a post from a Canadian government development agency to work over there. Histories of what Teju Cole (2012) calls the "white-savior industrial complex" complicate the frame. The sandbox itself also carries colonial tracings, originating as it did with Friedrich Froebel, the German founder of the kindergarten movement (Johnson, 2009). Questions about how pedagogies that promote learning materials like sandboxes travel to majority-world countries are important to consider.

\footnotetext{
${ }^{5}$ In her full-length volume Going Beyond the Theory/Practice Divide in Early Childhood Education, LenzTaguchi (2010) shares many examples from practice that recognize everyday early childhood materials and artifacts like pens, clay, construction materials, furniture, and bodies as impactful, performative agents. 
Paying attention to the sand relations brings other forces into view: for example, the hard unpaid labour of community women to trek the sand up to the nursery from the beach far below, or the roar of laughter that would erupt if I told them that in one Canadian province regulations state that any sand that falls out of the box has to be discarded, that there cannot be sticks or stones in the mix, and that "sand must be clean" (Alberta Health Services, 2014, p. 14). Language matters here, too-pedagogically, politically, and ethically. The birthday-party host is trilingual: She speaks fluent English and two local languages. She could communicate the rules of the birthday games to her nursery mates in ways I could only gesture at, whereas I was the only other person at nursery who knew all the words to "Happy Birthday." Lastly, the distancing effect of my earlier provocation "over there" rings hollow when environmental and ecological degradation is taken into account. The rainy season has brought devastating floods to southern Malawi that have displaced more than 200,000 people and washed most of the region's sandboxes away. Global climate change connects and affects us all, albeit differently and differentially so.

While bringing these "messy and mixed-up post-colonial" (Taylor, 2013c, p. xxiii) goings-on into the mix helps interrupt the interpersonal narrative I first told about the photo, it does not quite get at what the Common World Childhoods Research Collective is obliging in their common world pedagogies. In other words, it is not always possible to add in to the discussion what was not attended to in the first place, which in this case includes all those more-thanhuman existents that were always already there (but were too easily ignored). Taylor (2013b) speaks of the need to cultivate a certain "mode of attention" that allows educators "to pursue an understanding that there is always more going on than you think in multispecies encounters" (p. 13). What I've offered thus far does not put enough emphasis on the fact that not all actors are human, or that a common world pedagogy is one in "which all the actors become who they are in the dance of relating" (Haraway, 2008, p. 25). In this dance, the human-subject does not bop about solo because what were once categorized as objects and others are now partners in the dance: "The terms pass into each other; they are shifting sedimentations of the one fundamental thing about the world-relationality" (Haraway, 2004, p. 237). This kind of entanglement, Haraway (2004) explains, "defies autonomization of the self, as well as the objectification of the other" (p. 144). It is in this thick, fleshy tango that the worlds we thought we knew become otherworldly.

\section{Knowing, Doing, Learning}

Before delving into the specifics of Povinelli's symposium presentation, I want to first turn my attention to the thus-far neglected term other in the subject-object-other assembly that headed up the last section. In doing so, I consider the movement from the other to the otherwise as a key incitement for knowing and doing early childhood education in more worldly ways.

Subsequently, I look at how Povinelli's emphasis on learning-how unfolded into stories of Indigenous colleagues becoming-with place, comedies of quirky more-than-human and human trickster-teachers, and cautionary tales of relational and environmental change. Povinelli's depiction of learning-how invites a form of geontological learning in which nonhuman geographies, more-than-human existents, and human biographies are thickly enmeshed. Her stories get at the kind of "what elses" in the goings-on that I struggled to articulate with my photo-story. 
The other to the otherwise

What is the difference between the other and the otherwise? My understanding of Povinelli's conceptual differentiation is that the other already exists in the world; it is an already-known entity with an oppositional referent: for example, a child to an adult or a culture to a nature. In our everyday comings and goings we tend to invoke the other all the time; it is our commonplace way of thinking and speaking about social difference. On the other hand, the otherwise is a potential world in every actual world; it is a queer, differential spacing of the world rather than a territorialized space of difference already in the world. The otherwise invites concern not only for "what is (or was) but what is not and what could be" (Povinelli, 2012). The otherwise is not an object or subject that can be predetermined, but an immanent form of intra-active existence. The otherwise is about emergence, it is about becoming, and it is about becoming-worldly-with (Taylor, Pacini-Ketchabaw, \& Blaise, 2012).

A pedagogy associated with the other is about "world disclosure" (Povinelli, 2012). Affrica Taylor and Miriam Giugni (2012) have written of the tendency to "think about early childhood communities as bounded worlds of pre-existing differences" (p. 113). The notions of "bounded" and "preexisting" allow differences to be managed and included into what is already there; this "already there" then makes early childhood inclusion practices an additive process and not necessarily a relational one. Taylor and Giugni's (2012) reconceptualization of community is driven by their understanding of place as "dynamic and relational" and "an openended locus of difference" (2012, p. 113). Conceived in this way, community and place open up to thinking about "common worlds as dynamic collectives of humans and more-thanhumans, full of unexpected partnerships and comings together" (Taylor, 2013c, p. 78). This kind of dynamism reaches out to the otherwise; it is about what Povinelli (2012) calls "unclosure, a disturbance of the world wherein an otherwise ... can emerge" (n.p.).

Povinelli (2013) explains that the otherwise is "built into every arrangement of existence.... To raise a glass is to build into existence the possibility it will fall —or float - when let go" (n.p.). To put eyes to paper is potentially to read, or maybe to spark a daydream; to try and make sense of my words invites the possibility of cursing me out, or maybe smiling, or ... and.... While examples such as these might help us wrap our heads around the concept, translating the otherwise into practice is not so simple. The otherwise is not a goal or end point that we can reach or ultimately achieve because to grasp an otherwise would be to turn it into another other. The otherwise is unrelenting and multiple not yets. ${ }^{6}$ Hard questions rather than neat and tidy answers are provoked: How might we alter our early childhood imaginaries to think about early childhood communities, local places, and relationships with children as spacings of potential otherwises? How in everyday practice can we keep the possibility of the otherwise open? A reversal of the last question also has implications for practice: If there are otherwises all around (and this big, beautiful, weird, cruel world has convinced me there are), then why do we keep having the same (Povinelli, 2012)? What are the sames in our practices with young children?

\footnotetext{
${ }^{6}$ The not yet of the otherwise is a very different than the not yet of the child maturing to adult. In the latter the end result is predetermined whereas the otherwise is open and multiple.
} 


\section{Learning-how to learn-with existents}

The main plot points of Povinelli's (2014) story that I'd like to explore further can be summarized as follows: Povinelli and a small group of long-time Indigenous friends were camping on the beach at Bulgul in northern Australia. They had come to hunt, fish, visit family, and just get a little break away. It was early morning and Povinelli was tasked with making a campfire, only all the wood gathered up the day before had been soaked by the Tjebak - the snake-shaped early morning fog. Fighting swarms of mosquitos, Povinelli set about peeling back layers of bark to get to the dry wood underneath. She pleaded with Yilngi and Nuki, the two other early risers, to let her break open a lighter and use the fluid to set the blaze more quickly. They watched with amusement and insisted she "do it the right way." While her struggle with the wet wood continued, the older women supplemented her arduous task with important place-based tellings. This particular morning, they told stories of Tjebak: how she moved, how she smelled, and how her shape, smell, and movement allowed her to become-with creeks, mountains, and people far and near.

A moment that stands out for me in the story is when Yilngi first pointed to the dense layer of fog above a nearby hill and said something like, "You know that thing is alive." Povinelli replied, "What thing?" I chuckled as I imagined myself there, spinning around and around and squinting my eyes to make out another human or animal blanketed by fog off in the distance. Whereas my response may have been "what, you think the fog is alive?" Povinelli acted otherwise. Part of what I think Povinelli (2013) is trying to relay is that it is not the real, metabolic aliveness of Tjebak that should consume our focus - it is not the question of belief that is important, but a kind of obligation built up from experiences of learning-how. Much like Haraway's (2004) understanding that "knowledge is always an engaged material practice and never a disembodied set of ideas" (p. 199), the kind of learning-how Povinelli engages is a doing, an activity, a coming together and moving apart of human and other existents. It relates to Deleuze and Guattari's (1994) remark that "something in the world forces us to think. This something is an object not of recognition but of a fundamental encounter" (p. 139). Tjebak was not an object to be known by the beach visitors or the subject of a story at a symposium but a world-making encounter. For Povinelli and her Indigenous friends, learning-how and with other existents means "to be in a constant deep relationship with [them]" (Povinelli, 2014).

Barad (2007) writes that "knowing is a matter of part of the world making itself intelligible to another part of the world" (p. 185). To welcome this intelligibility requires a sort of worldly, relational mode of attention alluded to earlier. Povinelli (2013) had to pay attention to the "the conditions of formation and movement that allow the visibility and intelligibility" of Tjebak as existent. She learned how Tjebak smelled and emitted an odour, how she moved and shapeshifted as she navigated hills, creeks, and valleys, how she dampened tents, firewood, and human-existents in her wake, how she intra-acted with nearby Dreaming sites, how she pushed mosquitos down below her cover onto the beach below. And, as Povinelli learned Tjebak's habits, Tjebak did the same. Tjebak learned about Povinelli and her Indigenous companions: where they moved, the sites they visited, how they spoke, how they smelled, and what they ate. This learning was not only experiential but embodied; this knowing was a form of thickknowing because what Tjebak was included "what and how you were in relation to her" (Povinelli, 2014). "To know," Povinelli (2014) said, "was to pay attention to these processes of mutual becoming," and to learn-how was to become through mutually embodied relations. 
Geontological learning

Povinelli and friends are concerned with Tjebak's "geontological conditions and struggles," all those geological entities in the assemblage that co-shape her-the winds, rocks, hills, and creeks for example. The conditions and struggles also include air pollution, mining waste, and greenhouse gases, the rise of Australian multiculturalism wherein Indigenous knowledges were (for a time) celebrated for their difference, and the settler land claim policies of the national government that determine traditional ownership and designate "Indigenous Protected Areas." Over the years Povinelli, friends, and Tjebak had to adapt with these conditions and struggles in order to persist in being. These transfigurations are evident in the two Tjebak encounters storied by Povinelli $(2013,2014)$. Ten years have passed since the beach meeting, and they all smell different, sound different, look different, and move differently. Tjebak the fog-snake is becoming smog-snake, but so too is everyone else. As Tjebak changed, the winds shifted, diets changed, health declined - and, as winds shifted, diets changed, and health declined, so too did Tjebak. But this was not a simple linear digression. Yes, as Tjebak changed the weather changed, health declined, and so on - but this is not a deterministic relationship - it is not a motorized process of A affecting B and B affecting $\mathrm{C}$ and so forth. The whole alphabet gets involved and rearranged here. Co-constitution is a complex and messy form of worlding. This story then is about what Povinelli (2013) has termed geontology: It is not only a story of human change, of bios-graphy, but includes more-than-human emergence, transformation, and endurance - geos-graphy. Taking all this into account, Povinelli inspires a form of learningwith that can be called geontological learning.

Geontological learning is a very different kind of learning than the sort of learning-about that many of us in early childhood education know so well. Learning-about is the kind of learning that happens when we go to an encyclopedia and look up an entry on fog, or, more realistically these days, when we type "fog" into Google or Wikipedia. Learning-about consists of those existing truths out there in nature that children set out to discover. Learning-about questions are those we ask children when we already know the answer; they work to legitimize what is already known. Even when Povinelli and Tjebak were learning about each other's habits, what really stands out for me is the experiential, sustained, and embodied form of the relational practice. It also seems to me that common worlds pedagogies, as expressed below by Taylor (2013c), enact the kind of geontological learning Povinelli alludes to:

If we can recognize our common worlds and then utilize them as the collective 'new ground for meaning making together' ... we will inadvertently make a pedagogical shift-away from knowing about nature, or even in nature and towards learning with those others with whom we are already entangled.

(Taylor, 2013c, p. 120, emphasis in original)

Furthermore, geontological learning involves being "open to the quirky nature of all forms of existents" (Povinelli, 2014). Tjebak, Povinelli tells us, could always surprise! Also significant to note is that the teachers in Povinelli's stories are not limited to humans: Tjebak is a teacher and an important one at that. Tjebak exudes a sort of playful conviviality, a teasing and sauciness of sorts: she soaks the wood and she circles overhead as Povinelli dances about on the beach. I imagine Tjebak watching the scene and sharing a laugh with Yilngi and Nuki. Following Haraway (2000), we might consider Yilngi, Nuki, and Tjebak trickster teachers,

Volume 40 Number 22015

www.cayc.ca 
"witty agents and actors" that refuse any possibility of a nature/culture divide (p. 66). ${ }^{7}$

Trickster figures also serve "to caution us against anthropomorphism... It is a serious mistake to anthropomorphize your partners" (2000, p. 67)! So when I write of Tjebak teasing and observing Povinelli, it is not meant in a humancentric sense. This clarification brings us around again to the idea of otherworldly conversations where the tendency might be to think of human modes of speech, but Haraway's use of trickster-figures "is about the world that is also nonhuman, about all that is not us, with whom we are enmeshed, making articulations all the time" (2000, p. 67). How might we cultivate forms of attentiveness attuned to the articulations of more-than-human existents? How can we bring a kind of playful irreverence and openness to the quirkiness of existents into our daily relatings with children?

\section{Conclusion}

This article began by considering the limits of early childhood theories and pedagogies that are overorganized around the child as subject, object, and other. The refrain of "what else is going on here" marked moves toward an understanding of children's worlds as messy, complex, and embedded in broader geopolitical and geophysical relations. Encouraged by Povinelli's (2014) symposium presentation, I then attempted to unpack a form of learning-how that is attentive to the mutually embodied becomings of human and more-than-human existents. The emphasis on learning-how extended a proposal for geontological learning that shares many connections with the provocations posed by the Common World Childhoods Research Collective's common world pedagogies. The implications of these ways of knowing, doing, and learning for early childhood education oblige a move away from humancentric pedagogies, such as the one exemplified by my sandbox story, to an understanding of humans as intimately and inseparably enmeshed with other forces and existents, as the Tjebak story demonstrated. The challenge is to find pedagogies that keep the otherwise of common worlds open to a range of existents, a range of articulations, a range of challenges, a range of relations, and a range of not-yet possibilities.

\section{References}

Alaimo, S., \& Hekman, S. (2008). Introduction: Emerging models of materiality in feminist theory. In S. Alaimo \& S. Hekman (Eds.), Material feminisms (pp. 1-19). Bloomington, IN: Indiana University Press.

Alberta Health Services. (2014). Health and safety guidelines for child care facilities. Edmonton, AB: Alberta Health Services Environmental Public Health Department. Retrieved from: http://www.albertahealthservices.ca/EnvironmentalHealth/wf-ehhealth-safety-guidlines-child-care-facilities.pdf

\footnotetext{
${ }^{7}$ Haraway has addressed the complex ethical issues evoked in her use of the coyote-figure within the context of Indigenous appropriation in an interview (see Haraway, 2004, pp. 327-328).
} 
Australian Government Department of Education, Employment, and Workplace Relations. (2009). Belonging, being and becoming: The early years learning framework for Australia. Retrieved from: https://education.gov.au/early-years-learning-framework

Barad, K. (2007). Meeting the universe halfway: Quantum physics and the entanglement of matter and meaning. Durham, NC: Duke University Press.

Cannella, G. (1997). Deconstructing early childhood education: Social justice and revolution. New York, NY: Peter Lang.

Castañeda, C. (2002). Figurations: Child, bodies, worlds. Durham, NC: Duke University Press.

Cole, T. (2012, March 21). The white-savior industrial complex. The Atlantic. Retrieved from: http://www.theatlantic.com/international/archive/2012/03/the-white-savior-industrialcomplex/254843/

Colebrook, C. (2008). On not becoming man: The materialist politics of unactualized potential. In S. Alaimo \& S. Hekman (Eds.), Material feminisms (pp. 52-83). Bloomington, IN: Indiana University Press.

Deleuze, G., \& Guattari, F. (1994). What is philosophy (G. Burchell \& H. Tomlinson, Trans.)? London, UK: Verso. (Original work published 1991)

Duhn, I. (2012). Places for pedagogies: Pedagogies for places. Contemporary Issues in Early Childhood, 13(2), 99-106.

Government of British Columbia. (2008). British Columbia early learning framework. Victoria, BC: Ministry of Education, Ministry of Health, Ministry of Children and Family Development, \& British Columbia Early Learning Advisory Group.

Haraway, D. (1992). Otherworldly conversations; Terran topics; local terms. Science as Culture, 3(1), 64-98.

Haraway, D. (2000). How like a leaf: An interview with Thyrza Nichols Goodeve. New York, NY: Routledge.

Haraway, D. (2004). The Haraway reader. New York, NY: Routledge.

Haraway, D. (2008). When species meet. Minneapolis, MN: University of Minnesota Press.

Hultman, K., \& Lenz-Taguchi, H. (2010). Challenging anthropocentric analysis of visual data: A relational materialist methodological approach to educational research. International Journal of Qualitative Studies in Education, 23(5), 525-542.

Johnson, P. (2009). A brief history of the sandbox. Retrieved from: http://www.playscapes.com/play-history/pre-1900/a-brief-history-of-the-sandbox/ 
Lenz-Taguchi, H. (2010). Going beyond the theory/practice divide in early childhood education: Introducing an intra-active pedagogy. London, UK: Routledge.

Pacini-Ketchabaw, V. (2012) Postcolonial entanglements: Unruling stories. Child \& Youth Services, 33(3-4), 303-316.

Povinelli, E. (2012). The dwelling science: Embodiment, obligation, knowledge. Presentation at "Face and Artifact" symposium, Center for the Humanities, Wesleyan University, Middletown, Connecticut, February 26, 2012. Retrieved from: https://itunes.apple.com/us/itunes-u/center-for-humanities-fact/id468663132

Povinelli, E. (2013). Geontologies: Being, belonging, and obligating as forms of truth making. Presentation at "Knowledge, Governance and Organization Management Through Objects" symposium, Northern Institute, Charles Darwin University, August 30, 2013. Retrieved from: http://www.youtube.com/watch?v $=$ oRcEydtnM3w

Povinelli, E. (2014). Learning how to inherit from new to old media. Keynote presentation at "Learning How to Inherit in Colonized and Ecologically Challenged Lifeworlds" symposium, University of Victoria, British Columbia, September 27, 2014.

Rinaldi, C. (2006). In dialogue with Reggio Emilia. New York, NY: Routledge.

Sellers, M. (2013). Young children becoming curriculum: Deleuze, Te Whäriki and curricular understandings. London, UK: Routledge.

Spivak, G. (1996). The Spivak reader: Selected works of Gayatri Chakravorty Spivak. New York, NY: Routledge.

Taylor, A. (2013a). Caterpillar childhoods: Engaging the otherwise worlds of central Australian Aboriginal children. Global Studies of Childhood, 3(4), 366-379.

Taylor, A. (2013b). Child-kangaroo entanglements: From the cultural politics of settler Australian national belongings, to multispecies common worlds belongings. Keynote presentation at "The Cultural Politics of 'Childhood' and 'Nation': Space, Mobility, and a Global World" symposium, University of Newcastle, Australia, November 28, 2013.

Taylor, A. (2013c). Reconfiguring the natures of childhood. London, UK: Routledge.

Taylor, A., \& Giugni, M. (2012). Common worlds: Reconceptualizing inclusion in early childhood communities. Contemporary Issues in Early Childhood, 13(2), 108-119.

Taylor, A., Pacini-Ketchabaw, V., \& Blaise, M. (2012). Children's relations with the morethan-human world. Contemporary Issues in Early Childhood, 13(2), 81-85. 
University of New Brunswick Early Childhood Centre. (2008). New Brunswick curriculum framework for early learning and child care. Fredericton, NB: Government of New Brunswick. 


\title{
Entangled Frictions With Place As Assemblage
}

\section{by Sherri-Lynn Yazbeck and Ildikó Danis}

\begin{abstract}
Authors' Bios
Sherri-Lynn Yazbeck is an early childhood educator at the University of Victoria Child Care Services. Her academic background in psychology, philosophy, and early childhood education are combined with 14 years of practice as an early childhood educator. Inspired by ordinary moments with children, she is interested in the entangled multispecies relationships and encounters that take place in the classroom, playground, nearby forests, and gardens. She is intrigued by how these human and more-than-human assemblages create place and pedagogy in early education. She is also researching what it might mean to practice care and sustainability through these children/more-than-human relationships. Email: syazbeck@uvic.ca
\end{abstract}

Ildikó Danis is an early childhood educator at University of Victoria Child Care Services. She has a degree in early childhood education from Georgia State University and has worked in the field in Canada, the United States, and Hungary. Her interest in common worlds pedagogies spurred her curiosity about children's relations with place. She is currently focusing on how storytelling might help to connect with other species, with the material world, and with place. Email: idanis12@uvic.ca

\begin{abstract}
The focus of this paper is to tell stories and grapple with questions about place. We share documentation gathered during explorations in an art studio we created in an urban forest located next to our childcare centre. We work with multiple forms of knowledge about place in order to develop complex (and situated) forest pedagogies. Our stories engage with clay and the use of maps, and lend themselves to thinking of place as assemblage with more-than-human others. We conclude the paper with an examination of how our newly forming forest pedagogies creep into other stories - unfolding, changing, and creating frictions in our practice, explorations, and inquiries-just as English ivy does in our forest studio.
\end{abstract}

The children and educators at the University of Victoria Child Care Services are frequent visitors to Haro Woods, a neighbouring urban forest. Like Victoria, BC, the woods are situated on the unceded Coast and Straight Salish territories, specifically those of the Songhees and Esquimalt Nations. In September 2013, the children and educators along with our pedagogistas (Veronica Pacini-Ketchabaw, Vanessa Clark, Nicole Land, and Narda Nelson from the School of Child and Youth Care) set out on a new eight-month encounter with the forest to gain and assemble insight into Haro Woods with the hope of creating intricate forest art pedagogies Canadian Children JOURNAL OF THE CANADIAN ASSOCIATION FOR YOUNG CHILDREN 
(Pacini-Ketchabaw, 2013a) through three inquiries. Our inquiries were around place, specifically Haro Woods, thinking with more-than-human perspectives, and how art can create new possibilities for rethinking the woods as entangled in our common worlds.

Like most of our work, it was not our intention to find answers to these inquiries, but rather to engage in dialogue and spend some time "thinking about ongoing ethics and politics of living in heterogeneous (human and more-than-human) common worlds and of collectively responding to the challenges that they throw up" (Taylor, 2013, p. 78). It was imagined that these inquiries and resulting conversations would open us up to seeing the forest in a new way, through varied frames and multiple lines of flight, and ultimately inspiring and creating new trajectories and inquiries in our practice (Pacini-Ketchabaw, 2013a).

To think with the above inquiries, a forest studio was created in Haro Woods. The forest studio is an area of the woods, chosen by our pedagogistas, where small groups of children and educators gathered together once a week to work with clay in the forest. Separately, forest and clay are familiar to the children and educators. Child Care Services has a long history of gathering in the forest, engaging with fallen trees and rocks, wandering the trails, watching and wondering about those that live there. Similarly, we have history with clay. It is present in our centres, drawing us in, frequently mixing with water, blocks, and other materials in our space. The forest studio was born when we combined the familiar (forest and clay) with our thinking about living in heterogeneous worlds. A studio of ideas, inquiry, wonder and reflection, a coming together of materials, both human and more than human. A studio of ideas where we think about our work through Anna Tsing's concept of friction, as described by PaciniKetchabaw (2013b, drawing from Tsing, 2005, p. 1, and 2012, p. 510):

Anna Tsing has developed the concept of friction as a way to conceptualize the diverse and conflicting social interactions that make up our contemporary world. It is friction, Tsing says, that produces movement, action, and effect. When we pay attention to friction, she observes, we see relationships as transformative, and one is not sure of the outcome. Attending to friction opens our eyes to historical contingency, unexpected conjuncture, and the ways that contact across difference can produce new agendas. (p. 356)

While friction can include risk and complications, it can also open up children and educator practices to new transformations.

What follows are our stories of frictions in the forest studio as we attempt to grasp an understanding of place. The notion of place is vast, multifaceted, layered, and explored by many. For some, a place may be simply physical, a location on a map; for others, place involves a long history of cultural, spiritual, and political connection or disconnection. It can be connected to memories, family, friends, and moments or events in time. Place can be shared through stories connecting or disconnecting people to land, humans, and more-than-human others, giving identity and (trans)forming relationships. Massey (1994) suggests that places are dynamic social relations 
which have over time been constructed, laid down, interacted with one another, decayed and renewed. Some of these relations will be, as it were, contained within the place, others will stretch beyond it tying any particular locale into wider relations and processes in which other places are implicated. (p. 120)

In this sense place is in a constant state of flux, never static, a process, holding multiple identities and constructed by links places have to many places beyond it - a global sense of place (Massey, 1991). In our practice we are moving away from the humancentric view of place, striving instead to see place as an assemblage of human and more-than-human others entangled with past and present stories. The following narratives explore our engagement with clay, the forest, and the use of maps as we struggle with newly forming pedagogies of place and the thinking of place as assemblage with more-than-human others. We conclude with how our newly forming forest pedagogies have crept into other stories, unfolding, changing, and creating frictions in our current practices, explorations, and inquiries.

\section{Entangled Frictions: Forest-child-educator-clay-water-deer-pedagogy}

Drawing inspiration from the writings of Iris Duhn (2012) in Places for Pedagogies, Pedagogies for Places, we have come to see that the forest studio as a place acts as an assemblage - a collection or gathering of humans and more than humans, with properties emerging from interactions, unfolding into each other. Duhn (2012) suggests that

thinking of place as an assemblage is an attempt not only to make place visible as a social, material and discursive field, but also to pay attention to the humannonhuman multiplicities that 'can become expressive, that can intensify and transform living bodies' (Grosz, 2008, p. 11) when place is analyzed as a territory with porous boundaries. (p. 103)

What follows is a brief narrative of the first day at work in the forest studio, along with an encounter with the forest a few days later:

The children are given rectangular blocks of clay. Some hold clay tightly in their hands, while others drop it into the stream, watching it sink to the bottom and then disappear. Clay is broken into small pieces, pushed into the bark of trees, thrown like snowballs and flattened into the earth. One child marks the tree as a stop sign, a line not to cross as others begin to move out of sight. All the while the rain comes down, washing over us, the clay, and the forest studio. A few days later a group of children and I head into the forest to explore and climb on fallen trees. We see signs of the forest studio, traces and marks left behind on trees and plants and in the water. As we follow the stream, Emily turns to me and asks, "What will the deer drink? This water is dirty." As she speaks I look down and realize I am walking in a stream clouded by clay.

Curious about the effects of clay on the more-than-human participants in the forest studio, we consult a geologist and a First People Elder and we learn that the small amount of clay we used will cause no more ill effects then our being present in the forest. As we have come to learn, 
simply being, in or out of the forest, affects our relationships with it, as will be shown in the below discussion of the history of the woods and the extraction of the clay itself.

This forest-child-educator-clay-water assemblage "can be understood as a human-nonhuman multiplicity with qualities that emerge through interactions" (Duhn, 2012, p. 104). The desire to inquire, wonder, and explore with clay led to holding, throwing, pushing, and safety making. The desire to care for the deer and the small stream generated an encounter with a geologist and a First People Elder. These encounters transformed the forest, the clay, the children, and the educators, creating connection, collaboration, and tension. The attribute of this assemblage is concern and an awareness of our interconnection with the deer and the stream. Forest-childeducator-clay-water is a place, a place without clear boundaries, a place exposed to transformations, assemblages unfolding into each other (Duhn, 2012).

When exploring the notion of place as assemblage in our thinking with the forest studio, it is necessary to also explore pedagogy of place. When pedagogy of place is explored from a traditional frame of early childhood education, the centre is seen as a series of physical locations - the library, the block room, the daily living area, the toy table, the playgroundeach complete with a perimeter and its own set of rules, which limit and hold the potential of making place static (Duhn, 2012). This traditional frame in the practice of early childhood education makes us uncomfortable. It has the potential to limit becoming and stifle entanglements among humans, more than humans, and ultimately the becoming of place. As educators we strive to move away from this traditional view of pedagogy of place to a view that is open to ideas. Viewing the centre as a studio of sorts allows lines to become blurred, allows materials and bodies to move about the room, not bound by static locations or single identities. Kind (2012) talks of a studio over time becoming more like a verb, "an action and acting, a function and collection or rhythm of movements. It takes shape, moving, changing, becoming when we gather to listen, watch, question, respond, invent and experiment (p. 32).

Therefore, when the possibility of the forest studio was suggested, we were ecstatic. The notion of a forest studio in our minds did not fit neatly into the traditional frame and worked to disrupt the early childhood pedagogy of place. Yes, the forest is a physical place with a storied history, a name and boundaries set by current ownership; however, it evolves and changes, it involves a twisted entanglement of past and present stories, of human and more-than-human others. Interestingly, as sessions in the forest studio took place, we began to hear of unsettled feelings. What once was understood in this place was becoming unfamiliar for some; past entanglements among children, educators, and place were difficult to disrupt and new unfoldings and (trans)formations were unwelcome. For example, many children found clay to be wet and cold, making it uncomfortable to touch and be around, while others wanted to move beyond the forest studio to engage with those familiar to them from past encounters: fallen trees, rocks and the creek bed. Educators struggled with feeling that they may be imposing work with clay on the children and the forest. Safety concerns arose around the amount of water in the creek, and both children and educators worried about the environmental impact taking place. We wondered whether past connections to forest were so entangled, so laden with child and educator boundaries, that the forest became a capsule filled with specific past activities and closed to new transformations, closed to a forest studio with clay? 
Duhn (2012) compares area in place to matryoshka nesting dolls, describing how each area fits precisely with purpose into the logic of the place. She further explains that place as assemblage is not the opposite of organized fitting places like the nesting dolls, but rather is "part of the forces and forms that constitute place" (p. 104). Deleuze and Guattari (1987) would suggest that, "as in all things, there are lines of articulation, segmentarity, strata and territories; but also lines of flight, movement, deterritorialization and destratification" (p. 3). The forest studio exists within boundaries, lines of articulation that control the work-working with clay or staying within the studio area. Children are provoked by the desire to engage with those familiar to them from past encounters: the stream, fallen trees, and the area beyond the forest studio with clay. In this sense the forest remains recognizable as a forest, but it is not the same place when it is a studio with clay. Duhn (2012) argues that "pedagogies that are aware of how territories are made and remade are open to change" (p. 104); there is no rule or absolute boundary defining how forest or clay should perform or where forest or clay emerges.

According to Duhn (2012), both place and pedagogy are assemblages. Components of assemblages are heterogeneous and relate contingently, giving possibility to take one assemblage and insert it into another without destroying its identity, thereby constructing new assemblages within existing ones (De Landa, 2006; Duhn, 2012). De Landa (2006) states that parts of assemblages "may be detached from and plugged into a different assemblage in which its interactions are different" (De Landa, 2006, p. 10). This statement leads us to wonder, have we created a pedagogy, or even a rule of sorts, that dictates what the forest is - the kind of work that happens in it, closing off ourselves, the children, and the forest to a forest studio with clay, closing off a different line of flight for us, a refusal to detach or unplug? Duhn (2012) argues that "places are made of flows of desire, or intensities. Pedagogies of places negotiate flows, and create spaces where matter, desire, human and more than human come together to modulate self in relation to the world" (p. 104). The development of our pedagogy of place as assemblage in the forest studio is just beginning. We are learning to look beyond past encounters to create spaces for matter, negotiate new ways to encounter the forest, and find ways to become, to bring about new assemblages while remembering the histories and stories of this place.

\section{Entangled Frictions: Forest-child-clay-maps-music}

Our second story begins with a question, initially posed by a child, Hugo, but wondered by all of us: "Where does clay come from?" The clay regularly purchased by Child Care Services comes from Medicine Hat, Alberta, and is mined by Plainsman Clays Ltd. Plainsman has multiple mining sources in Montana, Alberta, Saskatchewan, and Manitoba, and the company declares on its website, "Plainsman mines thousands of tons of clay at a time. We understand the deposits well, most of them are limitless, very consistent and produce raw clays that are balanced and very well adapted to pottery" (Plainsman Clays Ltd., para. 1). The Canadian Minerals Yearbook (Dumont, 2008) documents that in 2008 Canada exported close to 80,000 tons of clay valued at close to $\$ 22$ million. The extraction and processing of clay has the potential to significantly change landscapes and alter ecosystems.

Leanne Simpson (2013, interviewed by Klein, 2013), an Anishinaabe scholar, tells a story of colonialism and its entanglements with extraction: 
Extraction and assimilation go together. Colonialism and capitalism are based on extracting and assimilating. My land is seen as a resource. My relatives in the plant and animal worlds are seen as resources. My culture and knowledge is a resource. My body is a resource and my children are a resource because they are the potential to grow, maintain, and uphold the extraction-assimilation system. The act of extraction removes all of the relationships that give whatever is being extracted meaning. Extracting is taking. Actually, extracting is stealing - it is taking without consent, without thought, care or even knowledge of the impacts that extraction has on the other living things in that environment. That's always been a part of colonialism and conquest. Colonialism has always extracted the indigenous - extraction of indigenous knowledge, indigenous women, indigenous peoples. (para. 11).

Our work in the forest studio had barely begun when we were immediately made aware of our messy entanglements. We encountered contradictions in our practice of supporting initiatives of preserving and honouring landscapes, people, and more-than-human others while at the same time buying into the multimillion-dollar clay extraction industry.

Once he knew the origin of the clay, it became apparent that Hugo wanted to know not only the exact location but also how the clay came to be with us in the forest studio. For Hugo, at age four, reading maps, memorizing roads and addresses, and assembling trips around Victoria and the world are important processes.

What follows is a brief narrative of a few children tracking the possible journey of clay from Medicine Hat, Alberta, to Victoria, British Columbia:

Maps of Alberta and British Columbia were spread out on the carpet in the childcare centre. The maps had a newly unfolded "crinkle" to them, and a few pieces of dry clay hidden underneath prevented them from laying flat. The child pointed to Medicine Hat and with his index finger began mapping the clay's way to Victoria. He did this several times, finding different routes and naming aloud a few landmarks: major highways, mountains, towns, and the ferry crossing. In the beginning, other children and I watched as he slowly slid his finger across the map. Soon others joined him, tracing the routes he had discovered. As the children moved about the area, touching and stepping on the map, it too began to move. Hannah dropped a small block on the map, creating a "plop" sound as it landed. Hugo laughed at the sound and repeated it, "plop, plop, plop," while Lena declared, "Music!" We took turns creating rhythms, following each other's unspoken direction and enjoying the map's musical stories.

Continuing to think with the previously discussed theory of place as assemblage is complicated by the above narrative with its use of maps. Merriam-Webster (2015) defines a map as "(1) a picture or chart that shows the rivers, mountains, streets, etc., in a particular area; (2) a picture or chart that shows the different parts of something." Thinking of maps in this way zeroes in and reduces our above narrative into a single truth - a static roadway with set boundaries packaged and neatly folded when not in use. Further, as noted by Goeman (2008), "colonial spatializing of our lands, bodies, and minds has occurred since contact; maps, travel logs, 
engravings, newspapers, almanacs, and many other forms of colonial writings formed a systemic practice of confining and defining Native spaces from land to bodies" (p. 296). However, when thinking with place as assemblage, maps and mapping have the potential to become dynamic assemblages taking into consideration not only the temporal and geographical nature of place, but also the social, cultural, and storied diversity of place. Waghorn (2011) writes that, while architect and landscape urbanist James Corner (1999) does not deny that maps have been used as a means to exact colonial power, in his view, "it is the process of mapping itself, with the actions of recognising, assembling, and making visible that constitutes the territory or place" (p. 203). Corner acknowledges the heterogeneous nature of place as assemblage, stating:

Reality, then, as in concepts such as 'landscape' or 'space' is not something external and 'given' for our apprehension; rather it is constituted or 'formed' through our participation with things: material objects, images, values, cultural codes, places, cognitive schema, events and maps. (p. 223)

This notion of the map as a link in place as assemblage gives room for our above narrative to unfold, to become a dynamic part of our assemblage of place in the forest studio. Crinkling maps, clay on carpet, children gathering, conversation exploding, blocks dropping, and music erupting creates place as assemblage - properties form, unfold into each other. The desire to understand where clay comes from and how it comes to be in our hands and our forest guided us to maps, gathering, conversation, and music. The concern and desire to understand extraction led to research, readings, and stories of the land, its peoples, and its more-thanhuman others. Forest-child-clay-maps-music is a place - a place without clear boundaries, a place exposed to transformations, assemblages unfolding into each other (Duhn, 2012). Opening up pedagogies of place as assemblage in the forest studio gives new and necessary ways to create spaces for matter, giving room to negotiate how children, educators, clay, and forest come together or withdraw, allowing us to begin to learn how to honour land, stories, and people of this place.

\section{Entangled Assemblages: Pedagogies-place-practice-new inquiries}

Our inquiries in the forest studio and our thinking with place as assemblage has crept into our practice, creating frictions, new explorations, and unfolding inquiries. Specifically, thinking with place as assemblage, "being wholes whose properties emerge from the interactions between parts" (De Landa, 2006, p. 5), leaves us with understanding place as dynamic, interdependent, not bound but braided and interconnected, exposed to transformations, allowing assemblages to fold and unfold into each other. The work has revealed to us the importance and necessity of seeking out and opening up our pedagogies of place as being of a heterogeneous nature, entangled, in the case of the forest studio, with past stories of colonialism and Indigenous ontologies.

These inquiries have led to further exploration with our pedagogistas, building on the common world framework in our practice, "resist[ing] the nature/culture divide and situat[ing] childhoods within entangled human and nonhuman, Indigenous and non-Indigenous, social and environmental, issues and concerns" (Pacini-Ketchabaw, 2014, p. 1). We are beginning to use 
a process of storying "that ... emerges out of an ability to engage with happenings in the world as sequential and meaningful events" (van Dooren \& Rose, 2012, p. 3), to think and engage with common world ideas in our practice. For example, we are beginning to wonder with the children about what it means to care for and practice care of the other species we encounter daily in our playgrounds, on campus walks, as we dig in the garden and engage with the forest. By being present and attending, we are able to "learn through observation with the animals instead of projecting learned ideas about how and why" (N. Nelson, personal communication, January 11, 2015). We are mindful of our messy togetherness and are beginning to understand, as Puig (2012, cited in van Dooren, 2014) states, our "inescapable troubles of interdependent existences" (p. 292). Those human and more-than-human others that make up our stories are not static or fixed, but rather parts of assemblages, finding meanings in their relationships. We are wondering about their histories, how they move and exist in this place, and we are thinking more with Massey's (1991) global sense of place, linking those beyond what can be seen in our classrooms, forests, and neighbourhoods. Our entangled stories draw on the work of Taylor (2013), who asserts:

First, children's common worlds are not separated, pure and natural utopic spaces. They are mixed up worlds in which all manner of things co-existincluding the manufactured and the organic, the living and the inert, entities and forces, and humans young and old. Second, humans are not the only ones making or assembling the common worlds - doing the common worlding. Common worlds are produced through heterogeneous relations between all of these things. In other words, children's common worlds are impure and emerging worlds, produced through ongoing heterogeneous relations that take place within and between a host of actors (living beings) and actants (things and non-living forces). (p. 80)

When we think with a common worlds framework, our stories overflow with curiosity and questions: What stories and other representations are we telling, and are they ours to tell? Where do these stories come from? Why do certain stories and representations spread, while others become blocked? What are you/they feeling? How do you/they receive? What have we done to each other? How and what do you carry on from my story, from my presence with or in the story? How do we grapple with shifts in dirty and messy togetherness? How do we come to know and understand our/your becoming? And how do we accept more than humans as narrative subjects and weavers of stories (van Dooren \& Rose, 2012)? At times these questions settle nicely; other times they fade away; most often they create frictions, entanglements, and (trans)formations with other stories in our practice.

Much like the English ivy, that runs rampant through the forest studio and is itself a sticky result of settler colonialism, much work is needed to disrupt the widely dispersed root system and complex, intertwined network of pedagogies present in our practice. Our pedagogies, like the ivy vines, while not always directly connected to each other are deeply intertwined and at times incredibly difficult to dislodge. For example, moving away from traditional early childhood pedagogies of place as static and humanistic to form pedagogies with multiple identities and assemblages consisting of human and more-than-human others can be challenging for those educated in traditional early childhood pedagogies of place. Exploring 
place as assemblage through storying and a common worlds framework has the potential to disrupt the hold of our current pedagogies and allows us to find, in Haraway's words (2008, p. 301, quoted in Taylor \& Giugni, 2012, p. 117), "new ways of flourishing together in difference without the telos of a final peace."

\section{References}

Corner, J. (1999). The agency of mapping: Speculation, critique and invention. In D. Cosgrove (Ed.), Mappings (pp. 213-252). London, UK: Reaktion Books. Retrieved from: http://www.cfa.arizona.edu/ahgsa/files/ahgsa/Corner_Agency-of-Mapping1.pdf

De Landa, M. (2006). A new philosophy of society: Assemblage theory and social complexity. London, UK: Continuum.

Deleuze, G., \& Guattari, F. (1987). A thousand plateaus: Capitalism and schizophrenia (B. Massumi, Trans.). Minneapolis, MN: University of Minnesota Press. Retrieved from: https://www.ntnu.no/wiki/download/attachments/21463142/deleuzeguattarirhizome.pdf

Duhn, I. (2012). Places for pedagogies, pedagogies for places. Contemporary Issues in Early Childhood, 13(2), 99-107. Retrieved from:

http://www.wwwords.co.uk/pdf/validate.asp? $\mathrm{j}=$ ciec\&vol=13\&issue=2\&year=2012\&art icle=3_Duhn_CIEC_13_2_web

Dumont, M. (2008). Canadian minerals yearbook 2008: Clays. Retrieved from: http://www.nrcan.gc.ca/mining-materials/markets/canadian-mineralsyearbook/2008/commodity-reviews/8528

Goeman, M. (2008). (Re)Mapping Indigenous presence on the land in Native women's literature. American Quarterly, 60(2), 295-302. Retrieved from: http://muse.jhu.edu.ezproxy.library.uvic.ca/journals/american_quarterly/v060/60.2.goe man.pdf

Kind, S. (2012). The studio project: Creating a collaborative space of inquiry. In George Brown College School of Early Childhood \& Ryerson University School of Early Childhood Studies (Eds.), Leading the way: Recognizing the role of early learning lab schools in Canadian universities and colleges (29-33). Retrieved from: http://www.ryerson.ca/content/dam/ecs/news/events/General_Public/images/Leading_t he_way_v2.pdf

Klein, N. (2013, March 5). Dancing the world into being: A conversation with Idle No More's Leanne Simpson. Yes Magazine. Retrieved from: http://www.yesmagazine.org/peacejustice/dancing-the-world-into-being-a-conversation-with-idle-no-more-leanne-simpson

Merriam-Webster. (2015). Dictionary. Retrieved from: http://www.merriamwebster.com/dictionary/map 
Massey, D. (1991). A global sense of place. Marxism Today, (June), 24-29. Retrieved from: http://www.unz.org/Pub/MarxismToday-1991jun-00024

Massey, D. (1994). Space, place and gender. Minneapolis, MN: University of Minnesota Press.

Pacini-Ketchabaw, V. (2013a). Forest studio in Haro Woods [course syllabus]. Victoria, BC: University of Victoria, School of Child \& Youth Care.

Pacini-Ketchabaw, V. (2013b). Frictions in forest pedagogies: Common worlds in settler colonial spaces. Global Studies of Childhood, 3(4), 355-363. Retrieved from: http://dx.doi.org/10.2304/gsch.2013.3.4.355

Pacini-Ketchabaw, V. (2014). Common world pedagogies: University of Victoria Child Care Services professional development series [course syllabus]. Victoria, BC: University of Victoria, School of Child \& Youth Care.

Plainsman Clays Ltd. (n.d.). About Plainsman Clays. Retrieved from: http://www.plainsmanclays.com/index.php?menupath=18

Taylor, A. (2013). Reconfiguring the natures of childhood. London, UK: Routledge.

Taylor, A., \& Giugni, M. (2012). Common worlds: Reconceptualizing inclusion in early childhood communities. Contemporary Issues in Early Childhood, 13(2), 108-119. Retrieved from: http://www.wwwords.co.uk/pdf/validate.asp?j=ciec \&vol=13\&issue=2\&year=2012\&art icle $=4$ _Taylor_CIEC_13_2_web

van Dooren, T. (2014). Care. Environmental Humanities, 5, 291-294. Retrieved from: http://thomvandooren.org/2014/07/19/care-some-musings-on-a-theme/

van Dooren, T., \& Rose, D. B. (2012). Storied-places in a multispecies city. Humanimalia: A Journal of Human/Animal Interface Studies, 3(2), 1-27. Retrieved from: http://www.depauw.edu/humanimalia/issue 06/pdfs/van dooren rose.pdf

Waghorn, K. (2011). Place as assemblage: Montreal garden mapping. In S. Caquard, L. Vaughn, \& W. Cartwright (Eds.), Mapping environmental issues in the city: Arts and cartographic cross perspectives (pp. 197-208). Berlin: Springer. 


\title{
The Colour of Country
}

\section{by Adam Duncan}

\begin{abstract}
Author's Bio
Adam Duncan is a proud Biripi man and an early childhood educator currently working with Reconciliation Australia. He lives on Ngunnawal Country in Canberra, Australia. He works with early childhood educators and young children to explore concepts of contemporary Aboriginal identities and ways in which to relate to Australia's Indigenous cultures in meaningful ways. He engages with these cultures and histories through story, drawing on his Aboriginal heritage and the Indigenous concept of Dreamings. Email: Adam.Duncan@Reconciliation.org.au
\end{abstract}

\begin{abstract}
This article explores my relations to Country through colour. It is accompanied by three art pieces I have recently painted. It has a particular focus on my changing relationship to Biripi and Ngunnawal countries in Australia and the ways this relationship was impacted by my travelling to the "Learning How to Inherit in Colonized and Ecologically Challenged Lifeworlds" symposium in Victoria, British Columbia. As depicted in the paintings, my understandings of Country are coloured by the heritage-based connections to land that continue to shape my contemporary Aboriginal identity, my growing engagement with and understanding of the contemporary common worlds I inhabit, and the discussions of place and identity that took place at the symposium.
\end{abstract}

Country in Aboriginal English is not only a common noun but also a proper noun. People talk about country in the same way that they would talk about a person: they speak to country, sing to country, visit country, worry about country, feel sorry for country, and long for country. People say that country knows, hears, smells, takes notice, takes care, is sorry or happy. Country is not a generalised or undifferentiated type of place, such as one might indicate with terms like 'spending a day in the country' or 'going up the country'. Rather, country is a living entity with a yesterday, today and tomorrow, with a consciousness, and a will toward life. (Rose, 1996, p. 7)

Deborah Bird Rose interviewed many different Aboriginal people across Australia for her 1996 Nourishing Terrains. In some ways, the shared definition of Country that she reported on - as lively, living, and familial — speaks to me as an Aboriginal Australian. But I do not have the lived and traditional ways of understanding this definition. I was born in Sydney, New South Wales, 357 kilometres south of my traditional Biripi lands, or Country. I have never spent 
more than a week on Biripi Country, and I do not understand its lively nature from first-hand experience.

This paper reflects a small portion of my journey toward understanding my Aboriginality, and my connections to Australia as a "lively" landscape. This journey has been shaped by my participation in the Common World Childhoods research project (Duncan, Dawning, \& Taylor, 2015) and my recent travel to Victoria, British Columbia, for the September 2014 "Learning How to Inherit in Colonized and Ecologically Challenged Lifeworlds" symposium. This journey has also been impacted by my ongoing explorations of Aboriginal visual arts traditions, techniques, and, in particular, the use and contrast in colour across the landscapes I continue to explore. In this article, I discuss the ways in which my artwork has changed and speak to the influences on my artwork before, during, and after my involvement with the Common World Childhoods research project and the "Learning How to Inherit in Colonized and Ecologically Challenged Lifeworlds" symposium. I explain how the colours of Country have allowed me to explore my ideas of Aboriginality, Country, and common worlds.

\section{Locating Myself}

I have been working as an early childhood educator for the last six years in a community-based preschool and long day care service ${ }^{8}$ in Canberra, in Australia's Capital Territory. Canberra is built on the lands of the Ngunnawal people, an Aboriginal language group who have ancestry in the area spanning back 50,000 years. I belong to a different language group, known as the Biripi people, whose traditional lands are the coastal lands of the Manning River region on the New South Wales (NSW) mid-north coast. The traditional lands of the Biripi and the Ngunnawal are quite different, one coastal and warm temperate and one in the cool temperate highland limestone plains. The distance between them is 585 kilometres. Because I did not grow up on Biripi Country, my understandings of traditional coastal Biripi culture and Country are extremely limited. After beginning to work with young children I endeavoured to learn more about my culture in order to share what little I could with the children with whom I work.

I was restricted to speaking to the contemporary nature my indigeneity, and to the idea that my understandings of what it means to be Indigenous are wholly informed by lived experience. I worked to embed some of this living culture in my practice with young children through practicing my culture, without focusing on how authentically "Aboriginal" that culture might have been.

The disconnection I feel with Biripi land and community has forced me to think about my Aboriginality in reference to the ways that it is understood and "done" by Aboriginal people in the other communities in which I have lived. These are the Ngunnawal and Wiradjuri communities of Canberra and Bathurst, both towns that are surrounded by grazing country. Outside my intangible grasp that I am, in fact, a Biripi man, much of my early understandings, like those of most other Australians, came from media portrayals of Aboriginal peoples in

\footnotetext{
${ }^{8}$ The term long day care is used in Australia. Long day care centres typically operate for at least eight hours a day on normal working days. For more information, see 
Australia. The negativity that continues to be portrayed by Australian media could potentially leave me dissatisfied with my lot in life. Social and political issues, lower life expectancy figures, and tokenized, archaic, and misappropriated imagery flood media coverage of Aboriginal Australia. I worried that I lacked the connection to place that would allow me to share my culture with my preschool students. I began looking elsewhere, and I found a point of connection: Artwork.

\section{Aboriginal Art}

The visual arts have a rich and varied history in Australian Aboriginal cultures; however, I have been most influenced by the works of traditional Australian Aboriginal artists. In particular, I have been drawn to the central desert paintings, which are the Aboriginal artworks that Australia's dominant Western culture has deemed most noteworthy. The works of the Papunya Tula artists of central Australia are particularly famous, and the colours they use are representative of the deep red earth and blue sky of the desert and arid regions that take up more than $70 \%$ of Australia's landmass (Australian Government, 2013).

The Papunya Tula art movement started with a public mural commissioned by school teacher Geoffrey Bardon and painted by local Luritja and Pintupi men (Papunya Tula, 2014). The name of the artists' collective, Papunya Tula, is derived from the name of a settlement, Papunya, which is located northwest of Alice Springs in the central desert of Australia. Traditionally, Aboriginal artwork was not done on boards or canvases for public display. It contained culturally significant and sensitive information for use in sacred ceremonies that was not appropriate for a general audience. This culturally sensitive art was often painted on people's bodies or on the ground, and always in-situ on sacred sites where ceremony took place. The Papunya Tula artists endeavour to remove the sacred elements of these traditional practices and techniques while maintaining the visual style and appeal of the central desert art style. These artworks depict traditional concepts of Country in contemporary style. They are visually appealing, but the symbols of desert Country have little relevance to someone living in the grassy, mountainous, and relatively temperate region of Canberra, where the colours and the temperatures are much more moderate. When I first began to paint, I experimented with the style and colour of the Papunya Tula artists because it was their artworks that originally influenced my understanding of Aboriginal art. This experimentation led to the development of the work depicted in Figure 1. 


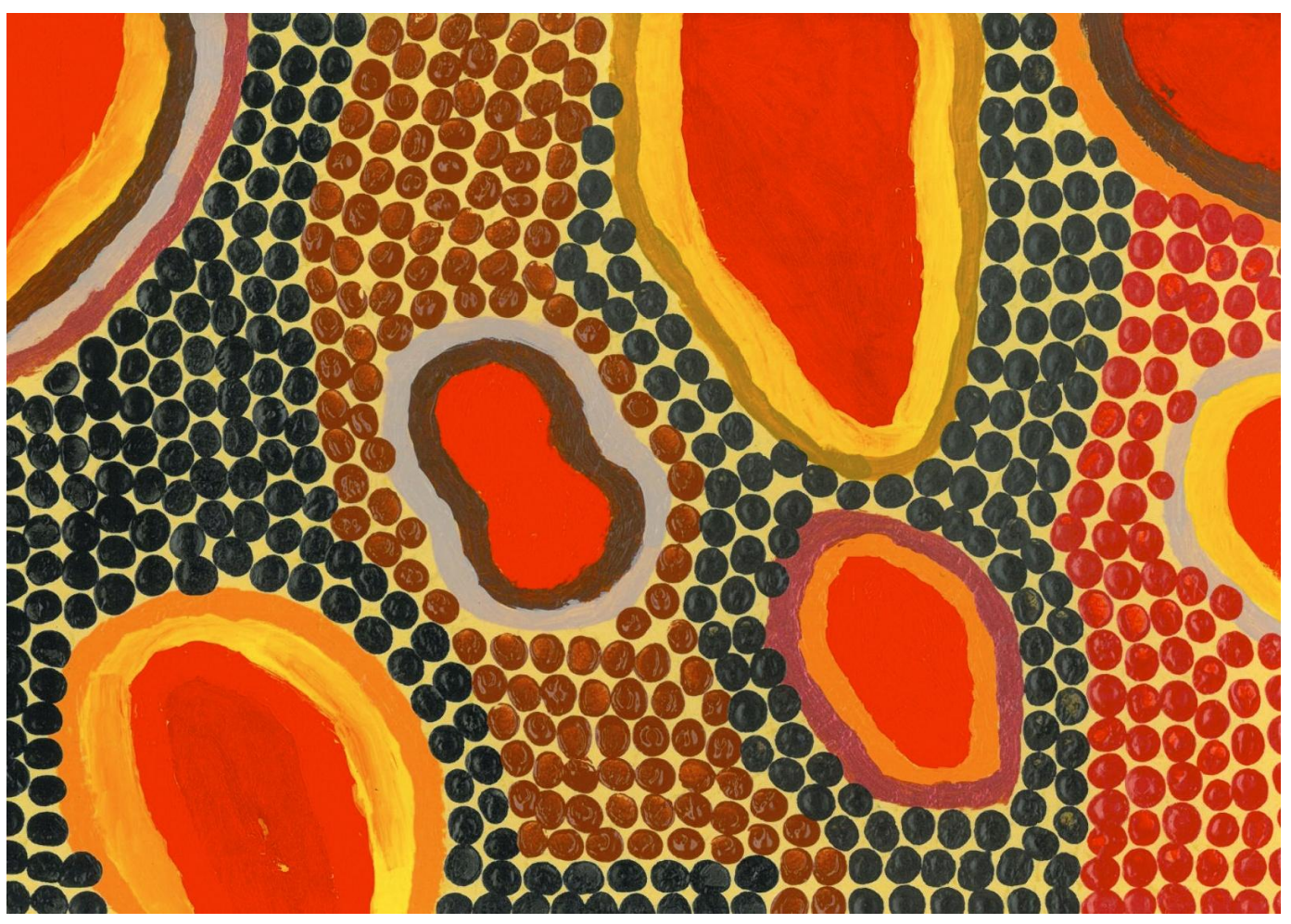

Figure 1. "Heartland," painted by the author.

All the time that I have been painting in desert dot painting style, I have known that a huge part of Aboriginal identity is connection to place, or Country. The importance of this connection is based on relationships and on traditional and lived knowledge of the place and its human and more-than-human inhabitants. I did not have any of this knowledge or connection to my own Country because I had never walked Biripi land and had never met the key members of the Biripi community that my ancestry ties me to. My only points of connection were that my grandparents lived in Taree, the main town built on Biripi land. I can claim ties to the Country through my grandparents; however, I do not know what it means to live on and understand Country as "nourishing terrain" (Rose, 1996). I began to long for some understanding that transcended my essentially Westernized and theoretical understanding of Country-as-land. I wanted to be able to paint and to learn how to relate to and understand land-as-Country through my own direct relationships with it. I wanted to be able to explore the nourishing part of Country that I live in, to feel myself be nourished by it and express this nourishment in my artwork.

\section{Common World Childhoods Research}

As well as being influenced by the Papunya Tula central desert artists, I also found myself making connections to Aboriginal culture and Country within the community in which I was living. These were not traditional, spiritual, or even necessarily Aboriginal connections, but academic ones. Working in an early childhood centre on the campus of the University of Canberra, I met Affrica Taylor, an academic researcher with a background in Aboriginal education and an interest in Aboriginal and non-Aboriginal people's relationships to place or 
Country. Affrica was working on a project called Three Sisters, which linked up three early childhood education sites that were either run by Aboriginal educators or had a strong interest in Aboriginal education. This project explored the ways in which Aboriginal perspectives were offered in these three early childhood centres, all in vastly different locations. I was invited to be a part of this research, and I was lucky enough to travel with my new colleagues to Atitjere, a remote Aboriginal community of Eastern Arrente people north of Alice Springs. We also travelled to Redfern, an inner Sydney suburb and a community with a long urban Aboriginal history that is built on the land of the Gadigal people of the Eora language group. I met Aboriginal and non-Aboriginal people working in early childhood education, and this experience broadened my understandings of how differently the identities of Aboriginal peoples in different parts of the country are formed.

For the last two years, I have been participating in a Common World Childhoods research project with Affrica and the children from the Wiradjuri Early Childhood Centre (for more information on this project, see Duncan et al., 2015). Relatedness to place is a huge focus of our common worlds research. The common worlds framework we use in our research regards children's lives as influenced by much more than their social and cultural backgrounds and contexts. It follows how children learn from the more-than-human common world environments in which they live, in particular from the plants and animals that are there with them (Taylor, 2013; Taylor \& Giugni, 2012). The relationships I have observed between these Canberra children (many of whose families come from other parts of the world) and the plants and animals of their common worlds in Ngunnawal Country have begun to change the way in which I relate to Country as both an early childhood professional and as a Biripi man living off Country. Simply spending time with the children, plants, and animals every week in a particular bush area of Canberra was enough, to begin with. As I witnessed the burgeoning relationships that the children developed over time with more-than-human others of this place, I began to see more myself. This was not so much a traditional spiritual awakening as one prompted by very ordinary, everyday encounters with a well-colonized and damaged place. The land we visit and relate to is far from pristine, and many of our encounters with the morethan-human include exploring our shared relationships with a damaged natural environment that is regularly littered with rubbish and waste. These relationships and the explorations of them led to the development of the artwork shown in Figure 2. 


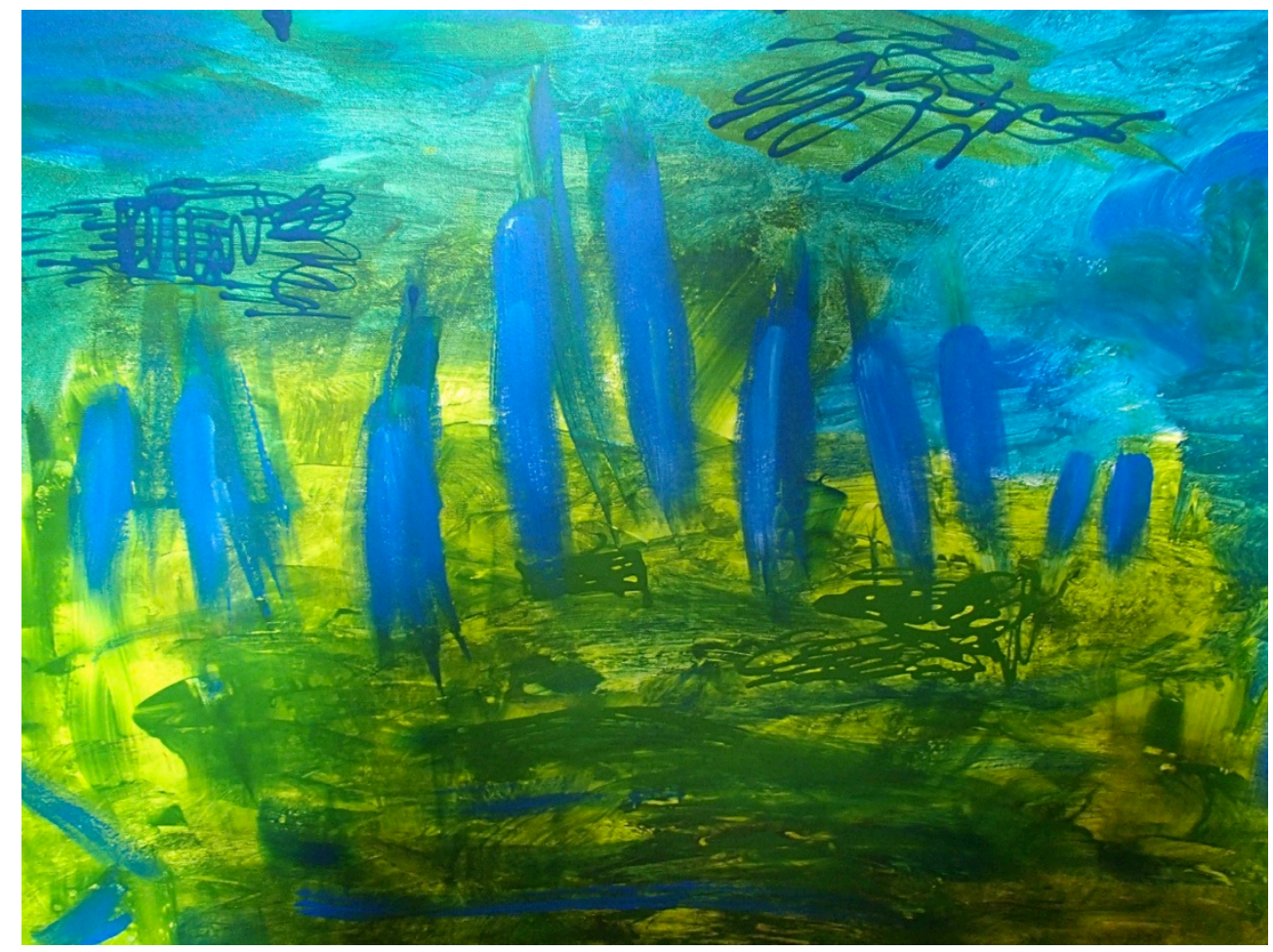

Figure 2. "In The Undergrowth," painted by the author.

My use of colour in this piece (Figure 2), like my understandings of Country, has changed. Instead of drawing solely on my cultural heritage and my view of Country as filtered through the lens of traditional desert Aboriginal art, the blue and green elements of this painting reflect my shifts into the increasingly familiar common worlds of academia and Ngunnawal Country. This painting depicts how I shared these spaces with children, plants, animals, waste, and geological formations that all sit apart in their uniqueness and yet are interconnected because they are now together and in relation to this place on Ngunnawal Country. I began seeing beyond my human differences and noticed that our presence on Country was not special in any distinct way. The above painting is more abstract and "messy" than the one depicted in Figure 1; it reflects the lack of professional control I felt, the nature of the shared environment, and the presence that we, as colonized, contemporary, and relatively "unrelated" individuals have within these common worlds.

\section{“Learning How to Inherit” Symposium}

In September, 2015, I was invited to attend a symposium organized by the Common Worlds Research Collective (http://commonworlds.net/) called "Learning How to Inherit in Ecologically and Environmentally Challenged Lifeworlds." It was held in Victoria, British Columbia, on the unceded lands of the Coast Salish peoples. I had never been away from Australia before and I did not anticipate that travelling away from the country in which I had spent my whole life would have such a big impact on me. I relished the idea of travelling to British Columbia, though, because I had been told that the culture of its First Nations people was still very strong and present. I landed in Vancouver and travelled directly to the ferry 
terminal, and while I was struggling to come to grips with being driven on the opposite side of the road to the one driven on in Australia, I reflected on the colours of the countryside. I could not see any of the sharp primary colours from the Australian colour palette that I am so accustomed to - its deep iron-rich red soils, its dry yellow grasses, its bright azure blue skies that cover all the different Australian landscapes and which are reflected in the oceans surrounding it. The colours I noticed in Vancouver and Victoria were whites, greys, greens, and both lighter and darker tones than those I was accustomed to seeing. Even the ocean seemed a steely grey-blue. These radically different hues and colours spoke to the distance I had travelled from the south to the north of the globe, and to what a physically different place I had come to.

The symposium was a hugely exciting experience for me. It not only extended my world view as an early childhood educator by building on my professional philosophy about the importance of continuing to decolonize early childhood education and by extending the common worlds focus of my current practice to include, for example, a complicated and ongoing relationship with waste, but it also spoke to me as an Indigenous Australian interested in deepening my understanding of Indigeneity.

A number of experiences at the symposium helped me see the similarities between Tsawout, Anishinaabe, and Australian Aboriginal peoples' understanding of the liveliness of place, land, or Country. The first was speaking with Tsawout Elder Earl Claxton Jr. at his greenhouse in the WSÁNEĆ community. Claxton showed us the ways in which plants from the local area have been traditionally used to ensure good health, literally to nourish his people. Hearing Vanessa Watts-Powless (2014) speak about her Anishinaabe people's understandings of land and the importance of ceremony in her talk "Indians, Animals, Dirt: Place-Thought and Agency Amidst Indigenous Cosmologies" ${ }^{\prime \prime}$ brought home the parallels between Anishinaabe understandings of agency and thought as originating in place and the widespread Aboriginal Australian belief that Country is alive, has a consciousness, and produces a "will toward life" (Rose, 1996) in both physical and spiritual ways. Watts-Powless spoke to an all-encompassing agentic notion of place as producing everything, including all of the other species that came before us and the instructions for human social organization. She made it clear that placethought and agency determine all relationships. This idea made me even more resolved to foster my relationships with places back in Australia - with my traditional Biripi Country and with the Ngunnawal Country in which I now live.

\footnotetext{
${ }^{9}$ Watts-Powless's presentation can be viewed at http://commonworlds.net/learning-how-to-inherit-colonized-andecologically-challenged-life-worlds/
} 


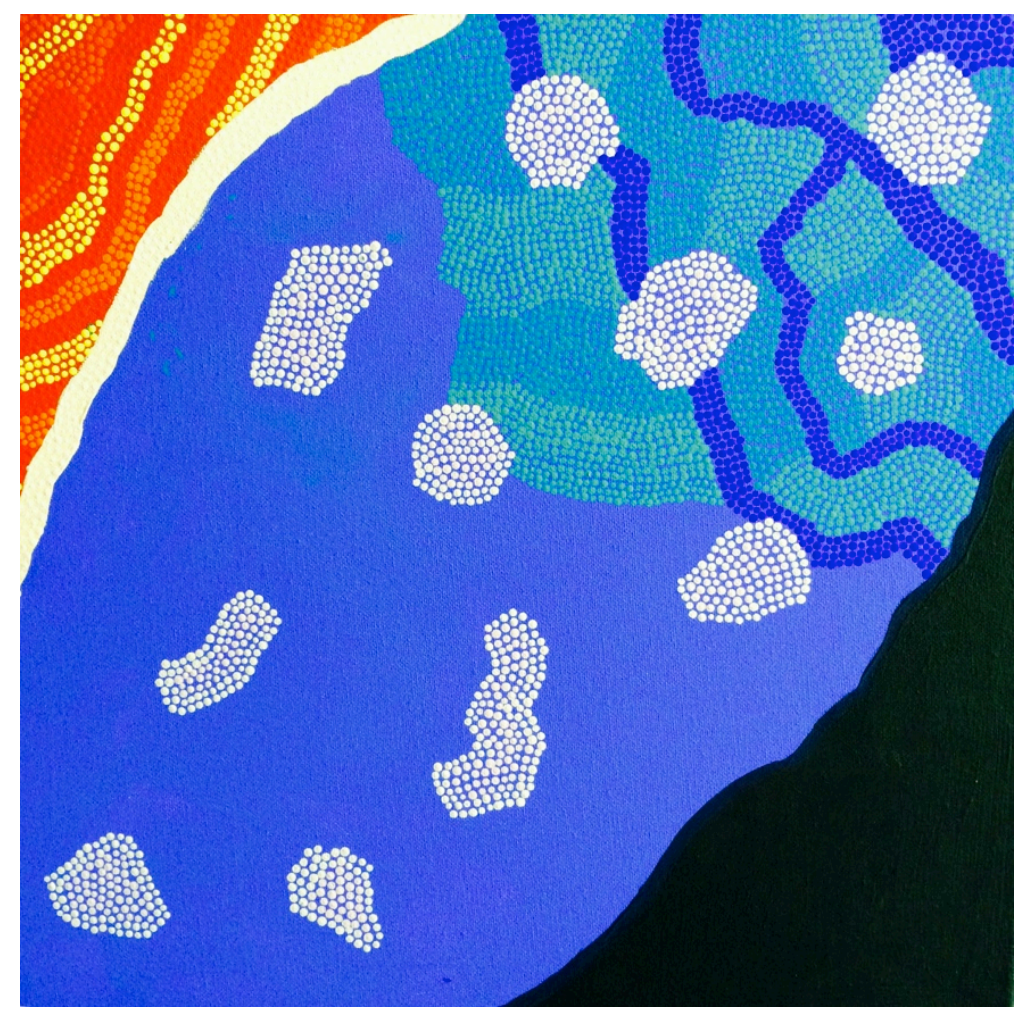

Figure 3. "Learning Journey," painted by the author.

As I journey to places for greater understanding, my work changes. The complexity of these ideas and the journey I am undertaking is an ongoing one, and I continue to learn while painting. My latest work attests to the complexity of my journey, including the learning experience of painting, writing this article, travelling the world, and building relationships, communities, and my understandings of Country. My experiences while in Victoria, BC, have inspired a new, more complex artwork, as seen in Figure 3. It depicts two land masses, Australia and Canada, separated by an ocean. The design of the ocean not only represents the continuous motion of the ocean, but also symbolizes the life within. The liveliness of Country is worldwide.

I continue to draw on the art of Papunya Tula, utilizing the popular dot painting style and shapes, but I do so as a way of recognizing the significance of their influence on me, and through an appreciation for the aesthetic. I have, however, tried to incorporate the differences of place in the respective colour palettes I witnessed while travelling in each country. The colour palette of Australia incorporates the iron-rich soil, golden grass, and warmth, whereas the Victorian colour palette focuses on the dark green of foliage, black volcanic stone, and steely blue-grey oceans. Between both the rufous Australia and the dark green Victoria, the ocean separates and connects the two lands with streams of shared understandings crossing the ocean's surface in threads of rich ultramarine. These streams of shared knowledge, this flowing interchange of ideas and thinking, I hope will continue to develop, and I hope the relationships that I have with the lively Australian and Canadian Countries will only deepen with time. 


\section{Conclusion}

The academic and early childhood educator common worlds communities who were present at the "Learning How to Inherit in Colonized and Ecologically Challenged Lifeworlds" symposium continue their work, as do Affrica and I, to relate much more strongly to place. We do this in the ways we can, understanding our place in the world from our own particular cultural viewpoints and bringing to our reflections a countless number of life experiences and world views. My particular understandings of place, Country, indigeneity, and my place, not only within Australia but in the world, continue to influence my artwork.

Finding that understandings of Country and land relationships are so very synchronous across Aboriginal Australian and First Nations cultures has shifted my understandings of community, culture, and Country yet again. The agency and liveliness of Country, as discussed in Nourishing Terrains (Rose, 1996), is present across the world, and this liveliness is not solely the experience of Biripi, Ngunnawal, or Wiradjuri peoples of Australia. I am beginning to understand also that all the lively and agentic places that the world's Indigenous peoples are witness to, and relate to, can be experienced in a myriad of ways, and that indigeneity need not be an integral part of these relationships.

In exploring different relationships to place during the symposium, we were firmly within the cultural interface (Nakata, 2007) of Indigenous/non-Indigenous place relationships. My position added to the interface of Canadian/Australian Aboriginal world views. The cultural interface that exists between Indigenous and non-Indigenous knowledge systems is where these relationships with place can be formed. Although the cultural interface involves ongoing tensions around the legacies of colonial relationships, perhaps it is through journeying in the cultural interface of Indigenous/nonIndigenous/Canadian/Australian/Biripi/Tsawout/Anishinaabe that we, as a community, might reach a truly shared sense of the significance of Country. For me the cultural interface is the palette on which "black" and "white" Indigenous and non-Indigenous knowledges blend, where differing world views can be recognized and understood to be different, and where our shared understandings can be viewed as unique but sharing a common world of focus.

It feels as though my journey toward better understanding my relationship with lively Country is only just beginning. My artwork helps me reflect on the learning I have done during my work with the Common World Childhoods research project and my travels to British Columbia. I feel that as I continue to read, write, and paint, I will engage with new thinking, new ideas, and new world views that will continue to expand my palette, making my view of the world more colourful, and leading to more vibrant and varied depictions of thought, relationship, and Country as nourishing terrains.

\section{References}

Australian Government. (2013). The Australian desert: The outback of Australia. Retrieved from: http:/www.australia.gov.au/about-australia/australian-story/austn-desert-outback 
Duncan, A., Dawning, F., \& Taylor, A. (2015). Unsettling yarns: Indigenous architectures, contemporary dreamings and newcomer belongings in Ngunnawal country, Australia. In V. Pacini-Ketchabaw \& A. Taylor (Eds.), Unsettling the colonialist places and spaces of early childhood education (pp. 259-291). New York, NY: Routledge.

Nakata, M. (2007). Disciplining the savages: Savaging the disciplines. Canberra, Australia: Aboriginal Studies Press.

Papunya Tula. (2014). Papunya Tula Artists Pty. Ltd: History. Retrieved from: http://papunyatula.com.au/history/

Rose, D. B. (1996). Nourishing terrains: Australian Aboriginal views of landscape and wilderness. Canberra, Australia: Australian Heritage Commission.

Taylor, A. (2013). Reconfiguring the natures of childhood. London, UK: Routledge.

Taylor, A. \& Giugni, M. (2012) Common worlds: Reconceptualising inclusion in early childhood communities. Contemporary Issues in Early Childhood, 13(2), 108-120.

Watts-Powless, V. (2014). Indians, animals, dirt: Place-thought and agency amidst Indigenous cosmologies. Keynote presentation at "Learning How to Inherit in Colonized and Ecologically Challenged Lifeworlds" symposium, University of Victoria, British Columbia, September 27, 2014. 


\title{
Engaging With the Messiness of Place in Early Childhood Education and Art Therapy: Exploring Animal Relations, Traditional Hide, and Drum
}

\author{
by Narda Nelson, Emily Coon, and Anna Chadwick
}

\section{Authors' Bios}

Narda Nelson is a master's student in the School of Child and Youth Care at the University of Victoria. She works as part of a multispecies inquiry in early childhood education. Her research and presentations focus on multispecies relations and nature pedagogies within early childhood spaces. Email: nelsonn@uvic.ca

Emily Coon is a master's student in the School of Child and Youth Care at the University of Victoria in Canada. She is Haudenosaunee from Tyendinaga Mohawk Territory in Ontario. As a traditional singer and drum carrier, her practice and research focuses on the decolonizing possibilities that arise when children are in relationship with Drum. Email: eccoon@uvic.ca

Anna Chadwick is a master's student in the School of Child and Youth Care at the University of Victoria. She works as an art therapist for children and youth in northern British Columbia. Her current research focuses on arts-based methodologies with Indigenous youth in northern Canada.

Email: Anna.Chadwick@sd87.bc.ca

\begin{abstract}
How place is conceptualized impacts the way everyday moments and relationships unfold. This paper explores possibilities for shifting our practices by engaging with an ethic of doing. Drawing on ecofeminist, nomadic, and Indigenous perspectives, we aim to open up space for more accountable, political practices that acknowledge the diverse realities of the children and youth we work with. We present vignettes from our practices to illustrate possibilities for (re)conceptualizing the deeply embedded, normative colonial assumptions in the places we work, and introduce political, contextual, and messy ways of doing in place.
\end{abstract}


In this paper we, Narda (white settler), Anna (racialized settler) and Emily (urban

Haudenosaunee), explore the ways in which our practices with children and youth contribute to understandings of place. While excited about the potential our work holds for promoting inclusive, ethical relationships, we are keenly aware that our practices are dominated by EuroWestern theories of childhood development (Burman, 2008; Cannella \& Viruru, 2004; PaciniKetchabaw, Nxumalo, Kocher, Elliot, \& Sanchez, 2015). Much of what we do in our work goes on without consideration as to how we might be perpetuating the colonial values still prevalent in contemporary Canadian society. We feel the need to interrupt colonial manifestations in an effort to (re)conceptualize place as more than a neatly contained backdrop against which childhood development happens. To open up our understandings of what accountable practices might look like, we engage with a contextualized, reflexive ethic of doing to attend to the tensions of being present in place.

\section{Settler Colonialism in Canada}

Rendering Canada's colonial history visible reveals the link between dominant theories of childhood development and the continuing effects of settler colonialism in the places we practice. The devastating project of settler colonialism, with its ongoing drive to measure and order terra nullius for the colonizers' primary benefit, brought attitudes and assumptions about how people should be categorized and controlled (Taylor, 2013). As such, the way children and youth continue to be conceptualized in Canada is "simultaneously colonial (with privileged, invisible viewers and hypervisible, temporalized, and embodied others) and administrative (ranking, judging, making efficient and productive)" (Lesko, 2001, as cited in PaciniKetchabaw et al., 2015, p. 25). Founded on prescriptive notions of linear and normative development, this approach subsumes children, youth, and the places they inhabit under modernity's universalizing project (Burman, 2008; Pacini-Ketchabaw, 2011; Taylor, 2013). In this way, the homogenized view of anywhere childhood must be seen as a simultaneous operative alongside colonialism.

\section{Introducing Our Practices}

In the face of ongoing settler colonialism, we acknowledge the unique expressions of what it means to live here together, through experiences in place, in time, in culture, and in community. Accountability within our practices "requires an airing of neglected, marginalised or silenced place stories as a central political task" (Taylor \& Giugni, 2012, p. 116). While settler colonialism manifests itself differently in early childhood education (ECE) and art therapy, we share vignettes to collectively explore ways of acknowledging and rethinking these tensions in our practices.

Narda's engagement with predominantly white settler children in an urban Vancouver Island setting focuses on the ways young children's relations with animals, plants, and landscapes are framed. She sees her work as political, drawing on ecofeminist and environmental humanities perspectives to "interrogate preset codes of ethics for their colonial legacies" (PaciniKetchabaw, et al., 2015, p. 175), as explored through everyday worm-child encounters. 
Anna, an art therapist, works with Indigenous youth in an isolated rural community in northern British Columbia. Drawing on nomadic perspectives of "borders," she focuses on significant moments of gathering and creating with girls and cultural leaders to sew with traditional moose hide. These collective acts impact the community she works with, her practice, and personal connections to land. Anna notes how noticing and reflecting on these moments of "doing" is vital to ethical practice.

In the final vignette, Emily draws on traditional teachings and Indigenous and decolonial theories to explore the impact of Drum's presence in a colonial childcare setting. By sharing her urban-off-reserve tensions of bringing Drum into place with young children, Emily grapples with opening up space for an ethical and political Indigenous presence amid the settler colonial notions of child development prevalent in her ECE practice.

The work we engage in is unsettling at times and far from simplistic. We see potential in moving away from colonial (re)productions in our practices by foregrounding collective engagements and embodying an ethic of doing.

\section{Inspiring Practice}

To disrupt settler colonialism's universalizing effect, we engage with an ethic of doing by drawing attention to the way place stories are co-constituted, profoundly relational, and emergent (Taylor \& Giugni, 2012). We employ a politicized ethic to honour unique histories and heterogeneous, material entanglements that happen in the places we work. Just like the individuals we work with, the messiness of place is never done-it is constantly unfolding and distinct. This approach must be contextualized as we alter our perceptions of viewing children through a generic lens, thereby more accurately reflecting the diverse contexts of our practices (Pacini-Ketchabaw et al., 2015). With these values, we hope to subvert the anthropocentric, transcendent ethical paradigms privileged in colonial reproduction and foreground silences, histories, and new possibilities.

As human services practitioners, we need to ask ourselves where the dominant stories have brought us. Who or what is missing from the grand narratives underwriting Euro-Western theoretical approaches to childhood development? Are we bold enough to foreground the messy, sticky unknowns and turn away from the prescriptive lens that has brought us to this point? Our engagement with an ethic of doing is not an easy proposal to transcend settler colonialism. In response to the messy moments we encounter in practice, we aim to risk doing in a way which allows the multispecies relationships, fleshed moose hide, and unsettling voice of Drum to coshape the ways we interact with children, youth, and place. Everyday practice necessitates a constant doing, but this ethic is also about being, here, persistently reflexive in place (Saraceno, 2012). What happens when we are fully present in these uncomfortable moments of doing differently? We offer the following vignettes to illustrate such moments.

\section{Worm-Child Encounters: Messy Animal Relations in Early Childhood-Narda Nelson}

My practice is situated on the Lekwungen and WSÁNEĆ territories in southwestern British Columbia. It is a far cry from the Woodland Cree territory where I grew up as a white settler in 
northern Alberta, and I am reminded of this each time I go for "animal walks" with the young children and educator colleagues I work with. Oak-moss-stone-cedar-crow-child-deer encounters are not the same as the moose-poplar-hawk-muskeg-mouse-coyote memories I recall from my own childhood. And yet there is something similar. The children, educators, and I walk together, locating ourselves in this colonized place through stories and embodied engagement. Noticing. Being noticed.

Paying attention to the messiness of multispecies relating requires vigilance on my part to avoid simply reproducing Euro-Western frameworks of quantifying "others" through our inquiry. By drawing on ecofeminist and environmental humanities perspectives, I offer the following moment with its simultaneous engagement of the ongoing power dynamics and toxic residues of colonialism and industrial consequences.

\section{Corporeal connections}

Holding hands, stomping leaves, avoiding traffic, and joking about deer, elephants, crows, and other animals we might see along this walk, we turn down a residential sidewalk with noses held to stop them from filling with the belch of diesel fumes produced by a nearby idling van. Gas fumes and muffler drips produce residue on the pavement and in our lungs. Children hold noses and squint eyes when passing through.

"Worms!" Worms are abundant above ground after the rain. Thin, determined membranes inch along under the close gaze of children. How do they navigate gasoline rainbows that span segments of wet concrete?

Gas and worms both come from under ground. Worms willingly come up after the rain to cover distances more easily. Gasoline/diesel is forced by humans from the earth, emerging through the millennia of carbon animal forms compressed deep within the ground. In a corporeal sense, through our shared carbon remnants, we are connected to the gasoline as well as the worms (van Dooren, 2014). Fossil fuel residue (pollution/climate change) ripples throughout geopolitical-environmental-sovereignty debates, Burnaby Mountain stand-offs, and Defend Our Coast protests, which also inform this moment.

Little feet, hands, eyes stop to take a closer look at the worms. Some are bloated from the rain; a few are dry, stranded on concrete and seemingly dead. But not! One end wiggles, surprisingly resilient, proving otherwise. Life and death coexist here. Children stop for worms to take a closer look, moving one onto the grass where it "belongs." Dead or alive, a worm in any form on concrete produces a curl of human heads to ponder. Together:

\section{Is it dead?}

He is my friend. I'm moving him so he is safe.

But I won't step on him.

Cover him with leaves to protect it!

I'm going to step on him! 
No!

He is my friend too.

Where are the (other) animals?

Worms do vital decomposition work, creating rich soil that supports a flourish of plant life (Taylor \& Pacini-Ketchabaw, 2015). But worms can be colonizers too. Some worms, such as Arctiostrotus vancouverensis, have coevolved on Vancouver Island and the Olympic Peninsula for thousands of years, decomposing moist, cool, organic matter such as conifer logs. Canadian night-crawlers, Lumbricus terrestris, were introduced by settler farmers and/or fishermen to enhance livelihoods (Sayler, 2012). This invasive species, with its particular eating habits and ways of relating, alters the balance struck between Arctiostrotus vancouverensis and its west coast counterparts, consuming the forest floor organic layer at a pace that pushes out native species such as worms, salamanders, and ground-nesting birds (Sayler, 2012). Regardless of origins, all worms invite the children's attention to the subterranean worlds they co-inhabit, affecting them through moist-body-wiggles and "karate kicks" against palms.

We stop to look at a glaucous-winged gull and see what it is doing. It looks back, watchful, removing worms from the pavement too. In their own way, these gulls embody the histories of this place through the disruption of their coastal diet; ecological changes over the past 30 years have forced the birds inland to rely on worms and garbage instead of a traditional shoreline diet of shellfish (Crawford, 2015). For very different reasons, gulls and children are connected through a cofascination with worms in this place.

One child tells me that she knows animals because she watches Animal Planet on TV. Another child yells, "More animals! More!" after each creature encounter. I am reminded of a biologist's lament about giving wildlife tours to people who approach such moments through the lens of nature shows, where on-screen action is choreographed and non-stop. Commodification seeps into the places childhood co-inhabits in a variety of forms. Engaging multispecies pedagogies within early childhood education involves much more than observing children in so-called nature spaces (Taylor \& Pacini-Ketchabaw, 2015).

Multispecies relations

Multispecies interconnections emerge as an unpredictable but positive way of subverting societal preoccupations with individual (human) achievement (Taylor, 2013; Taylor \& PaciniKetchabaw, 2015). Who else shares this place? Learning moments with even the tiniest of creatures, such as worms, helps pull us out of our human reveries in the way they refuse to "exclusively follow human plans, wishes and desires" (Taylor \& Pacini-Ketchabaw, p. 20). It is a mistake, however, to assume that these relationships are neutral; the reverberations of colonial histories, ongoing sociopolitical power relations, and ecological impact exist here too. ECE work is messy, complex, and far from innocent, including my own position as a white settler on this colonized land. 
My practice is also situated within the paradox of a growing societal demand for nature-based early education and a heightened sense of urgency regarding the rapid human-induced loss of biodiversity and the threat of extinction facing many forms of life on the planet (Collard, Dempsey, \& Sundberg, 2014; Rose et al., 2012; Taylor \& Pacini-Ketchabaw, 2015). While the richness of these experiences coupled with romanticized conceptualizations of "children in Nature" may soothe my own eco-anxieties (Taylor, 2013), the growing demand for land-based education cannot be separated from ongoing colonial processes in this country. I am concerned about the potential for reinscribing colonial assumptions and values through "back to the land" approaches to early childhood education. Whose land are we "getting back to"? Colonialism forcibly removed Lekwungen-speaking peoples from this place. Images of predominantly white, middle-class children in "pristine Nature" inadvertently serve as a neocolonial repackaging of the notion of terra nullius (Taylor, 2013). And, ironically, as nature-spaces get eaten up by residential, industrial, and commercial development, First Nations reserves "are becoming the de facto greenbelts for urban areas" (Penn, 2006, p. 4).

The childcare centre I work with goes on weekly walks with an intention of engaging with the landscape and its inhabitants as part of a multispecies inquiry initiated by the educators. We attend to creatures found on a residential sidewalk as readily as we do those found in a forested area. The environment exists with(in) and around us. Everywhere. Children's indiscriminate creature curiosities inform the way we think about the environment, making it easier to resist the tendency to conceptualize nature as separate from society and position them in binary opposition (Taylor, 2013). The way the educators and I notice, together with children, constitutes the places we live in as multispecies achievements versus human-only spaces (Rose et al., 2012). It also gives us a chance to learn through observation with plants, animals, rocks, etcetera instead of projecting ideas about how and where they should live, thereby undermining colonial understandings of how this place should be ordered, populated, and managed. There is much more happening here than the manicured lawns and institutional concrete suggests.

Worm-child engagements help reorient narrow understandings of land (as physical, for example) to a relational place wherein children learn to consider plants, animals, etcetera as active, coshaping agents with their own stories (Pacini-Ketchabaw, 2012). Acknowledging place as relational also interrupts colonial extraction-assimilation frameworks; as Leanne Simpson (2013, interviewed by Klein, 2013) explains,

the act of extraction removes all of the relationships that give whatever is being extracted meaning. Extracting ... is stealing - it is taking without consent, without thought, care or even knowledge of the impacts that extraction has on other living things in that environment. (para. 11)

Intentions, assumed roles, and sociopolitical-economic histories walk with us, ready to ebb and flow. Ready to serve purpose. If my purpose through practice is not political in response to the continued power struggles that impact the way place is understood, I have to question what it is I am doing here. Shifting pedagogical approaches away from prescriptive, status-quo ways of being and doing that have brought us to this point feels imperative in the face of the ecological challenges ahead. Opening up possibilities for more sustainable, ethical futures by recognizing 
interdependencies and subjectivities across species lines is exciting and compelling to engage with as I attempt to do differently in practice (Saraceno, 2012).

\section{Transformation in the Borders: Gathering, Creating, and Intermingling With Moose Hide_Anna Chadwick}

The youth I work with live in an isolated northern Canadian town surrounded by beautiful, contested land; they are related to the Tahltan Nation who has occupied the territory since time immemorial. As a school art therapist, I struggle to create a practice where youth feel honoured and supported. My work is imbued with geographic, material, relational, and symbolic colonizations; messiness and tensions assemble in this place, not just on the land we occupy, but in borders of places that encompass "co-inhabiting with differences" (Taylor \& Giugni, 2012, p. 113). Drawing on theories of nomadic feminism in this vignette, I reflect on an experience of gathering together with Indigenous girls aged 12-14 to sew with moose hide in what became an ethic of doing - a collective act that expanded connections to land and community and understandings of belonging.

The portable

Excited by a request from the girls to "make stuff and hang out together," I asked two cultural leaders, Penny Louie and Sonia Dennis, to gather together to sew at the school once a week. I have deep gratitude and respect for these women, who bring strength, determination, wisdom, and courage to our group and the broader community. In their words and actions, Penny and Sonia create belonging and a sense of "collectivizing" (Simpson, 2011, p. 144). They explicitly convey that there is no place for exclusion in the space we occupy.

We gather in a school portable, moved years ago from of an old mining community-a common story of abandoned spaces in isolated northern places. The portable is institutional: a square room, fluorescent lights, a blackboard, plastic chairs, and vinyl tables. It is spring. Flies buzz in the air, and the smell of rotting wood reveals the history of the room. I struggle with being together in this place. The land outside these walls is vast and beautiful; alpine meadows and the powerful Stikine River flow through the land, yet we sit in this portable with

flies and decay. I watch the flies buzz around us and I feel messy tensions as I strive to create a space where the girls feel a sense of belonging and inspiration.

How do I create belonging in a place where "school" evokes memories of residential schools, marginalization, and disconnection from place and land? How do I create inclusion in a school dominated by Euro-Western discourses where culture and land are classified, analyzed, and divided? Taylor and Giugni (2012) acknowledge that "local places are a locus of 'throwntogether' differences and thus constellate local/global spatialities of power" (p. 114). Placed on traditional territory, the girls' school-portable is an uneasy place of spatial politics embedded with binaries, boundaries, and divisions. How do I create alternative possibilities in these places? Despite these discomfort zones, productive tensions can create positive potentials (Perkins \& Somerville, 2003). I have found promising alternatives focusing on the borders, not the boundaries, in my work (Skott-Myhre, 2012). Where we gather in the portable, we find potentials to disrupt the tensions of colonial structures. 
I have become accustomed to the difficult tensions of colonial divisions and potentials of borderlands. I was born in Zambia; my family immigrated because the marriage of my British father and my Tamil mother was illegal in apartheid South Africa. Raised in Canada, I was keenly aware of the harsh injustices created by the violence of apartheid. Having lived and worked in this northern community for several years, I am situated outside the Tahltan nation. Being welcomed in "the margins" by generous leaders like Penny and Sonia has been transformative. My sense of belonging in the north has expanded my connection to land and community.

In my practice with girls in this place, there are many tensions and possibilities. The process of art therapy is an entangled relationship of messiness, unease, and hope. I am reminded that creativity is always an act of courage. However, this relationship generates opportunities to unearth silenced stories created by colonial boundaries and Euro-Western culture. In order to attend school, many of the girls travel from a reserve 90 minutes down the highway; they travel in and out of borders created by colonial and government agendas. Most of the girls are related to the Indigenous nation that has inhabited the land for centuries, but identify with a culture of globalization - a global Euro-Western culture that emerged from economic systems of colonial extraction and domination. Before we start the group, the girls hide their iPods in their hoodie pockets and chat about the latest gossip from Facebook.

Penny brings moose hide to our group. The hide is rich, steeped in the smell of smoke and animal and infused with culture, relations, and connection to the land; the hide transforms the space. Conversations and activities in the room shift and the girls put down their beads and scissors to explore its smell and texture. One of the girls wraps a piece of hide around her hand and sits with it for a while. The girls talk about mitts and slippers made by their grandmothers from "homemade" hide. Their conversations are filled with pride, excitement, and curiosity that bring culture, relations, and memories into the space from a place forgotten, buried beneath a dominant culture and a colonized education system.

Fleshing moose hide

A week after our group, I am invited by Penny to "flesh" moose hides. Fleshing moose hide is imbued with reclaiming Indigenous knowledge, relationships, community, and land. However, the process of fleshing hide in spring is not a romantic, back-to-the earth, idyllic nature experience. It is a "messy entanglement," and I am reminded that "learning through encounters with species, is not always harmonious, pleasant and egalitarian" (Massey, 2006, p. 137).

I arrive in the morning when the temperature is below zero. We cut the hair off a hide and stretch it into a frame of spruce trees. The hide is laid flat and the frame is tied to stakes. I sit precariously on the skin and rhythmically hit the skin with a carved moose femur to release a thin fatty layer on the interior of the hide. The experience is visceral; I am sitting on the inside of the animal, connecting with its flesh, hair, and fat. My hands and arms are covered with skin and hair. At the end of the day, the air is warm and the smell of flesh permeates the air; the spring flies have found their niche. Penny is resolute about making sure the moose femurs are carefully put away - they were her mother's. 
Penny shows how fleshing hides is infused with meaning, intense labour, and tension. I sense the urgency in what she teaches: She does not want this knowledge to be lost, buried in a catacomb with other pieces of her Nation's traditional cultural knowledge. Penny creates "a space of storied presencing, alternative imaginings, transformation, reclamation-resurgence" (Simpson, 2011, p. 96).

Fleshing hides altered my perception of "homemade" moose hide. It is not an Indigenous static museum relic or a token souvenir of an Indigenous Nation long forgotten - it is filled with hope, innovation, ancestral teachings, and relation to land. This experience shifted my connection to the land and my awareness of how significant these connections are to the youth I work with. According to Skott-Myhre (2012), "when the sense of land and one's connection to it is redefined, one's identity is similarly disturbed" (p. 305).

The experiences I describe in this vignette are not bold political acts; they are collective acts of belonging and creativity that create an ethic of doing vital to ethical practice. The request by the girls to "hang out and sew" had "mutually transformative effects" (Taylor \& Giugni, 2012, p. 112) that evoked their presence. According to de Finney (2014), "girls enact presence when they contest their position as invisible by physically, spiritually, and symbolically (re)occupying the places that hold their ancestral connections to First Peoples" (p. 18). With this in mind, ethical practice is mutually established through welcoming acts of presence in the face of colonial division and accepting and extending ongoing invitations to engage. I am inspired by this ethic and doing differently. What other voices will be heard in the community? What other possibilities can unfold?

\section{Drumming Politics and Presence (Back) Into ECE—Emily Coon}

ECE is often seen as apolitical and innocent (Burman, 2008; Cannella \& Viruru, 2008). My work with young children compels me to explore the presence of settler colonialism in these seemingly neutral spaces. By bringing Drum into my practice, I am interested in connecting children to the diverse realities of place. Drawing on Indigenous and decolonial theories, this vignette engages with teachings of Drum to move beyond colonial (re)productions toward a practice of embodied resurgence.

Navigating multiple worlds: Naming my tensions

To open this vignette, I need to locate myself as an urban Kanien'keha:ka woman learning to walk in multiple, colliding worlds. Due to my grandmother's disenfranchisement-which stripped her of her Indian status and ability to live on reserve-I do not have a strong connection to my community since I grew up off reserve. This is how I came to carry both Haudenosaunee and Anishinaabe teachings while living on unceded Lekwungen and WSÁNEĆ territories. My journey is flawed and full of unease as I navigate the rocky terrain of reclaiming my (pan)indigeneity on colonized land.

How do I begin to navigate these urban-off-reserve-disenfranchised tensions? I start with Drum. Being gifted the responsibility of carrying a drum was a defining moment in my life. Nishnaabeg scholar Leanne Simpson (2011) articulates decolonization as "pick[ing] up the things we were forced to leave behind ... and bring[ing] them into existence in the future" (p. 
50). How do I bring Drum into my practice to untangle myself from the paralyzing grip of colonialism? What are the protocols of bringing an Anishinaabe Drum to the territories of a distinctly different Indigenous Nation?

In Victoria, British Columbia, my work in ECE involves weekly walks in a forest to drum with a group of toddlers, most of whom are settlers. Bringing Drum into my practice with young children reflects my personal process of learning how to embody resurgence and live my teachings in everything I do. How do I bring Drum into a colonial setting when there is a risk that these teachings could be appropriated? How do I discourage "settler moves to innocence [which] are ... strategies or positionings that attempt to relieve the settler of feelings of guilt or responsibility" (Tuck \& Yang, 2012, p. 10) for their ongoing occupation of Indigenous land? By bringing Drum into this place, are possibilities opened up that connect children to the political, historical, and contextual realities of their lives?

\section{Heartbeats and All My Relations: Teachings of the Drum}

My teachings about Drum are that she is female, called my Grandmother, and inherently tied to the land, waters, and skies. I use Drum as a proper noun to honour her Spirit as an active and contributing member throughout our journey. Drum brings her teachings to me in moments where I am opening up space to share her voice with others. How do I express these teachings when they are not linear? They are circular, endless, and entangled. As I attempt to twist the intangible into something solid, finite, and simple, such as the written words on this page, I must name the resistance and frustration that accompanies this process. I also struggle to cite my teachings, but I would like to express my gratitude to Jean Becker and Kelly Laurila for their ongoing wisdom, support, and encouragement.

Drum and I embark on this journey together because her very presence opens up space to (re)connect to land; her heartbeat reminds us of where we come from, and to live in harmony with All Our Relations. Drum's teachings tell me that she echoes the heartbeat of Mother Earth and that this is the core of Creation: "the thoughts and the vibrational sound of the heartbeat created the star world, the sky, and the universe" (Simpson, 2011, p. 37-38). It is my responsibility, as her human carrier, to honour these teachings. It is my responsibility to create the space for her voice to be heard. This is how I am embodying resurgence. Being in relationship with Drum reminds me that I am always in relationship with the land and this is where my cultural knowledge is rooted (Simpson, 2011; Watts, 2013). How can I use these teachings to bring attention to the silenced Indigenous land relations that exist in the places I share with children? What are the ethics of bringing Drum to a contested and colonized place with settler children?

\section{Meaningful connections to Drum}

William's ${ }^{10}$ body always finds the same spot to sit, wait, listen, and experience when Drum and I come to visit. His body is still. His eyes are watching. It is as if he is taken to a place of complete and focused attention. A place where Drum's voice transcends time and space. Drum and William are entangled in a fleeting moment of meaning and presencing.

\footnotetext{
${ }^{10}$ Child's name and all other identifiable information has been changed to protect confidentiality. 
Developmental theories conceptualize children and place as homogenous, which conceals the political and historical realities that are continually shaping and reshaping them (Cannella \& Viruru, 2008). Masking these realities through sanitized classrooms and playgrounds disconnects children from the messy and political entanglements they are fully situated in. How do I begin to unpack these unrealistic universal notions and reveal the settler colonial stories that are hidden in the forest we visit with Drum?

Simpson (2011) explains meaning as "derived from the experience of individuals, relationships and connections through action or "presencing"'(p. 96) and I begin to wonder how, or if, this moment between William and Drum was meaningful. William was patient, focused, and stillwas Drum's presence able to connect his settler body to the land, to the heartbeat of Mother Earth, to All His Relations? By watching William encounter with Drum, I am fully aware of his settler privilege and that he still occupies Indigenous land, but it is clear that he is experiencing Drum in a significant way. Why is this encounter with Drum different than the music and drumming that children make in ECE? Has Drum brought attention to the entangled politics, contexts, and history that have been so carefully removed from early childhood spaces? While I interpret this moment as being meaningful for William, what else could happen here? Is drumming enough to (re)centre Indigenous sovereignty? Is being present with Drum enough to build a different relationship with this place?

It is important for me to acknowledge the uneasy politics and uncertainty that accompany bringing Drum into colonial places. As I embody my teachings and do differently in my practice, is it appropriate to share Drum's Indigenous teachings with settler children? In these moments, I do not aim to be exclusive because I have been taught that Drum benefits all bodies. I believe that Drum's presence has ripple effects to open up space for all children to hear her teachings, while simultaneously interrupting the normalizing discourses that are evident in ECE. Is it possible to create meaningful experiences with Drum that will resonate in the future of these settler children? Will William be more sensitive, aware, or respectful with Indigenous peoples because he was exposed to the beauty and power of Drum? While hopeful, I realize that this can never be so simple.

The places we inhabit are not innocent - settler colonialism has removed Indigenous bodies from the land for their own benefit. Homogenizing place serves to silence the Indigenous presence that continues to exist in the land. Vanessa Watts (2013), a Haudenosaunee and Anishinaabe scholar, explains that "we (humans) are made from the land; our flesh is literally an extension of the soil" (p. 27), and I wonder how this implicates our relationships with the land. As the children run, laugh, and play, I realize that they do not understand the messy, erased histories that dwell in this forest. What are my responsibilities and ethical considerations in these moments? Drum - with her unsettling, disruptive, and political presence - brings awareness to the active resurgence and decolonizing efforts that Indigenous peoples are engaging in to reclaim their knowledge as equally true and valuable amid the erasure perpetuated by dominant colonial thinking. How do I continue to foreground Indigenous relations as I attempt to rethink the way that place is conceptualized? How do I continue to do meaningful political work with young settler children? What else needs to be done here? 


\section{Conclusion: Complicating Matters}

Embracing the messiness, tensions, and discomfort that accompany interrupting dominant colonial discourses, we offer these vignettes to reflect on the potential of doing. Narda focused on (re)storying place by paying attention to encounters among the plants, animals, landscapes and young children, acknowledging the tensions her own position as a white settler creates in this endeavour. Anna looked at ways of opening up space through accepting invitations and listening to stories that created a sense of belonging for those she works with. Emily struggled to bring Drum's teachings into her practice, to honour the erased Indigenous relations that exist in place and land. In our diverse practices and places, we illustrate the difficulties of working against mainstream disciplines of control, conformity, and containment. We are challenged to confront power dynamics embedded in standardized ways of practice. Despite unsettling feelings, we are learning to strive, as best as we can, to let alternative possibilities play out. We have attempted to ask ourselves: What else is happening here? Whose voices are privileged in such moments?

The diverse children and youth we work with are entangled in political tensions, often obscured by colonial, Euro-Western theories of development. Through our ethic of doing, we hope to avoid (re)producing the erasure and silencing of those who do not fit into normative standards. How do we continue to be political? To unsettle? To do differently?

\section{References}

Burman, E. (2008). Deconstructing developmental psychology $\left(2^{\text {nd }}\right.$ ed.). New York, NY: Routledge.

Cannella, G. S., \& Viruru, R. (Eds.). (2004). Childhood and postcolonization: Power, education and contemporary practices. New York, NY: Routledge.

Collard, R. C., Dempsey, J., \& Sundberg, J. (2014). A manifesto of abundant futures. Annals of the Association of American Geographers, 105(2), 1-9. doi:

10.1080/00045608.2014.973007

Crawford, T. (2015, February 28). Seagull population cut in half over 30 years, UBC research warns. Postmedia News. Retrieved from: http://www.canada.com/technology/Seagull+population+half+over+years+research+wa rns/10848660/story.html

de Finney, S. (2014). Under the shadow of empire: Indigenous girls' presencing as decolonizing force. Girlhood Studies, 6(2), 8-26.

Klein, N. (2013, March 5). Dancing the world into being: A conversation with Idle No More's Leanne Simpson. Yes Magazine. Retrieved from: http://www.yesmagazine.org/peacejustice/dancing-the-world-into-being-a-conversation-with-idle-no-more-leanne-simpson 
Massey, D. (2006). Landscape as a provocation: Reflections on moving mountains. Journal of Material Culture, 11(1-2), 33-48.

Pacini-Ketchabaw, V. (2011). Rethinking developmental theories in child and youth care. In A. Pence \& J. White (Eds.), Child and youth care: Critical perspectives on pedagogy, practice, and policy (pp. 19-32). Vancouver, BC: UBC Press.

Pacini-Ketchabaw, V. (2012). Postcolonial entanglements: Unruling stories. Child \& Youth Services, 33(3), 303-316.

Pacini-Ketchabaw, V., Nxumalo, F., Kocher, L., Elliot, E., \& Sanchez, A. (2015). Journeys: Reconceptualizing early childhood practices through pedagogical narration. North York, ON: University of Toronto Press.

Penn, B. (2006, June). Restoring camas and culture to Lekwungen and Victoria: An interview with Lekwungen Cheryl Bryce. Focus Magazine, 1-5. Retrieved from: http://www.firstnations.de/media/06-1-1-camas.pdf

Perkins, T., \& Somerville, M. (2003). Border work in the contact zone: Thinking Indigenous/non-Indigenous collaboration spatially. Journal of Intercultural Studies, 24(3), 253-266.

Rose, D. B., van Dooren, T., Chrulew, M., Cooke, S., Kearnes, M., \& O’Gorman, E. (2012). Thinking through the environment, unsettling the humanities. Environmental Humanities, 1(1), 1-5.

Saraceno, J. (2012). Mapping whiteness and coloniality in the human service field: Possibilities for a praxis of social justice in child and youth care. International Journal of Child, Youth, and Family Studies, 2(3), 248-271.

Sayler, R. (2012). Are worms natural? The global warming debate. Nature@WSU Science, Culture, Future. Retrieved from: http://wsu-nature.org/2012/01/29/are-worms-naturalthe-global-worming-debate/

Simpson, L. (2011). Dancing on our turtle's back: Stories of Nishnaabeg re-creation, resurgence and a new emergence. Winnipeg, MB: Arbeiter Ring.

Skott-Myhre, K. (2012). Nomadic youth care. International Journal of Child, Youth and Family Studies, 2\&3, 300-315.

Taylor, A. (2013). Reconfiguring the natures of childhood. New York, NY: Routledge.

Taylor, A., \& Giugni, M. (2012). Common worlds: Reconceptualising inclusion in early childhood communities. Contemporary Issues in Early Childhood, 13(2), 108-119.

Taylor, A., \& Pacini-Ketchabaw, V. (2015). Learning with children, ants, and worms in the Anthropocene: Towards a common world pedagogy of multispecies vulnerability. 
Pedagogy, Culture, Society [published online May 1, 2015]. doi:

10.1080/14681366.2015.1039050

Tuck, E., \& Yang, K. W. (2012). Decolonization is not a metaphor. Decolonization: Indigeneity, Education, \& Society, 1(1), 1-40.

van Dooren, T. (2014). Flight ways: Life and loss at the edge of extinction. New York, NY: Columbia University Press.

Watts, V. (2013). Indigenous place-thought and agency amongst humans and non-humans (First Woman and Sky Woman go on a European world tour!). Decolonization: Indigeneity, Education, \& Society, 2(1), 20-34. 


\title{
Walking With Place: Storying Reconciliation Pedagogies in Early Childhood Education
}

\section{by Catherine Hamm}

\begin{abstract}
Author's Bio
Catherine Hamm is an early career researcher in the College of Education at Victoria University in Melbourne, Australia. Her doctoral study investigated the connections between teacher identity and curriculum practices in early childhood. Catherine has a strong commitment to social justice and is interested in exploring the ways in which localized, specific Aboriginal knowledges can inform reconciliation pedagogies in early childhood education. Catherine's current work involves investigating children's relations with place, exploring the ways in which children might engage with the plants and animals that constitute the local places that children inhabit in postcolonial Australia. Email: Catherine.Hamm@vu.edu.au
\end{abstract}

\begin{abstract}
Knowing and understanding the land with Aboriginal cosmologies requires seeing much deeper than the surface. It involves feeling those deep connections that have existed for thousands of years and understanding trees, rocks, and rivers. Drawing on Vanessa Watt's concept of place-thought and Latour's emerging common world framework, I explore the notion of country in a specific place in the Australian context. This paper pays attention to the stories of Australia's colonial pasts, presents, and futures as I set out to generate new reconciliation pedagogies and engage with place during an experiential learning exercise: place-thought-walk. I argue that place-thought pedagogies that are inclusive, respectful, and reconciled to people of the local Aboriginal group can be put to work as a decolonizing practice. This practice exposes the layers of colonial inscription in the landscape, creating space for the land to be reclaimed and reinscribed with Aboriginal knowledges as the central frame.
\end{abstract}

\section{This Place}

It is a mild, sunny southern hemisphere spring day in this place, and the wind gently rustles the grasses on the volcanic plain. Here in this place at the edge of a city are rocks and trees, a network of creeks full of small freshwater crustaceans called yabbies; birds call to one another in beautiful voices. A network of creeks run through this place, hidden from most of us, known only to the few who have been able to hear the stories of this place. This place, significant for 
people of the Wurundjeri clan of the Kulin nation, holds many stories. The story of the seven brother volcanoes, charged with responsibility of watching over the grasslands and its peoples. Stories of thriving communities on the way to trade, celebrate, and conduct ceremony at the Werribee River, the meeting place of three of the Kulin nation clan groups: the Wurundjeri, the Boonwurrung, and the Wathaurong. The stories of this place are present in every leaf, rock, and particle of dirt.

Acknowledging Australia's Aboriginal history, culture, and ways of knowing as central to understanding the land around us requires thinking about place in a different way than the "Whitefella's way of 'coming up blind' and bumping into everything" (Rose, 2004, p. 9). In this paper, I draw on Watts's (2013) concept of place-thought as a method of thinking about place in a different way, drawing on the idea that the land is "alive and thinking" (p. 21). I extend this idea by exploring the ways in which thinking differently about the land, focusing on Australian Aboriginal ways of knowing, can be used as a decolonizing practice. I frame this thinking by drawing together Watts's concept of place-thought and Rose's (1996) definition of country as a way to think about the land in a different way. I also engage with Latour's (2004) notion of learning to be affected and King's (2004) concept of pastpresent as useful ways to pay attention, exposing the layers of colonial inscription in the land.

I work with the notion of place-thought as a starting point for thinking about the places around me in a different way, placing Aboriginal knowledges in the centre and privileging this knowledge as the way to think about place. I think about how, for Aboriginal people, place, belonging, and ceremony cannot be separated. As I begin to think about the land differently, I also begin to think about how these ideas could be enacted as reconciliation pedagogies. Thinking about the land in different ways opens up a space to explore the possibilities of generating new reconciliation pedagogies that are respectful and that recognize the local Aboriginal groups. Focusing on specific places that hold specific Aboriginal knowledges makes it possible to disrupt the idea of homogenous Aboriginal culture. This disruption acknowledges that Aboriginal Australia is diverse and that each group has its own stories of place, belonging, and ceremony.

I give three examples to illustrate how I am beginning to think about place in different ways. First, I show how hearing the stories of place makes me pay attention to place in a different way. Second, I share my experiences of taking a place-thought walk and thinking with the concept of learning to be affected. Third, I show how exploring a specific place, as a way of enacting the concept of place-thought, can be thought of as reconciliation pedagogies.

\section{Thinking With Place-Thought}

I draw on the notion of place-thought (Watts, 2013) as the inspiration for thinking about the environment around me in different ways. Watts's concept of place-thought is underpinned by the ways in which an Anishinaabe world view centres on the notion that the land is animate and has agency and that communication with the land is paramount for Aboriginal people. To illustrate the notion of place-thought, Watts tell an Anishinaabe creation story about how Sky Woman fell through a hole in the sky, landed on the back of a turtle, and formed the earth. Watts argues that creation stories are not myths or allegories, but are historical accounts of the 
interconnections between humans and the more than human. This historical account "describes a theoretical understanding of the world via a physical embodiment" (Watts, 2013, p. 21). Watts argues that this theoretical understanding is very different to a Euro-Western way of knowledge construction and that place-thought "is based upon the premise that land is alive and thinking and that humans and non-humans derive agency through the extensions of these thoughts" (Watts, 2013, p. 21). Watts also argues that land is important in the lives of Indigenous people and that they are part of the land. This relationship with the land requires communication and care, as well as interacting with the nonhumans that also make up the land. Watts states that colonization disrupted the Anishinaabe people's ability to have agency with the land, and that "our own ability to act and converse with non-humans and other humans became compromised" (p. 24).

\section{Thinking With Country}

Canada and Australia share colonizing histories and experiences. The arrival of settler societies to Australia rendered it terra nullius (empty land), the basis for which many Aboriginal land claims have been rejected. In fact the land was anything but terra nullius; it was alive and a central tenet to the Aboriginal way of life. The process of colonizing the land and its people resulted in the land being stripped of any sense of agency or role in the lives of Aboriginal people. This process inscribed the land in a settler image, covering traces of Aboriginal knowledges and moving culture and ceremony from the central frame.

Australian Aboriginal people's deep connection with the land (country) has been well documented. This description from Rose (1996) of country captures the importance of the land in the lives of Aboriginal people:

Country is a place that gives and receives life. Not just imagined or represented, it is lived in and lived with.... People talk about country in the same way they would talk about a person: they speak to country, sing to country, visit country, worry about country, feel for country, and long for country. Country is not a generalised or undifferentiated type of place ... country is a living entity with a yesterday, today and tomorrow with a consciousness, and a will toward life. (p. 7)

Rose wrote this definition of country while working on a number of Native Title land claims around Australia during the 1990s. She was attempting to communicate the role of country in the lives of Aboriginal people to the white settler judges who were presiding over the land claim tribunals. Many Aboriginal people had come before the courts and attempted to explain what country meant in terms of their culture, belonging, and ceremony. A focus of the land claim tribunals was that Aboriginal people were required to demonstrate continuous, unbroken connection with the land. In some areas of Australia this was very difficult because many clan groups had been removed from their country and placed onto "missions." Most Aboriginal clan groups rely on oral traditions as a method of passing on culture, and moving Aboriginal people onto missions resulted in the loss of language, culture, and ceremony (State Library of Victoria, 2015). 
There are synergies between Watts's concepts of place, thought, and agency framed by an Anishinaabe cosmological perspective and an Australian Aboriginal concept of country. I draw together these two ideas as a useful way to think about the land around me. This different way of thinking serves as inspiration for exploring the generation of reconciliation pedagogies. As I think with the concept of place-thought in an Australian context, I wonder how I can enact these thoughts as reconciliation pedagogies. How can learning about Aboriginal knowledges that are embedded in the places we live contribute to pedagogies of reconciliation in early childhood education?

\section{Reconciliation in an Australian Context}

The effect of colonization in Australia has positioned Aboriginal people as inferior "noble savages" for 200 years. The concept of reconciliation aims to build stronger relationships between Aboriginal and Torres Strait Islander people and non-Aboriginal people. The vision of reconciliation is "for everyone to wake to a reconciled, just and equitable Australia where stereotypes and discrimination are broken down" (Reconciliation, 2013). The message of reconciliation is a positive one, attempting to create a space in Australia's future where a spirit of peace and a shared future for Australia's Aboriginal and non-Aboriginal people can be enacted. In thinking about this positive message, it is also necessary to consider some tensions between the concepts of reconciliation and decolonization.

\section{Reconciliation and decolonizing practices}

The concept of reconciliation is a vexed one: How can disconnecting Aboriginal people from their lands and disrupting their culture and ceremony ever be reconciled? In 2008, the Australian prime minister at the time, Kevin Rudd, made an apology in Federal Parliament to "The Stolen Generations"" (Australian Government, n.d.a). This apology acknowledged the Australian government's role in the history of the forced removal of Aboriginal people from their land, culture, and ceremony. While this apology was welcomed by the majority of Aboriginal people as a gesture of reconciliation, it did not address the issue of decolonizing.

Tuck and Yang (2012) state that "decolonization in the settler context must involve the repatriation of land simultaneous to the recognition of how land and relations to land have always already been differently understood and enacted" (p. 7). This definition understands decolonization as a process that returns Aboriginal people to their land.

In thinking about decolonizing practices, I acknowledge that in order to decolonize, land, culture, and ceremony need to be repatriated to Aboriginal people. I argue that seeing the land differently, with specific local Aboriginal knowledges as the central frame, could be considered as a step in the decolonizing process. Considering the relationship between reconciliation and decolonization serves to create some thinking about broad structural changes that acknowledge more than just "learning about" Aboriginal people.

\footnotetext{
${ }^{11}$ Aboriginal people who were forcibly taken from their families.
} 
Reconciliation pedagogies

According to MacGill and Wyeld (2009), reconciliation pedagogies are "concerned with equality of recognition of Indigenous people and Australian Cultural Heritage in general" ( $p$. 558). This definition suggests that it is important for all Australians to become aware of, and value, Aboriginal ways of knowing. MacGill and Wyeld (2009) have explored the idea of reconciliation pedagogies for early primary school students, focusing mostly on historical perspectives as set out in the Australian Curriculum (Australian Curriculum, Assessment, and Reporting Authority, n.d.). Generating pedagogies of reconciliation requires a shift in thinking about the ways in which Aboriginal knowledges are framed within the wider Australian context. Aboriginal knowledges are not generally placed in the central frame as a way of interpreting the world around us. It is important to me to think differently about how Aboriginal knowledges are framed within the teacher education program I work in. Are we content to gloss over Aboriginal knowledges in a tokenistic way, or is there a way to embed Aboriginal knowledges as the central frame, as the cornerstone of our teacher education program?

\section{Grappling with my identity}

Reconciliation is important to me as a white settler woman, but also as a member of the Aboriginal community. My husband and children are members of the Yorta Yorta nation; their country is a three-hour drive from our home in Melbourne. It has taken some time for me to consider myself a member of the Aboriginal community, grappling with how I fit in. Although I am a non-Aboriginal person, I have been connected to the Aboriginal community for 25 years. At first, my connection was tenuous. Slowly, over time, I was accepted into the community, although acceptance was not easily gained. I had to learn many aspects of both traditional and contemporary Aboriginal ways of knowing. The questions "Who is your family?" and "Where are you from?" are critical to establishing connections, locating where you fit in. Understanding social connections is an integral part of Aboriginal cultural knowledge, and when I began attending community events, members of my family would ensure that my connections to the community were explained. My connection to the Aboriginal community frames my understanding of how important country is in the lives of Aboriginal people. I cannot claim to understand or feel country in the same way that members of my family do, but I am sensitive to the role of country in their lives. It is this perspective that I bring with me as I begin to think about the land around me in a different way.

\section{Exposing the Layers of Inscription: Pastpresent and Learning To Be Affected}

\section{Pastpresent}

In thinking differently about the land, noticing the layers of inscription, I draw on King's concept of pastpresent. King (2004) defines pastpresent as "quite palpable evidences that the past and the present cannot be purified from each other" (p. 459). Thinking with the concept of pastpresent provides the opportunity to look deeply at the places around us, exposing the layers of inscription, acknowledging that the past still exists in the present. Pastpresent is a useful way to think about placing Aboriginal knowledges in the centre as places are explored. The land is entangled in stories, ceremonies, and traditions; they are not gone from here, it is just a matter of paying attention in particular ways. As Rose (2004) explains, "country has origins and a future; it exists both in and through time" (p. 153). 
Learning to be affected

I also put to work Latour's (2004) notion of learning to be affected as a method of paying attention to the layers of inscription in this place. Latour presents the idea that learning to be affected "means exactly that: the more you learn the more differences exist" (p. 213). I take this to mean that in order to pay attention in different ways, you must be awake to many possibilities and proposals. Latour uses the concept of learning to be affected as a way to move beyond the binary of subject/object to become aware of multiple ways of seeing the world around us. Taylor and Giugni (2012) also take up this idea of being awake to differences as they challenge us to be curious about the places around us: "For it is only when we exercise curiosity to find out more about where we are, and who and what is there with us, that we find hitherto unknown dimensions to our common worlds" (p. 110). Paying attention in this way provides the opportunity to hear the stories of place, trace the layers of inscription, and see what has always been there but perhaps unnoticed by many in recent times. We can begin to notice places in different ways.

I return now to the place where I began, as a site for exploring reconciliation pedagogies. I draw together the concepts of place-thought, country, pastpresent, and learning to be affected as I participate in an experiential learning exercise.

\section{Thinking With Place}

This place, the Iramoo Grasslands - the traditional lands of the Wurundjeri people of the Kulin nation - has been overlaid with a university campus. Buildings, car parks, concrete paths, and fences have been constructed as a representation of colonial Australia. Trees and plants that came with the settlers are not as well equipped as the local plants to respond to the southern hemisphere seasons.

A group of white settler early childhood teacher educators have come to the Iramoo Grasslands to hear the stories of this place. As we walk on Wurundjeri land, we seek to reimagine, to think with Aboriginal knowledges. We each come to this place with different understandings and experiences, but we share a commitment to "acknowledge Aboriginal people as the first people of this land and that their voices have held and continue to hold unique stories of place, belonging and ceremony" (Victoria University-College of Education, 2014). We have come to hear the stories of this place in the spirit of reconciliation and value the importance of placing Aboriginal knowledges in the centre of the teacher education program that we deliver to early childhood students. We are exploring the concept of place-thought as a decolonizing process that will be embedded as a central tenet of our teacher education program.

Aboriginal histories of place

An Aboriginal colleague shares the stories of this place. Like in Anishinaabe creation stories, the land around us was formed in partnership between humans and nonhumans. We hear the story of how the volcanic plain was made by the seven brother volcanoes that keep watch across the plain. We hear how the spirits came to this place and transformed from animal to human form. We hear how this place has always been a vital part of Wurundjeri, Boonwurrung, and Wathaurong culture. The stories of this place highlight the connections between these local groups of the Kulin national and their country. 
As I listen to the histories of this place, I imagine the spirits descending and creating the volcanoes, the rivers, and the trees. Listening respectfully provides the opportunity for us to reimagine this place, to wonder how Kulin knowledges contribute to paying attention to the land in a different way. How can my understanding of the Kulin knowledges of this place inform the exploration of reconciliation pedagogies?

The grasslands

This place, the Iramoo Grasslands, is part of the greater Western Basalt Plains Grassland. The grasslands are a characteristic of the Victorian Volcanic Plain that stretches from the central north to the southwest of Victoria, Australia, covering an area of 2.3 million hectares (Friends of Iramoo, n.d.) The Iramoo Grasslands have been described as a "remnant" of the once-vast grasslands that covered much of the volcanic plain.

These descriptions of this place were inscribed by the settlers after they arrived in 1837 . Before the white settlers arrived, the grasslands acted as a natural bushfire barrier that was carefully managed by Kulin people. This management included burning the grasslands in a seasonal pattern to encourage new growth of the diverse plant species. The new growth also encouraged game to the grasslands, providing a food source for the Kulin people that came to them, rather than requiring Kulin people to travel to hunt (Australian Government, n.d.b).

The settlers could not hear the Kulin people's stories of this place. They removed the Kulin people and their stories, reinscribing this place with plants, animals, and ideas that did not belong here in this southern hemisphere. They ignored the creator spirit Bunjil's teachings. The settlers did not hunt when the time was right and they let their cattle loose in the Murnong (yam daisy) gardens. They did not regenerate the grasslands with fire; instead they created fields and fences. The grasslands are a site of entanglement in the pastpresent; they are entangled in the precolonial, colonial, and postcolonial time and space. The grasslands are entanglements of fences, concrete, birds, creeks.

Place-thought walk with the grasslands

When I walk with the grasslands, I feel the warm sun on my face. I close my eyes to better focus on what is around me. I engage all my senses as I attempt to pay attention to "who and what is in this place with me" (Latour, 2004a as cited in Taylor \& Giugni, 2012, p. 110). I begin with what is immediately noticeable. I can hear the sound of the rustling grasses and it raises my sense of curiosity. I want to move off the concrete path that runs beside the fencedoff grassland. I want to walk through the grasses, get close to the sound of the wind in the grass husks. I have been warned to "be careful of the snakes." I look at the grasses fenced off in the "nature" reserve (see Figure 1). The grasses are "protected" and humans are not allowed to walk through them for fear of damaging them. These grasses have been "saved" in an attempt to restore a natural order. 


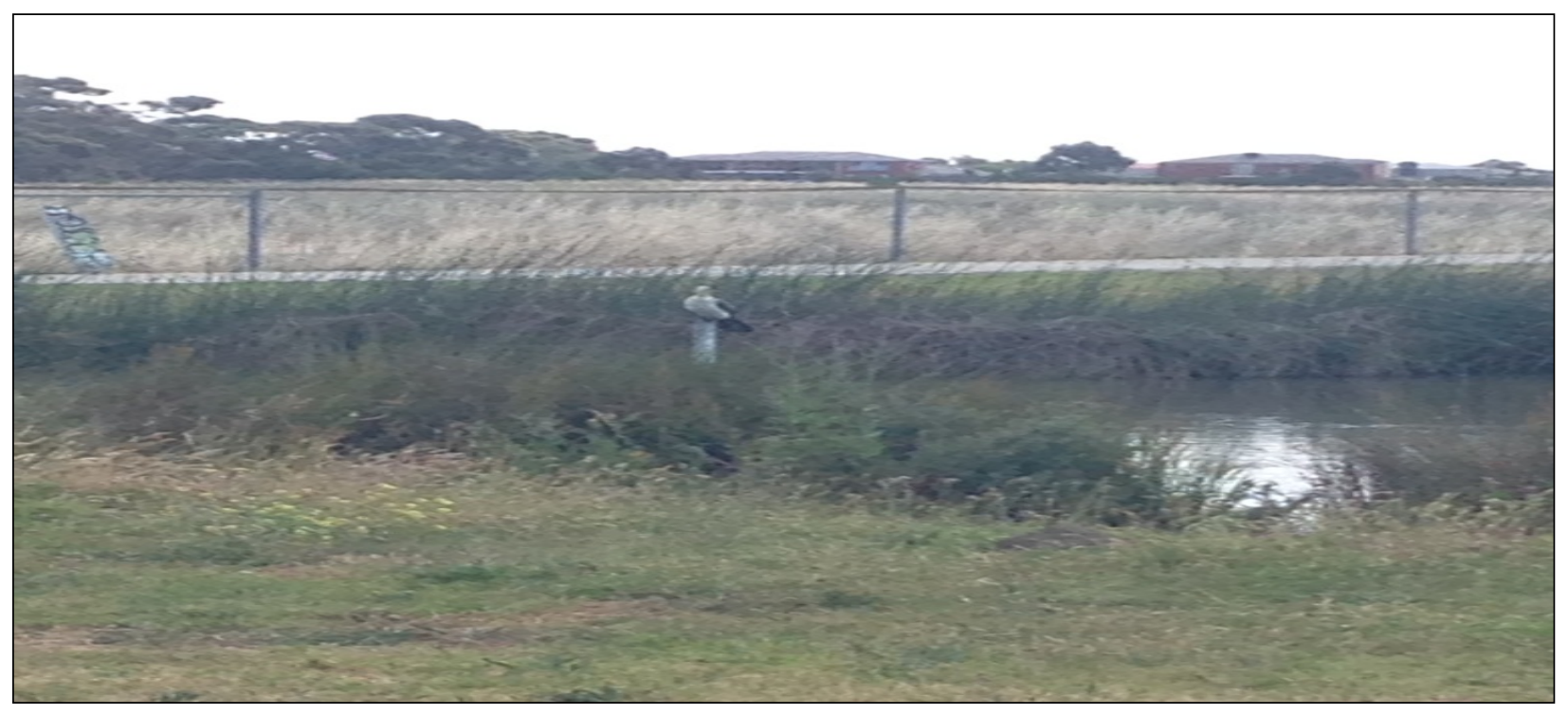

Figure 1. The grasslands.

I try and imagine this place as it was in precolonial times, before the white settlers arrived. I am curious to know how the grasses might have affected others who have walked in this place before me. I am becoming entangled with this place in the way that Anderson (2006, as cited in Instone, 2014) describes: "the emergence of affect from the relations between bodies, and from the encounters that those relations are entangled within, make the materialities of space-time always-already affective" (p. 80). The notion of entanglement of bodies, time, and space is also what Latour (2004) describes as learning to be affected. In learning to be affected, I begin to pay attention to the grasslands in ways that I have not done before. I begin to be concerned with the ways in which the grasslands might be "alive and thinking" (Watts, 2013, p. 21). Thinking about the grasslands in this way, I acknowledge that the Kulin creation stories that have been shared with me are central to my understanding about this place, rather than the layers of colonial inscription that I can also see around me being in the centre. In thinking with Kulin knowledges, I am also becoming entangled with grasses, animals, and pastpresent of this place in particular. This entanglement connects me to the knowledge, ceremony, and traditions of the grasslands as a way of thinking about and enacting reconciliation pedagogies.

\section{The burning}

One morning as I arrive at the campus, I see a lot of smoke: the grasslands are being burned. The university works with the Australian Government Department of Sustainability to "manage" the land using "traditional methods." These methods include the Kulin people's strategy described above of burning the grasslands in a regular cycle to regenerate the growth of the grasses and other plants. The government workers are dressed in coveralls to "protect" them from the burning. I stop to take a photograph (Figure 2), wanting to pay attention to how the grasses are being affected by this burning. 


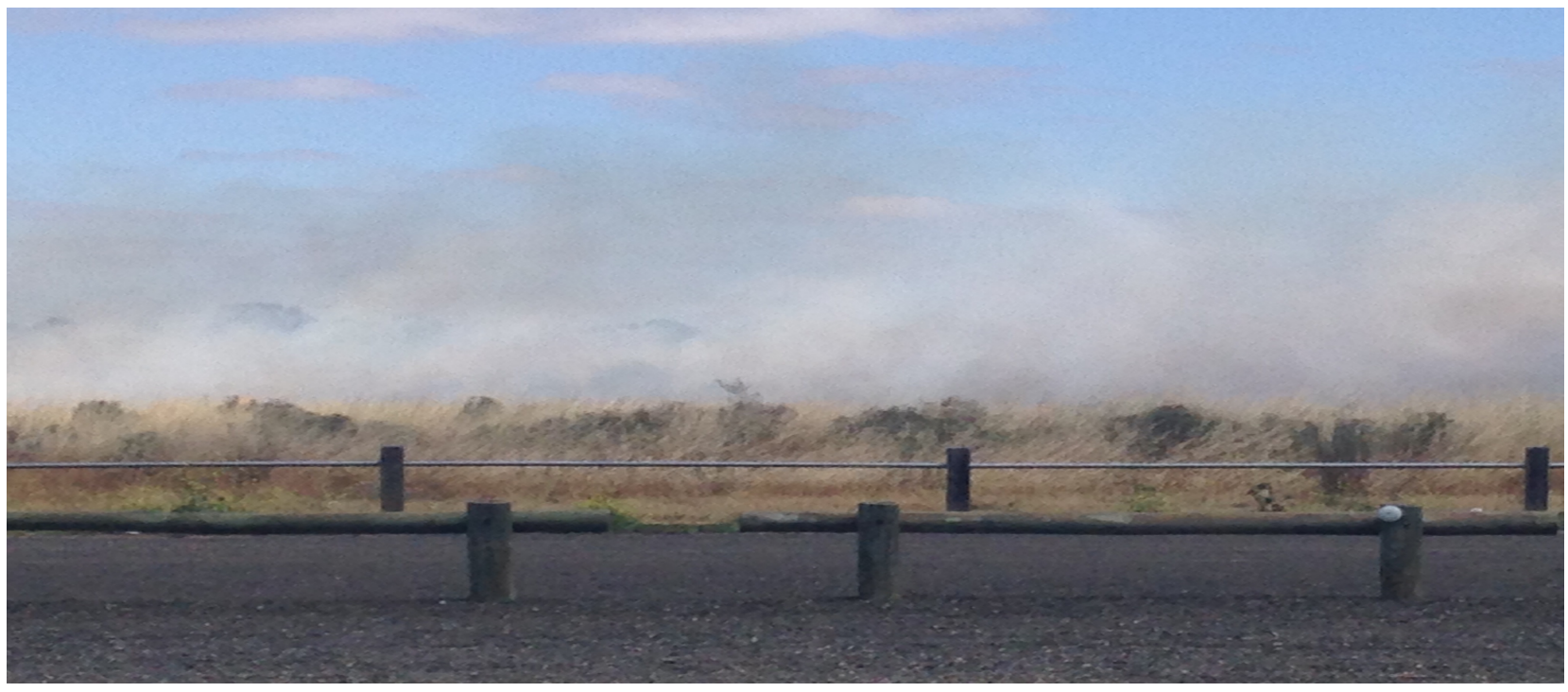

Figure 2. The burning.

The burning is causing a lot of smoke, and soon there are several cars stopped behind me. People are worried that something is "wrong." I explain to the worried onlookers that the grassland is being burned as part of managing its regeneration, using Aboriginal land management practices. I wonder how Aboriginal knowledges about caring for country can become part of everybody's knowing, "a proud part of everyday life" (Reconciliation, 2013).

\section{Generating reconciliation pedagogies}

I turn now to generating reconciliation pedagogies. How can the Iramoo Grasslands contribute to generating pedagogies of reconciliation? I have shown that it is possible to pay attention to the land in different ways. Thinking with the concept of place-thought provides an opportunity to place Aboriginal ways of knowing in the centre of understanding about the places where we live. In my role as an early childhood teacher educator, I can work to generate pedagogies of reconciliation with preservice teachers and colleagues by ensuring that I illuminate "alternate sites for productions of knowledge and the crossing of boundaries between them" (King, 2004, p. 459). I can work to expose the layers of colonial inscription on the grasslands, raising curiosity and enthusiasm to find out about this place. I can take preservice teachers into the environments where they are educated, on a place-thought walk, just as I did with my colleagues. I can ask the preservice teachers to notice things in their environment in a different way. Rather than looking at the environment in an innocent or romantic way, we can think about questions like these: What type of trees, animals, others are here with us? What can you see, hear, and feel in this place? How do you think this place might have looked before settlement? What plants and animals belong here from precolonial times, and what plants and animals came with the settlers? We can talk about the creek, the reconciliation rocks that symbolize coming together in the spirit of reconciliation, propagating seedlings of grasses that once dominated this place. Raising curiosity about the places around us provides the opportunity to think about place in different ways. Thinking differently has the potential to generate respect and knowledge of localized Aboriginal stories, traditions, and ceremonies, thereby disrupting the notion of homogenous Aboriginal culture. 


\section{Conclusion}

Every day as I come to this place, I pay attention in a different way. I do not just see the buildings or the car park. I notice the creek that runs under the bridge I cross, understanding that the creek has an essential role in nourishing the grasslands. I notice that in this place with me are legless lizards, water holes, and the sound of the wind in the grass. I look across the plain and see one of the brother volcanoes in the distance. I hear the call of Waa, the crow, and I look to see what she is doing.

When I talk with my colleagues and preservice teachers, I try to inspire them to also notice who or what is in this place with us. I do this by ensuring that Kulin knowledges are central to talking about this place in a respectful way, by restoring these ways of knowing to the centre, where they belong.

\section{References}

Australian Curriculum, Assessment, and Reporting Authority. (n.d.). Australian curriculum. Retrieved from: http://www.australiancurriculum.edu.au/

Australian Government. (n.d.a). Apology to Australia's Indigenous peoples. Retrieved from: http://www.australia.gov.au/about-australia/our-country/our-people/apology-toaustralias-indigenous-peoples

Australian Government. (n.d.b). Victorian volcanic plain. Retrieved from: http://www.nre.vic.gov.au/plntanml/biodiversity/directions/volcanic.htm

Friends of Iramoo. (n.d.).Western basalt plains grasslands@ Iramoo. Retrieved from: http://www.iramoo.org.au/about-iramoo/western-basalt-plains-grasslands

Instone, L. (2014). Unruly grasses: Affective attunements in the ecological restoration of urban native grasslands in Australia. Emotion, Space, and Society, 10, 79-86.

King, K. (2004). Historiography as reenactment: Metaphors and literalizations of TV documentaries. Criticism, 46(3), 459-475.

Latour, B. (2004). How to talk about the body: The normative dimension of science. Body \& Society, 10(2-3), 205-229.

MacGill, B., \& Wyeld, T. (2009). The need for reconciliation pedagogy: /educating for a more holistic, shared Australian cultural heritage. In E. Banissi, L. Stuart, T. G. Wyeld, M. Jern, G. Andrienko, N. Memon et al. (Eds.), Information visualization [proceedings of $13^{\text {th }}$ International Conference Information Visualization, Barcelona, Spain, July 2009], pp. 555-560. Los Alamitos, CA: IEEE Computer Society.

Reconciliation. (2013). Reconciliation. Retrieved from: http://www.reconciliation.org/ 
Rose, D. B. (1996). Nourishing terrains: Australian Aboriginal views of landscape and wilderness. Canberra, Australia: Australian Heritage Commission.

Rose, D. B. (2004). Reports from a wild country: Ethics for decolonisation. Sydney, Australia: University of New South Wales Press.

State Library of Victoria. (2015). Native title \& the Yorta Yorta. Retrieved from: http://ergo.slv.vic.gov.au/explore-history/fight-rights/indigenous-rights/native-titleyorta-yorta

Taylor, A., \& Giugni, M. (2012). Common worlds: Reconceptualising inclusion in early childhood communities. Contemporary Issues in Early Childhood, 13(2), 108-119.

Tuck, E., \& Yang, K. W. (2012). Decolonization is not a metaphor. Decolonization: Indigeneity, Education \& Society, 1(1), 1-40.

Victoria University-College of Education. (2014). Early Childhood Discipline Group statement. Unpublished document.

Watts, V. (2013). Indigenous place-thought and agency amongst humans and non humans (First Woman and Sky Woman go on a European world tour!). Decolonization: Indigeneity, Education \& Society, 2(1), 20-34. 


\title{
Wasps-Bees-Mushrooms-Children: Reimagining Multispecies Relations in Early Childhood Pedagogies
}

\author{
by Kim Atkinson
}

\begin{abstract}
Author's Bio
Kim Atkinson is an early childhood educator and a pedagogical facilitator with the University of Victoria's Unit for Early Years Research and Development. She also cocoordinates, with Danielle Davis, the Images of Learning Project-an exhibit, blog, and series of presentations that highlights the work of ECEs and the competencies of children (www.imagesoflearningproject.com). Email: klatkins@uvic.ca
\end{abstract}

\begin{abstract}
This article considers thinking with a common worlds framework in relation to reimagining our pedagogies to move beyond the nature/culture binary. Drawing on the work of scholars who engage with common worlds ethnographic projects, the author grapples with what it means to shift from humancentric perspectives of teaching children about nature toward attending to the interdependencies, mutual vulnerabilities, and responsibilities between humans and nonhumans. The article describes encounters between children, wasps, bees, and mushrooms as a means of illustrating how we might move toward different ways relating to the nature/culture divide, away from learning about toward thinking with.
\end{abstract}

At the centre where I work with educators and children on southern Vancouver Island, we regularly take walks into the forested park behind the childcare building. Our excursions are an important part of the program, and we eagerly anticipate finding mushrooms and worms, watching ducks, and listening for the local owl. On this day, Elsa is wearing her princess dress, a long, white satin gown that sways gently as she walks through the tall grass. Suddenly Elsa cries out; she is distressed to find that a tiny slug has attached itself to her dress. Gently I remove the slug, but for the rest of the walk Elsa holds her dress bunched up in her arms so as to avoid another slug. Elsa's companion, Fiona, is delighted to take the slug. She picks a flower, places the slug in the centre, and carries it carefully for the duration of our walk. 


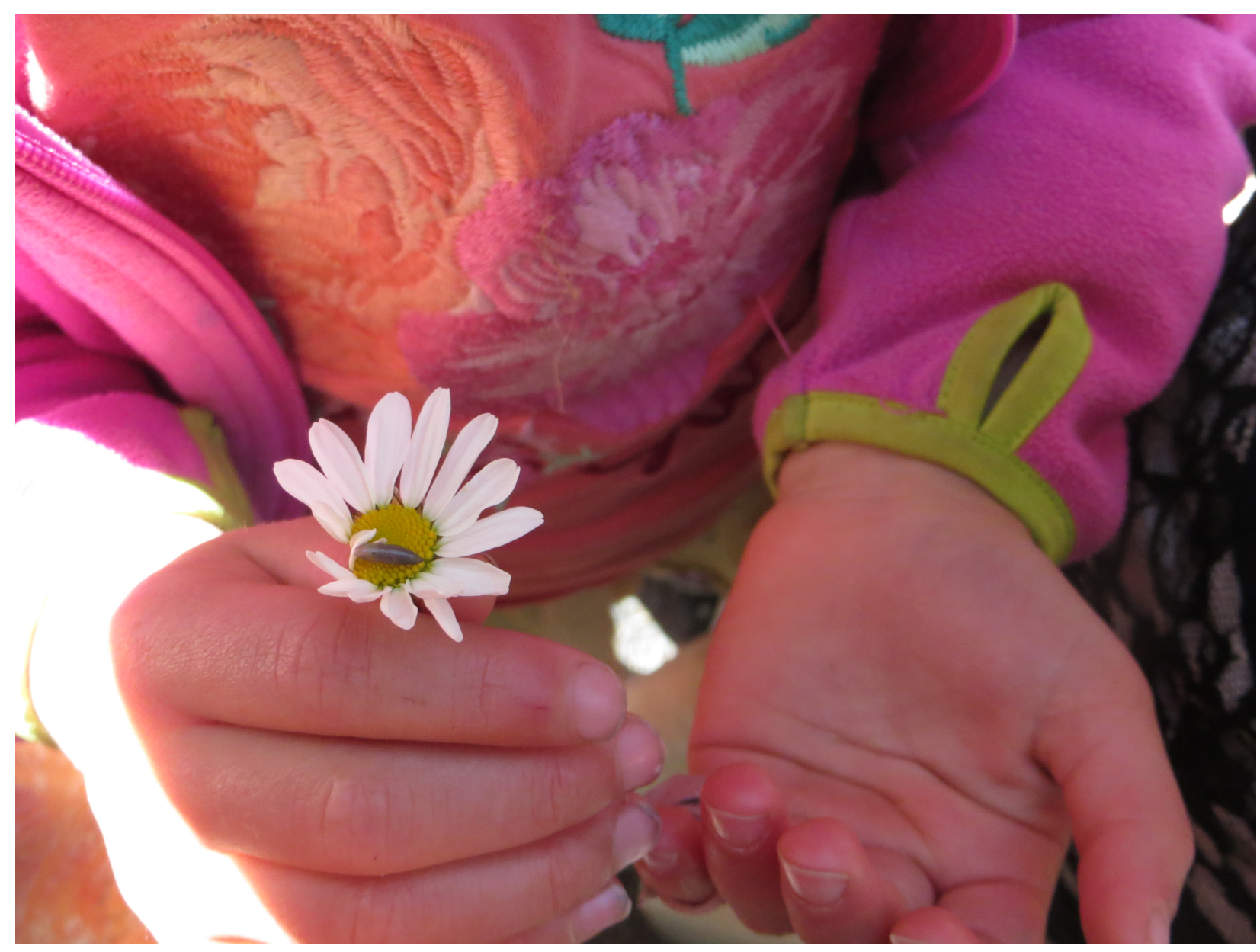

Figure 1. Carefully carrying a slug in a flower.

Encounters like this one in the park are seemingly simple, perhaps even innocent. Like many educators in British Columbia, we believe taking children outside into "natural" spaces is good for all of us (Nxumalo, 2014; Pacini-Ketchabaw, 2013). But as we walk I begin to wonder about the assumptions of "idealized childhoods in "pure nature" (Taylor, 2013, p. 4) that we hold as early childhood educators. I notice the contradictions in our thinking and actions when we ask children not to pick the daffodils but to pull dandelions instead, though both flowers seem alive in the field where we walk. Encounters with what the children call "red biter ants" alarm us, but we view the pretty ladybugs with awe. I think of the environmental crisis we face and wonder how we and the children might ethically respond. I am unsettled by the children's glee in stomping on an ant one day and showing care for a slug another day. I think about the garbage we find, the invasive English ivy that creeps up trees. I consider the park's histories, the stories that are told about this place and the stories that are silenced, the colonial histories that we are implicitly implicated within (Nxumalo, 2014). Our excursions in these spaces are not innocent at all (Pacini-Ketchabaw, 2013).

In this article, I grapple with these tensions that our walks in the park produce. I weave in the work of scholars who ask us as educators to reimagine our pedagogies, to shift our 
conventional humancentric perspectives of teaching about nature. I consider these scholars' invitations to engage with a common worlds framework (Taylor, 2013) and "to develop a multi-species ethics of environmental vulnerability" (Taylor \& Pacini-Ketchabaw, 2015) wherein we recognize our entangled mutual relations with the creatures, trees, and plants of the park.

\section{Recognizing Mutual Vulnerability}

The walks in the park provoke me to think about the impact of humans on the trees, creatures, and plants we encounter and to wonder at the world we are bequeathing to these children. We cannot separate ourselves from nature, or the fact that the environmental crisis we are facing is of our making. Scientists are alerting us to the reality of the impact of humans on the planet, telling us of climate change, extinction of species, and irreversible changes to geological and biological systems, all the result of human activity (Taylor \& Pacini-Ketchabaw, 2015). These human-induced changes to the earth in an era termed by environmental scientists as the Anthropocene (Crutzen, 2006) requires us to recognize that humans are indisputably entangled with nature. As Gibson, Fincher, and Rose (2010) state, "humanity's actions have become a new planetary force with accelerating effects on the biosphere. This new era, known as the Anthropocene, calls for new ways of thinking and knowing, and for innovative forms of action" (p. 3).

Scholars in the Common World Childhoods Research Collective (http://commonworlds.net/) are responding to the naming of the Anthropocene, urging us to move away from viewing nature as a separate object of study with humans as the sole actants, toward recognizing that we are all (humans, plants, animals, wasps, slugs, and others) entangled in this world, and that we are mutually dependent. A common worlds conceptual framework provides us with an "alternative way of thinking about the world we share" (Taylor \& Giugni, 2012, p. 111) and suggests moving from a view of the child as an autonomous learner in which place and child are distinct, toward seeing children as situated within messy and tangled interdependencies with the world. Working with this framework means setting aside romantic notions of children exploring the wilderness (Pacini-Ketchabaw, 2013) and reframing our pedagogies to attend to "our entanglements and mutual vulnerabilities with other species in these challenging ecological times" (Taylor \& Pacini-Ketchabaw, 2015, p. 3). It means recognizing that our human lives are inextricably linked with nonhumans, that we are mutually vulnerable.

Veronica Pacini-Ketchabaw and Affrica Taylor (2015), drawing on the work of Myra Hird, propose a multispecies ethics of environmental vulnerability wherein we acknowledge that we as humans may in fact be the most vulnerable species of all. Our long-held conviction of human superiority falls apart when we begin to notice how fragile we are within the enormity of climate change, and how our lives depend on the smallest of life forms, such as worms and bacteria, to make our life on earth possible. A multispecies ethics of environmental vulnerability calls us to take heed of our dependencies and fragilities in our work with children.

Taking on this view of entangled relations requires us to learn to notice differently, to pay attention to how other species and life forms are indispensable to our human survival. It means 
attending to what happens between children and slugs. It means expanding our idea of community to include nonhumans.

But what does this look like in practice? How can we move beyond the idea of a divide between nature and culture? How do we move toward different ways of relating, away from learning about toward thinking with?

In the following sections I describe small moments, such as encounters between bees, wasps, mushrooms, and children, that inspire me to think with the common worlds conceptual framework.

\section{Learning to Live With}

As we all become more familiar with the park we begin to venture off the paths, finding dark, shady spaces that are not groomed and managed but filled with piles of rocks, prickly mounds of garden debris, discarded pipes, tiles, and chunks of concrete. The children eagerly explore these spaces, naming them, climbing, collecting. One day a particularly interesting piece of concrete leaning against a log catches the children's attention. Together they push, straining together to tip it over. Finally the concrete chunk falls ... to reveal a wasp nest! Wasps fly crazily in all directions as the children squeal and hastily step back. Cara, an educator, kneels down a few yards away from the nest and begins to quietly talk. She asks the children to move slowly, to closely watch how the wasps move, to use quiet voices. The children are calmed by her voice, her stillness. They watch as the wasps disperse. No one is stung. 


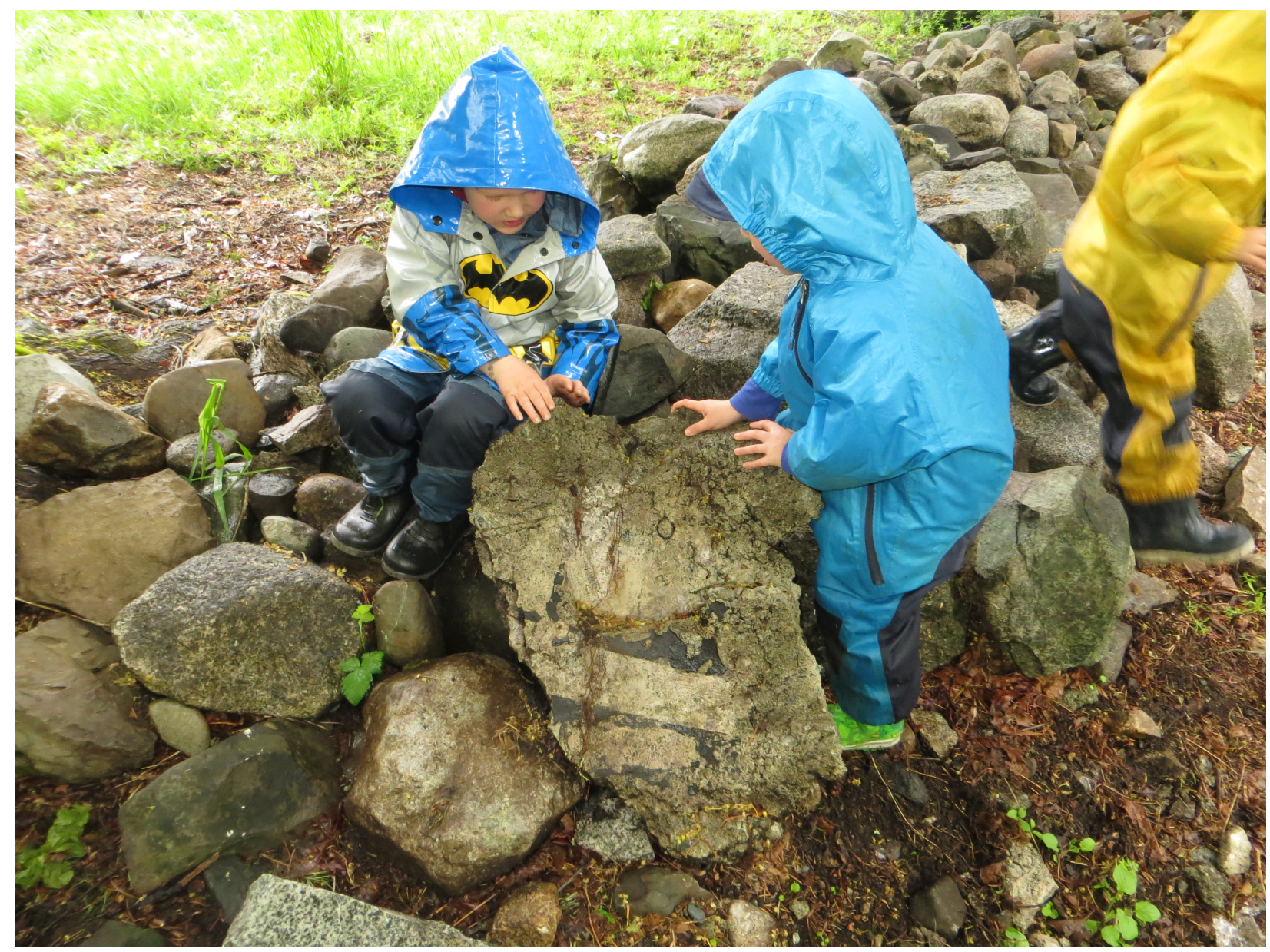

Figure 2. Tipping over a chunk of concrete.

In this moment Cara shifted away from conventional notions of protecting children from wasps, in which wasps are identified as dangerous creatures to be feared. Instead Cara recognized mutual vulnerabilities, that both wasps and children were affected by the turning of the concrete chunk. She sought to alleviate the distress of both the children and the wasps, acknowledging the vulnerabilities of both.

Ginn, Beisel, and Barua (2014) explore the ambiguities of living with multiple species, particularly species that sting or bite, or, as they call them, the "unloved others" (p. 114) They suggest an ethic of flourishing that requires us to look at the knotty relationships between human and nonhumans, to notice who prospers and who does not, who lives and who dies, and the vulnerabilities that emerge in multispecies encounters. These authors suggest becoming more comfortable with vulnerability and risk. They urge us to consider that encounters like the one involving Cara, the children, and the wasps, which hold possibilities for stings, can be part of generative engagements with nonhuman others that resist a humancentric perspective of dominance and superiority. They state: 
Becoming less uncomfortable with vulnerability and seeking to put ourselves at risk can be a productive ethical practice. We might learn to accept the risks more, to loosen the hegemonic idea of a self-certain subject to whom an outsider arrives to disrupt. (Ginn, Beisel, \& Barua, 2014, p. 118)

Thinking of wasps as a species to live with may seem like a small and insignificant way of attending to mutual risk, yet it suggests new possibilities for our pedagogies. We are learning to be together in the world (Taylor \& Pacini-Ketchabaw, 2015) in ways that accept the discomfort and complexity of multispecies relations. This is a shift away from sentimentalized notions of children's natural affinity to unsullied nature that is apparent in the recent trend of outdoor and nature-based child care (Pacini-Ketchabaw, 2013). This trend presupposes that nature is "good" for children and that through harmonious relations with plants, animals, and trees, children will become responsible environmental citizens. Iris Duhn (2011) notes:

The romantic image of a garden where innocent children can grow and develop according to nature's blueprint continues to shape Western early childhood education philosophy, curriculum and pedagogy (Brosterman 1997). Possibly due to this romantic legacy, early childhood education has largely shied away from critical engagement with the child/nature intersection and its implications for education for sustainability. (p. 19 )

This romanticized notion of children in nature focuses on the child's learning, the child's actions, what the child sees and hears and touches. Creatures, trees, and plants are seen as separate from humans. They are objects to be studied, collected, looked at with magnifying glasses, read about, put on science tables for display. However, in a common worlds framework, humans are not at all separate from nature; rather, humans are engaged in the changes to the earth that put our fate and the fate of all species into question.

Adopting new ways of thinking and knowing means seeing ourselves, for example, as coshaped by the forest we walk in. It means shifting our gaze away from what children are doing and attending to what happens between children, wasps, and slugs. It means "cultivating the capacity for deep listening to each other, to the land, to other species and thereby learning to be affected and transformed by the body-world we are part of" (Gibson, Fincher, \& Rose, 2010). We cannot continue to work and think in a pedagogical context as though only human agency matters. We might need to acknowledge worms, slugs, and wasps as having a role to play in our pedagogies, and in our mutual survival.

\section{Considering Small Moments Differently}

Carter is attentive to what is on the ground, and on this day he notices a bee moving through the grass. As he watches it intently he concludes that the bee has an injured wing. He says, "It's a hurt bee, it can't fly. We have to bury it. We have to make a nice place for it to die. We bury it because we bury people." After further intense observation, Carter concludes that the injured wing is, in fact, fully functional, but still he wants to save the bee from harm, saying, "We have to make a little zone for him." Using bark to make a protective house, Carter gently lifts the bee with a stick, gives it a ramp to climb, and uses his sleeve to carefully sweep the bee 
into the protected space. Suddenly the bee flies up and lands on Carter's leg. Carter calmly stays very still and calls to an adult for help. The bee is gently brushed off and lands in the grass. Carter immediately locates the bee to ensure that it has not been hurt in the fall.

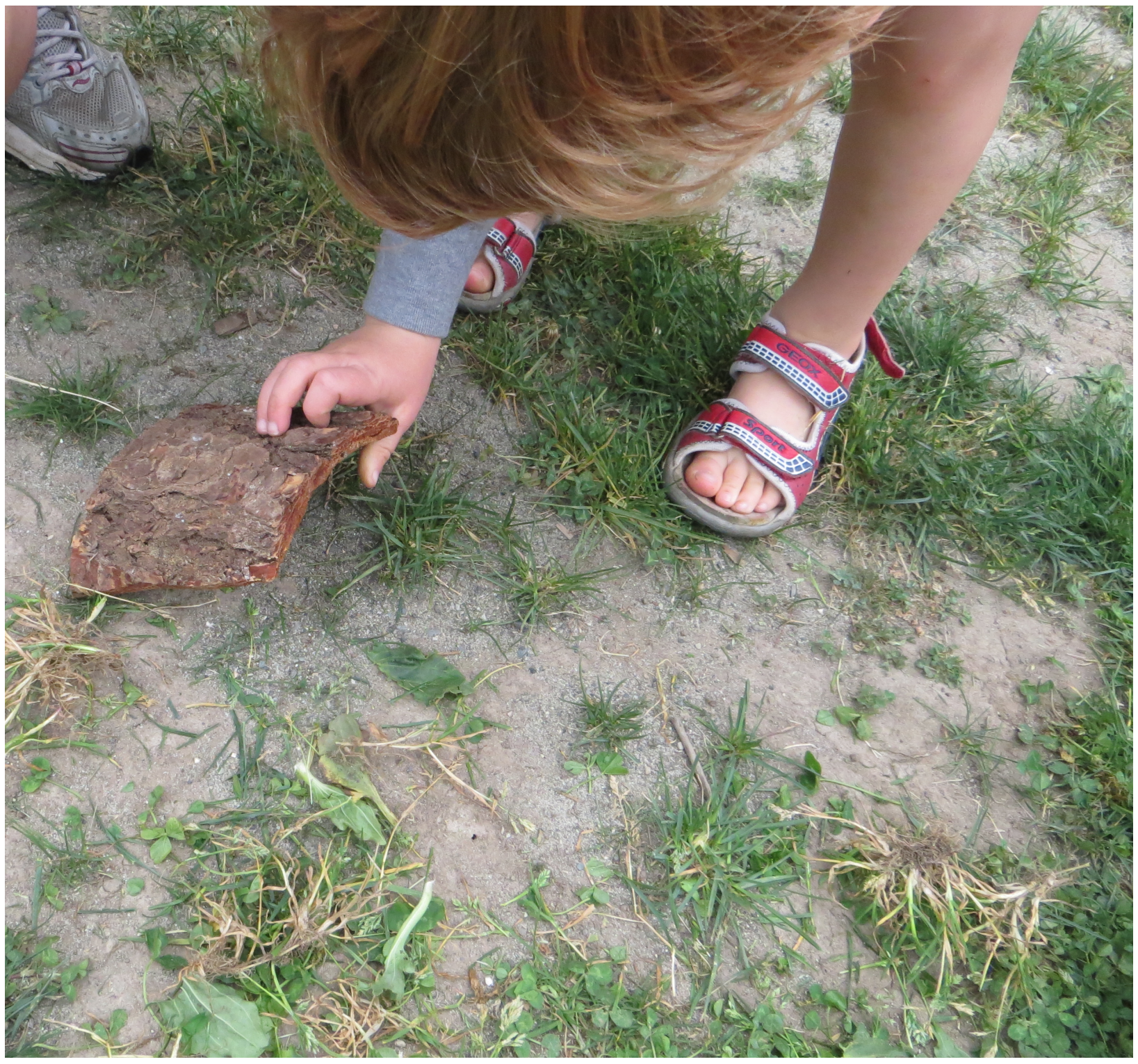

Figure 3. Making a zone for the bee. 


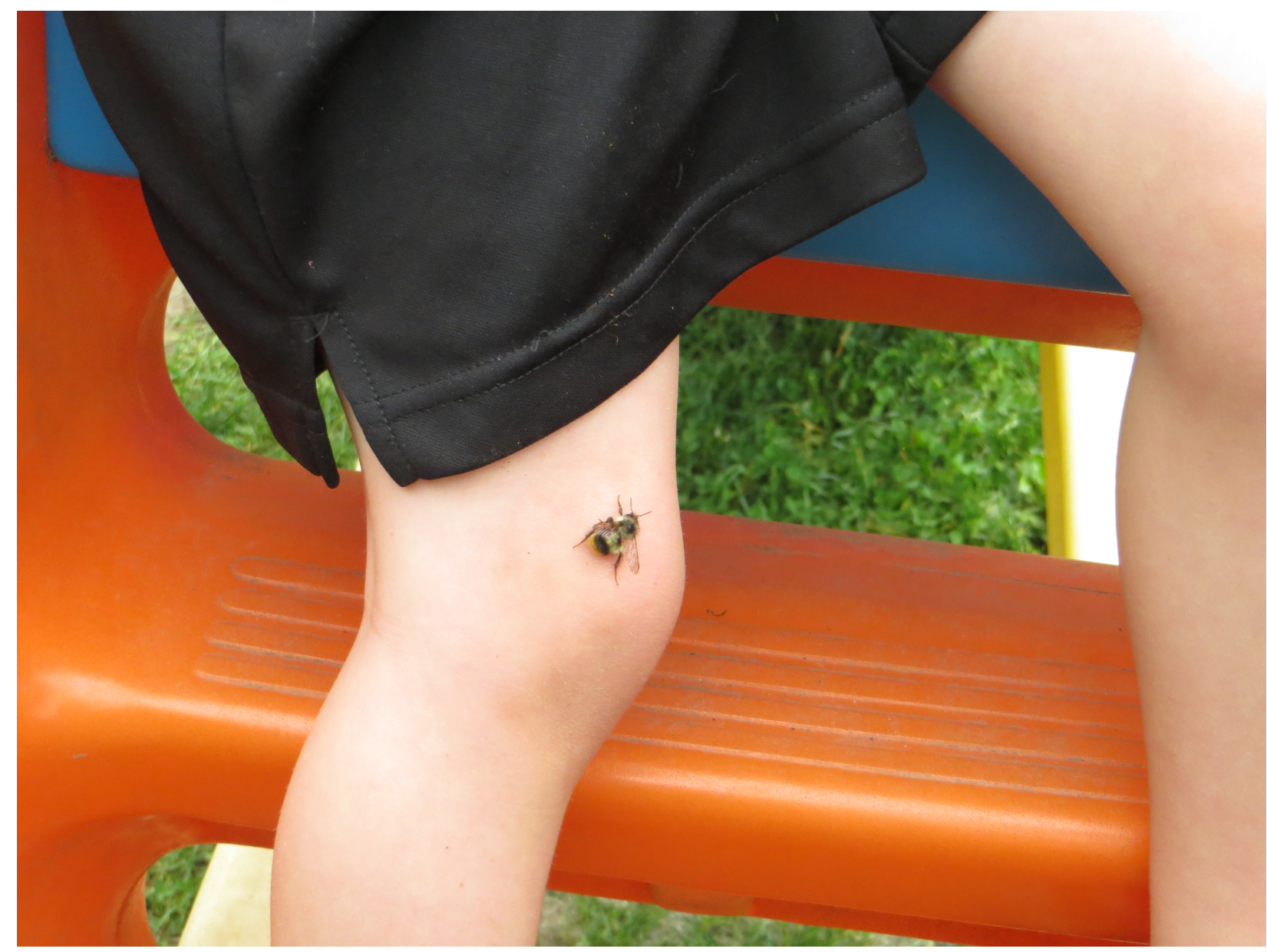

Figure 4. The bee lands on Carter's leg.

Moments such as this one with Carter and the bee are not unusual. We often notice children playing with small creatures, carrying worms, poking at ants. But what might emerge if we were to consider this moment differently? What if we put aside the notion of playing and consider that Carter is relating to the bee and the bee is responding to Carter? What if we think of Carter as learning, along with the bee, how to be together? Why did the bee land on Carter? Was there a mutual curiosity?

Bees are at risk in North America. Their colonies are disappearing at an alarming rate, impacting a multitude of ecosystems where bees facilitate pollination of many food crops (Green \& Ginn, 2014). Bees' role in food production means that our human lives are inextricably linked with the lives of bees. In other words, we share a common world. An encounter between a child and a bee, small as it is, has reverberations and opens possibilities to shift toward a pedagogy of common worlds. Taylor and Pacini-Ketchabaw (2015) urge us to work with pedagogies that emerge from small moments between children and the more-thanhuman, expressing this hope: 
We want young children to sense and register, in more than cognitive ways, that it is never just about us. And we also want to stay open to the possibility that other species and life-forms shape us in ways that exceed our ability to fully comprehend. (p. 6)

But these encounters are not simple. In our urban spaces on Vancouver Island, bees sting, slugs are squished, raccoons unlatch gates to venture into childcare centre playgrounds, deer wander the streets and are frequently hit by cars, and cougars who prey on deer and racoons move into urban forests and have been known to stalk children and small dogs (British Columbia Conservation Foundation, 2014). As an educator I am aware of my own uncertainties, the tensions of risk, of ethical responsibility, of pedagogies of care, and of what lives and what dies.

\section{Uncertainties and Tensions}

A group of eight infants and toddlers are well accustomed to hiking up the slope to the mossy plateau. Tree roots trip them, branches brush their faces and logs must be clambered over, there are plenty of tumbles and sometimes crying, but the children are not deterred and are delighted to visit this spot every day. Evan has a particular interest in mushrooms and knows where to find different varieties. His favourite are the clusters of tiny white ones he finds poking up through the moss and he stretches out on his stomach to inspect them close up, talking softly and lightly touching them. Evan finds a small twig and says "I cut mushrooms" as he very gently works the twig on the tiny mushroom until the mushroom is cut in two. 


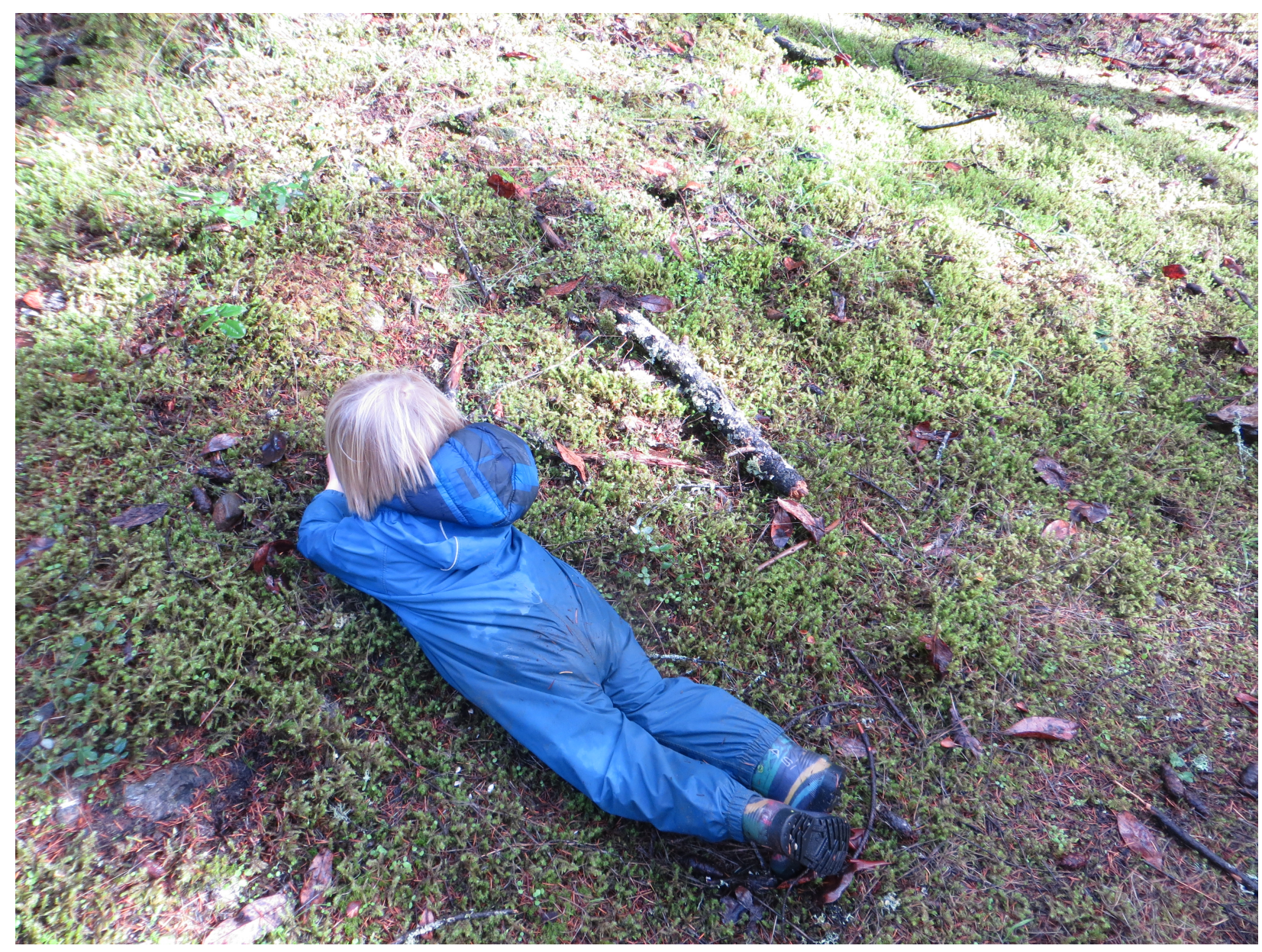

Figure 5. Looking closely at mushrooms. 


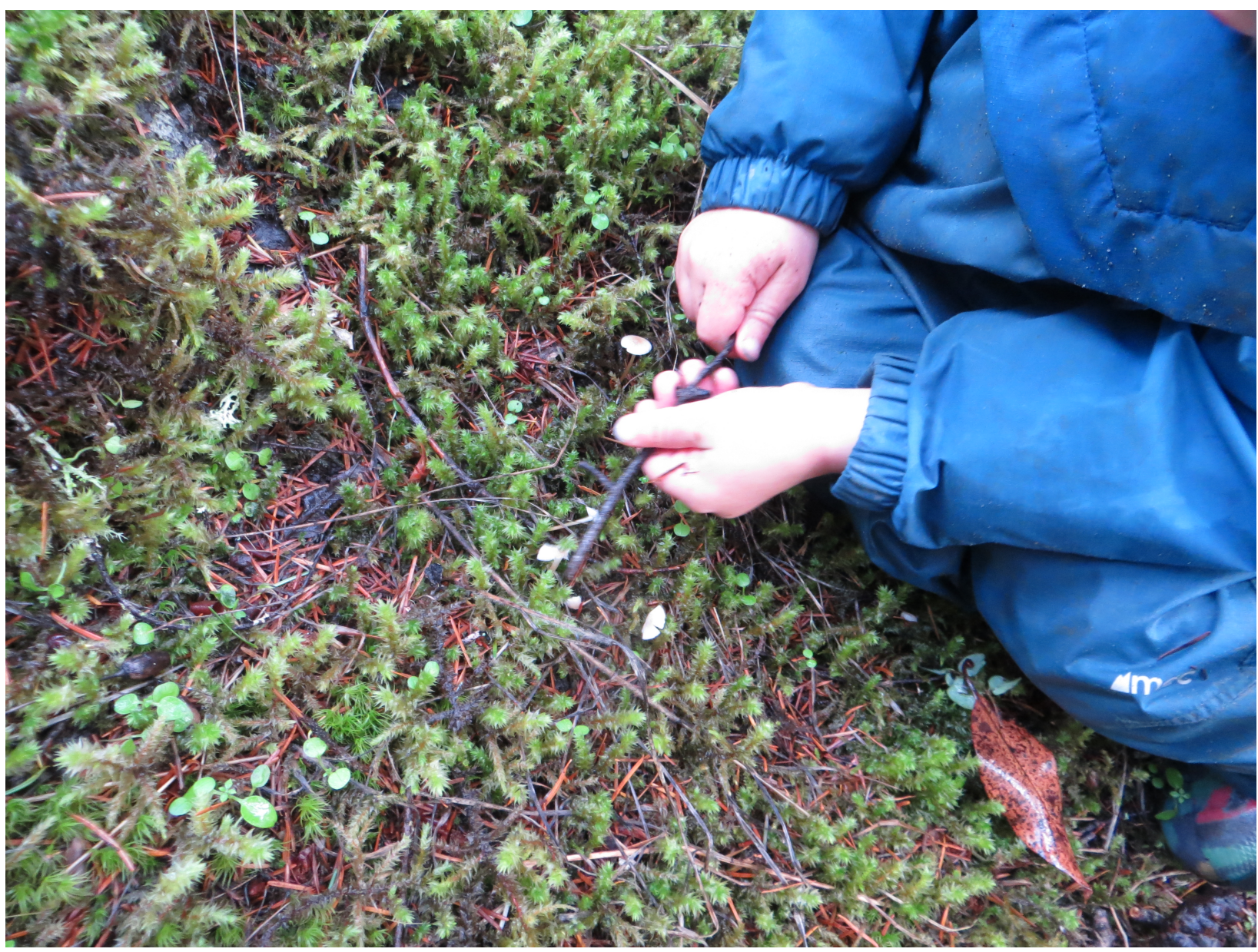

Figure 6. Cutting mushrooms gently with a stick.

In this encounter between Evan and the mushroom, the mushroom clearly dies ... and yet I don't stop him from cutting it. Something about the gentleness, the loving connection that Evan has with the mushroom holds me back. I am reminded of the work of Anna Tsing, who writes of people like Evan who have a loving connection to mushrooms, the foragers, botanists, gourmets, and artists who "love them with a breathless passion" (Tsing, 2011, p. 6). These people notice mushrooms and bring the passion of the arts and the knowledges of the sciences together to open new ways of connecting to mushrooms. Tsing describes the intricate and complex underground world of mushrooms, how mushrooms feed the trees and plants around them, how they take nutrients from organic material and rocks to make it available for absorption. She tells us how mushrooms are in symbiotic relationships with lichen, orchids, and Douglas fir seedlings, how mushrooms work to decompose dead wood to create conditions for regeneration. Tsing describes this world as a city of webs and filaments that lies under our feet, a city many of us fail to notice. She suggests that we humans could learn from the mushroom's example: "The role of fungi in ecosystem renewal makes it more than obvious that fungi are always companions to other species. Species interdependence is a well known fact-except when it comes to humans" (Tsing, 2012, para. 8). 
Evan has come to know the places where mushrooms grow. He notices and responds to the smallest of all the mushrooms and seeks them out every day, much as he might seek out a precious friend. What does Evan sense of this underground world? What does this underground world sense of these small human hands that come daily to touch them?

I wonder at my response to Evan's cutting of the mushrooms for days afterward, but I remain uncertain. Evan's attentiveness to mushrooms has led all of us, children and adults, to notice the mushrooms in the forest, to talk about them and think about them. Perhaps noticing is what is important, or, as Anna Tsing (2011) eloquently puts it, the "arts of inclusion" (p. 6). She asks: "How do lovers of fungi practice arts of inclusion that call to others? In these times of extinction, when even slight acquaintance can make the difference between preservation and callous disregard, we might want to know" (Tsing, 2011, p. 6). Perhaps Evan's love of mushrooms, even his gentle cutting of mushrooms, is a call to us, an invitation to become acquainted.

\section{Thinking With a Common Worlds Framework}

These mundane and ordinary moments filled with uncertainties, questions, and tensions help us grapple with reconfiguring our pedagogies within a common worlds framework. They bring us closer to thinking with wasps, bees, and mushrooms and help us glimpse possibilities for a multispecies ethics of environmental vulnerability. In this work with children we are shifting from humancentric notions of environmental stewardship toward a recognition of our interdependence with nonhumans, to consider our fragility. The tensions we encounter in these moments are everyday occurrences, but they are generative of new conversations with children, colleagues, and families about relating differently to the world. These conversations can open possibilities for new kinds of stories to be told of our entangled relations with other species, how we are co-shaped by and implicated in their histories. These conversations are fraught with challenges and complexities because there is no predictable trajectory or outcome. But, small as these are, these conversations demonstrate the possibilities that emerge when we shift our pedagogy to one that engages with our vulnerabilities as humans and invites creative listening to nonhuman others, recognizing that we are all connected to the world we share.

\section{References}

British Columbia Conservation Foundation. (2014). WildSafe BC: Cougar. Retrieved from: https://wildsafebc.com/cougar/

Common World Childhoods Collective. (2014). Common World Childhoods website. http://www.commonworlds.net/

Crutzen, P. J. (2006). The “Anthropocene.” In E. Ehlers \& T. Krafft (Eds.), Earth system science in the Anthropocene: Emerging issues and problems (pp. 13-18). The Netherlands: Springer-Verlag. 
Duhn, I. (2011). Making 'place' for ecological sustainability in early childhood education. Environmental Education Research, 18(1): 19-29

Gibson, K., Fincher, R., \& Rose, D. B. (2010). An ethics for living in the Anthropocene. Academy of Social Sciences in Australia workshop report. Retrieved from: https://cms.assa.edu.au/.pdf/reports/ASSA_WorkshopReport 73.pdf

Ginn, F., Beisel, U., \& Barua, M. (2014). Flourishing with awkward creatures: Togetherness, vulnerability, killing. Environmental Humanities, 4, 113-123.

Green, K., \& Ginn, F. (2014). The smell of selfless love: Sharing vulnerability with bees in alternative apiculture. Environmental Humanities, 4, 149-170.

Nxumalo, F. (2014). Unsettling encounters with "natural” places in early childhood education. Doctoral dissertation, University of Victoria, Canada.

Pacini-Ketchabaw, V. (2013). Frictions in forest pedagogies: Common worlds in settler colonial spaces. Global Studies of Childhood, 3(4): 355-365.

Taylor, A. (2013). Reconfiguring the natures of childhood. London, UK: Routledge

Taylor, A., \& Giugni, M. (2012). Common worlds: Reconceptualising inclusion in early childhood communities. Contemporary Issues in Early Childhood, 13(2), 108-119.

Taylor, A., \& Pacini-Ketchabaw, V. (2015). Learning with children, ants, and worms in the Anthropocene: Towards a common world pedagogy of multispecies vulnerability. Pedagogy, Culture, Society [published online May 1, 2015]. doi: 10.1080/14681366.2015.1039050

Tsing, A. (2011). Arts of inclusion, or, how to love a mushroom. In Unloved others: Death and disregard in a time of extinction [special issue]. Australian Humanities Review, 50, 521.

Tsing, A. (2012). Unruly edges: Mushrooms as companion species. Environmental Humanities, 1, 141-154. 


\title{
Entangled Dialogues on Learning How to Inherit in Colonized and Damaged Lifeworlds
}

\author{
by Fikile Nxumalo, Sera Oh, Jacky Hughes, and Saaiza Bhanji
}

\begin{abstract}
Authors' Bios
Fikile Nxumalo holds a PhD in early childhood studies from the University of Victoria. She is an instructor in early childhood education at Capilano University and is a pedagogical facilitator at Simon Fraser University Childcare Society as part of the Investigating Quality in Early Learning Environments Project. Email: fnxumalo@uvic.ca
\end{abstract}

Sera Oh is a senior early childhood educator at the Morningside program at Simon Fraser University Childcare Society. She has been in the ECE field for over 13 years and has been involved in the Investigating Quality in Early Learning Environments Project for the past 3.5 years. Sera is passionate about pottery, inquiry-based learning, and researching with children. Currently, she is engaged in thinking with common worlds pedagogies and possibilities for ethical coexistence with more-than-human others.

Jacky Hughes is a program director at Simon Fraser University Childcare Society. She has held a diploma in early childhood education with a focus on quality child care for 20 years. Jacky has been involved with the Investigating Quality in Early Learning Environments Project since 2011 and currently sits on the ECEBC Leadership Link committee.

Saaiqa Bhanji is a senior early childhood educator at Simon Fraser University Childcare Society. She has been in the ECE field for seven years. She holds a bachelor of arts in psychology with a minor in early childhood education from Simon Fraser University. She is passionate about providing children with rich opportunities to revisit their ideas, gain new perspectives, and provoke critical thinking.

\section{Abstract}

In this article we engage in a dialogue about some of the ideas that resonated with us in connection with the "Learning How to Inherit in Colonized and Ecologically Challenged Lifeworlds" symposium that took place at the University of Victoria in September 2014. Our aim is to begin to consider together the possibilities and challenges these ideas might bring to our everyday practices with young children. Using examples from our everyday pedagogical encounters, we shape our discussion through the pedagogical implications of Canadian Children JOURNAL OF THE CANADIAN ASSOCIATION FOR YOUNG CHILDREN 80 
inheriting colonial legacies and responding to children's relations with threatened and not-easy-to-live-with animals.

As a group of four early childhood educators, we recently met to discuss our engagements with the "Learning How to Inherit in Colonized and Ecologically Challenged Lifeworlds" symposium that took place at the University of Victoria in September 2014 and to think about the potentials and the tensions that the discussions and ideas from this conference bring to our practices with young children. While our discussions ranged across many areas, the focus of this article is in relation to our dialogues on ethical multispecies relations with threatened and not-easy-to-live-with more-than-human others and on grappling with inherited colonial relations. In our unique location on Burnaby Mountain, we co-inhabit this place with many more-than-human others. This locality brings ongoing possibilities for experimenting with how we might situate our work with young children within nonanthropocentric ${ }^{12}$ place-attuned relations.

\section{Responsive Witnessing}

Deborah Bird Rose's keynote brought attention to the importance of continually engaging with what meanings, understandings, and practices of responsible and ethical relationships with more-than-human others might look like within current times of anthropogenic species loss. We wonder how our pedagogies with young children might interrupt the "human indifference and tolerance" that Deborah so evocatively spoke of in relation to its connections to current times of damaged multispecies interactions in which we are all implicated. We resonate with witnessing as hopeful, attentive, affirmative, and responsive practices that do not shy away from the messiness of co-inhabiting damaged lifeworlds. Here are some of our still-ongoing dialogues on connecting these important considerations in our everyday practices with young children.

FIKILE: Deborah Bird Rose challenged us with the question of what constitutes ethical witnessing in the current anthropocentric era of immense and often irreversible plant and animal species loss. She discussed how paying attention to and nurturing multispecies cobecomings is an ethical responsive act of bearing witness. Sera, I wonder if you could share your story on noticing the dead bees and responding with children, as I think it is perhaps an example of the responsive and hopeful witnessing that Rose suggests is needed in these times of extinction, where the loss of pollinators in Canada is a real threat, not only for bees but for multiple forms of human and more-than-human interdependent life, an important illustration of how, as Rose (2014) reminds us, "we are multispecies becomings in [entangled] webs of complexity" (n.p).

\footnotetext{
${ }^{12}$ Nonanthropocentrism challenges the separation of humans and nonhumans, in particular through privileging humancentric ways of encountering the world. This separation is eloquently challenged by Donna Haraway (2008), who notes that "if we appreciate the foolishness of human exceptionalism then we know that becoming is always becoming with, in a contact zone where the outcome, where who is in the world, is at stake" (p. 244).
} 
SERA: We usually encounter many bees at around the same time every year in the spring. There is an apple tree in the playground which the bees really love, and in springtime, when we go outside, children will often yell out, "I see dead bees," referring to the dead bees in the yard. We also often encounter dead bees on our walks around the campus. It's been several years now and we still notice dead bees with children every spring. This often leads to many conversations, questions, and theories about how the bees died, and when we are walking around the campus the children notice dead or dying bees and will often pick them up. In the past, our emphasis was more on teaching the children about bees. We would bring out books and talk about, for instance, the body parts of the bees. But more recently, since our learning circle discussions on multispecies relations, we started thinking about and noticing children's relationships with more-than-human life. We noticed children were very interested in watching the bees "eating" and were relating to the bees in different ways. For example, when we encountered some bees that were not flying but were not dead, the children wondered if they were sick or hungry and asked if they could give them food. Also, there were moments when children collected these bees from the ground and built a house with clay to "block all the wind for the bees."

FIKILE: What happened with the apple tree? Was it the children or you pollinating?

SERA: My dad always told me that sometimes we have to pollinate plants ourselves if there are not enough bees. He said you might want to bring out your brush and start pollinating the tree. So I brought out the brush and I started doing it. The children were curious about what I was doing, so we engaged in conversations about why I was pollinating the tree and we talked about what bees do. Children then asked to join me.

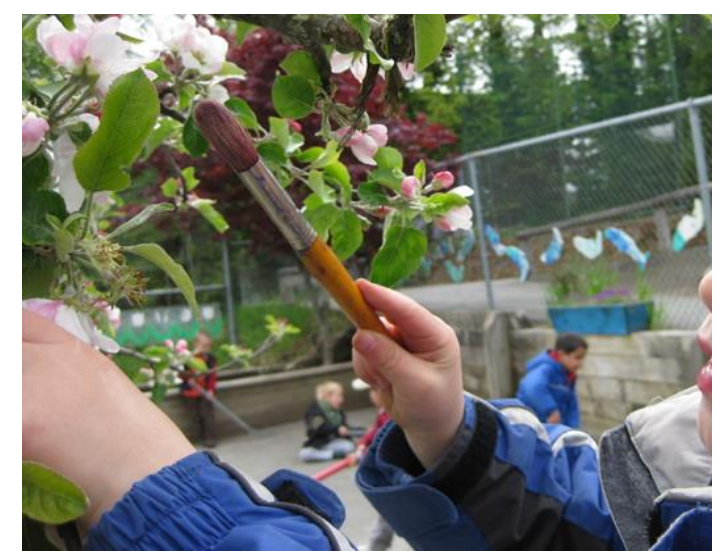

Figure 1. Pollinating apple tree.

FIKILE: That's wonderful. And I think you were saying children were perhaps humanizing the bees by relating to the bees as tired, sick, and hungry, but I think what you are doing with the children are everyday interruptions to the anthropocentric idea that it's "all about us, " while at the same time interrupting the normative idea of stewardship. I think it's important to complicate the idea that children are the ones who are now responsible and are going to save the planet, and I think these experimental practices of multispecies caring within children's 
"real-world" immediate contexts hold possibilities for negotiating this trap in "nature education."

JACKY: Yes, when you started out, Sera, I was like, why are the children holding these bees? I was thinking "this is wrong, they shouldn't be that close to bees," and then we talked about what kinds of bees we were encountering.

SERA: Yes, these are mason bees, so they will only sting you to protect themselves or their colony. So we educators have also done some research on the bees we encounter here.

JACKY: And I think we are seeing connections between having those encounters with dead bees, having dialogues with children about the bees, and then children helping to pollinate because there are no bees at this point to pollinate the tree. Where there is a lot more compassion and empathy that I believe has a direct connection to children's relationships with the animals and plants on the mountain.

JACKY: I also think our practices have changed, for instance, when I think about the raccoon encounters. [Many raccoons live on Burnaby Mountain; several often come to the child care centre playgrounds and the children and educators also encounter them around the campus.] The other day the raccoon was up the tree and there were children lying down on the ground looking up at the raccoon while it was looking down at them. To think that before when we would have seen a raccoon in the tree if we were outside, we took everybody inside or we would all have to go for a walk and leave. We weren't willing to adapt to them and were not seeing that relationship where the children aren't scared of them. We are noticing that as we've shifted our own responses, both the raccoons and the children seem to understand that while there are some boundaries needed, we can be in the same environment together.

FIKILE: And yet it's not a perfect or idyllic relationship either with the raccoons. Tensions remain.

SAAIQA: Yes, we are still negotiating that relationship. Personally I am still scared of the raccoons, but I am also more aware of how I am reacting to their presence and how children see me react. I'm keeping our dialogues in the learning circles and the symposium in mind while also considering safety. The other day there were four of the raccoons in a really, really tall tree in the playground, and I was watching how the raccoons and the children seemed to have this invisible but mutually respected boundary between them.

FIKILE: I think there is also a mutual curiosity, like the raccoons were watching the children for a long time, but from way up high, and the children were looking up for a long time as well.

SAAIQA: Yes, they were so curious and there was concern too from the children about how the raccoons were going to get down from that tree because they were really high up. 


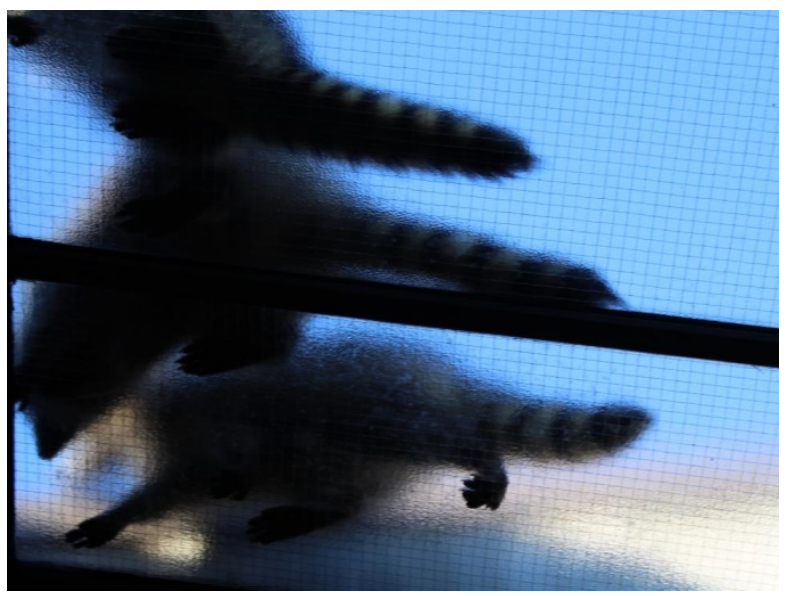

Figure 2. Raccoons at the childcare centre.

JACKY: They don't even get up very far up the trees at the Skyfire childcare centre, but we have never had a problem with the raccoons in that nobody's ever been hurt. And I think it's important that we think about the history that we have of co-existing with these raccoons.

FIKILE: Those are all great examples of rethinking what ethical relations with creatures that are threatened or not easy to live with might look like with children. I think these everyday encounters and your ongoing critical reflections powerfully illustrate some multiple, experimental, necessary responses to the messy, ecologically damaged worlds we inhabit with children and more-than-human others.

\section{Inherited Colonial Legacies}

A recurring concept through several of the symposium discussions was the inextricable entanglement of current human/more-than-human relations within settler colonial relations in the contexts of North America and Australia. For example, Elizabeth Povinelli (2014) spoke of the challenges of learning how to inherit in colonized worlds where colonial imaginaries already govern what inheritance is, such as inheritance as primarily structured within an othering frame of culture. In the following conversation we begin to consider the provocations some of these ideas might bring to reimagining and experimenting with "learning-hows" that interrupt the colonial governance modes in which we are all entangled.

Fikile: One thing that I think the symposium discussions perhaps challenge us to do is to think about ways to nurture children's ethical relationalities with the imperfect places we inhabit, but at the same time foregrounding that these places come with past-present colonial histories. I was curious about what your thoughts are on this in connection to practice. What do you see yourself engaging further with and continuing to work with or grapple with in your practice?

SERA: One thing that has emerged for me is that I think as educators we need to reflect on colonialism and consumerism and what we say to children. Usually when we go to the forest or have Earth Day, we pick up garbage with the children and I say to the children "we are going to protect the earth." But after the symposium dialogues, I realized, okay, I thought I didn't 
have colonial thinking but now I'm thinking when I say protect the earth, we don't own the earth to protect. Colonial thinking is so embedded that I think as educators, we need to constantly be thinking about what we say to children.

JACKY: And how we respond. For me, I came back from the symposium very unsettled. I think it was an uncomfortable feeling not coming back with answers, in that I'm used to going "oh, yes, I can fix that for you! We can do this!" I'm still unsettled. I still want to fix!

FIKILE: But I think even with not "fixing" there are these small, everyday responses like these child-bee, child-apple-tree, and child-raccoon stories that we've been discussing. So I think it's not that we 're not doing anything differently or that we aren't going to continue experimenting with different ways to respond with children. I think there are already these responses that are happening with children that we can continue to work with. At the same time, we can also experiment with new ethical responses for co-inhabiting with more-than-human others. So to take inspiration from Deborah Bird Rose, I think we're grappling with these difficult questions and engaging with how we might be ethical and responsive witnesses. I'm also wondering, if we consider that there are multiple and often contested or conflicting stories of a place, whereby certain stories dominate, what and whose stories do we tell of the places we inhabit with children? I'm also thinking, for instance, of some of the perspectives from Vanessa WattsPowless's (2014) keynote, which centred places as knowledge, knowing and knowledge making-important interruptions to the idea of place as passive and without agency. What might some of these interruptive perspectives open up with regard to multiple possibilities for relating to place with children?

JACKY: I think an interesting question is what do we choose to bring up with children in relation to colonial place relations? And how do we know to wait to bring up certain things that are already there?

FIKILE: And will they ever come up?

JACKY: Yes, will they ever?

FIKILE: In terms of place stories, an example that comes to mind for me are the ancient cedar tree stumps we encounter in the forest that have emerged from extensive colonial logging in the forest so that this is now a second-growth forest. And I keep thinking, how can we relate differently to those tree stumps and bring different Indigenous cedar stories to children? But then, at the same time, I' $m$ also thinking about potential slippages around appropriation and how we might relate to this place in ways that are meaningful and respectful to the knowledges and relationships that are already there and that precede us. 


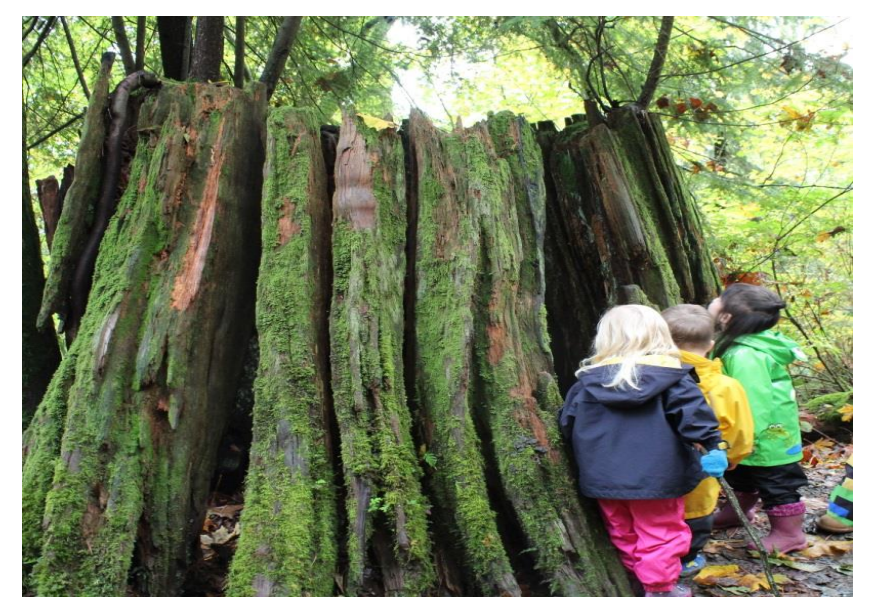

Figure 3. Old tree stump on Burnaby Mountain.

JACKY: In relation to learning the histories of this place, I think that one-time experiences are not enough; sustained dialogues and encounters are important. I also think that children's place knowledges can emerge from multiple relations and perspectives, including relations with elders, families, and more-than-human others. Through ongoing forest encounters, children and educators also build new histories.

SAAIQA: In our ongoing place learning with children, we are engaging with the multiplicities of Burnaby Mountain. For example, in addition to beginning to build relations with local Indigenous knowledge holders, we are participating in encounters with diverse literatures, architectures, arts (such as through children's encounters with the SFU art gallery), histories, and geologies of this place. We also work from a sense that we can never fully know or understand the complicated histories of Burnaby Mountain.

SERA: Yes, I also think that we can build relationships with this place through our (children's and educator's) own experiences, dialogues, and the acts of noticing. I also think it is important for place learning to be reciprocal. For instance, at Morningside centre, through pedagogical narration, we have been sharing our forest encounters with the broader Simon Fraser University and Burnaby communities.

SERA: When I think about colonialism and consumerism in the classroom, I am wondering about how I can talk to children to shift some of those discourses of consumerism and control. For instance, in our conversations about water during our inquiry, some of the children's responses around water were that if there was no water we could just go buy it in the store.

FIKILE: I think, though, that you started to bring in some important interruptions to that with your inquiry on thinking with water. Do you want to say something about that?

SERA: We experimented with possibilities for different ways of relating to water beyond typical scientific approaches that might involve learning to control water. For instance, we experimented with just having a glass bowl of water and no other containers, and entering into 
dialogues with children and water. I think new water stories as well as different ways of noticing, relating, and really paying attention to water emerged from these encounters.

\section{Conclusion: Still-Ongoing Entangled Dialogues}

During our discussions for this article the three of us have only just begun to consider what it might mean for us situate our practices, the specific places we inhabit, and the plant and animal species we encounter within settler colonial relations and legacies with social, ethical, and political implications. We hope to continue productively grappling with both the hopeful responses as well as the frictions that learning within the entanglements of colonial legacies and ecologically damaged landscapes brings to our everyday practices.

\section{References}

Haraway, D. (2008). When species meet. Minneapolis, MN: University of Minnesota Press.

Povinelli, E. (2014). Life and death in geontology. Keynote presentation at "Learning How to Inherit in Colonized and Ecologically Challenged Lifeworlds" symposium, University of Victoria, Canada, September 27, 2014.

Rose, D. B. (2014). Kinship and witness in this time of loss. Keynote presentation at "Learning How to Inherit in Colonized and Ecologically Challenged Lifeworlds" symposium, University of Victoria, Canada, September 29, 2014.

Watts-Powless, V. (2014). Indians, animals, dirt: Place-thought and agency amidst Indigenous cosmologies. Keynote presentation at "Learning How to Inherit in Colonized and Ecologically Challenged Lifeworlds" symposium, University of Victoria, Canada, September 29, 2014. 


\title{
Wandering With Waste: Pedagogical Wonderings About Intergenerational Ecological Justice-to-Come
}

\author{
by B. Denise Hodgins
}

\section{Author's Bio}

B. Denise Hodgins holds a PhD and MEd in early childhood education. She has worked in the human services sector since 1989, including in school-age childcare, preschool education, and nonprofit program and service delivery. She is a sessional instructor in the School of Child and Youth Care at the University of Victoria and also works as a pedagogical facilitator and researcher in child care. Her work reflects a commitment to making visible and engaging with issues of equity in, through, and for pedagogy and research. Email: dhodgins@uvic.ca

\begin{abstract}
This article considers pedagogical approaches for dealing with waste in early childhood settings. Early childhood education is overtly complicit in the leaky wastes of fabrication and consumption, yet this complicity is rarely addressed in pedagogy in ways that move beyond anthropocentric and heroic framings buoyed by neoliberal consumerism and governmentality. Moments from two collaborative inquiries with materials, children, and educators are included to act as provocations for questioning the responsibility of early childhood education in intergenerational ecological justice-to-come. Theoretical insights from feminist science studies are drawn on to (re)imagine pedagogies of waste as emerging through less-than-seamless, often unequal, always imperfect relatings.
\end{abstract}

The twenty first century marks a threshold where waste - as concept, as excess, as object - begins to issue an imperative that we refigure our relations with waste within our communities, waste as constituting our environments, and [waste as] poised, we might say, to become an organizing, biospherical feature of global society. (Canada's Waste Flow, n.d., para. 10)

I have begun to gather up the small and large pieces of material that have been left on the floor, tables, and chairs, remnants from the morning's textile exploration. Small pieces of fabric are laid into two plastic containers, each one maybe the size of two shoeboxes put together. I need to lay the pieces flat and press them tightly together in order to get the lids to the containers back on. The larger fabric pieces are folded, piled, and placed into a carrier sac. Other remnants-long knitted sweater seam scraps that were given to the centre by someone who repurposes sweaters into handmade gloves-I gather separately into a plastic 
bag. To this bag, I add the now rerolled ribbons. I take the bags and bins (in two trips) to the centre's storage closet and look for space on the shelves. There are many shelves with many, many different kinds of toys and materials on them (as well as on the floor). I have to work at finding space for our textiles. We have added so much to our fabric and yarn collection that I can now barely squeeze all this stuff onto the shelf.

In this article I address pedagogical approaches for dealing with the "waste presents" we inherit and the "waste futures" we bequeath in this era of the Anthropocene, a term that many scientists are now using to define a distinct epoch in which humans are a geophysical force. The Anthropocene is characterized by human-driven changes to the environment, particularly through the enormous expansion in the use of fossil fuels with industrialization, changes that now threaten our life-support system (see Steffen, Crutzen, \& McNeill, 2007). Between the various kinds of energy used to operate centres and classrooms, the water that flows through daily routines (e.g., hand washing, table wiping, dishes and toy cleaning, water play), and the purchasing and use of many varieties of materials (some of which are kept for years but many which run through a quick buy-use-dispose cycle), practices with/in early childhood are complicit in the leaky wastes of fabrication and consumption. While early childhood practices are certainly not the only consumers and users of energy and resources, our connection to the production and disposal of waste is neither innocent nor insignificant.

To consider the responsibility of early childhood practices in attending to waste, I include in this article moments from two collaborative inquiries - an exploration with paint from a few years ago and a current ongoing inquiry with textiles - as provocations for questions and wonderings. I draw on theoretical insights from feminist science studies, in particular the work of Haraway $(1992,1994,1997,2008,2012)$, Barad $(2007,2010)$ and Hird (2012, 2013, 2014; Hird, Lougheed, Rowe, \& Kuyvenhoven, 2014), to help me (re)imagine pedagogies of waste beyond anthropocentric and heroic framings as emerging through less-than-seamless, often unequal, always imperfect relatings. My approach to addressing pedagogies of waste in early childhood practices is a diffractive one (Barad, 2007; Haraway, 1992, 1994, 1997), a wandering with and through several waste-related moments in, near, and far from the classroom of our inquiries. Haraway (1992) explains that "diffraction is a mapping of interference, not of replication, reflection, or reproduction. A diffraction pattern does not map where differences appear, but rather maps where the effects of difference appear" (p. 301). To think with diffraction is to attend to the effects of differences and relationalities and is "a commitment to understanding which differences matter, how they matter, and for whom" (Barad, 2007, p. 90). For Haraway (1994), "the point is to get at how worlds are made and unmade, in order to participate in the processes, in order to foster some forms of life and not others" (p. 62, emphasis added).

With a diffractive methodology, my intention is not to synthesize different perspectives or knowledges related to waste and early childhood practices and end up with a solid solution for pedagogy and curriculum. Rather, reading my wanderings with waste through each other produces many pedagogical wonderings about attending to intergenerational ecological justice, or, as Barad (2010) might rather suggest, justice-to-come. With her materialist Derridean understanding of justice, Barad suggests that "doing justice is a profound yearning, a crucially important if inevitably unachievable activity, an always already inadequate attempt to respond 
to the ethical cry of the world" (Barad, interviewed in Kleinman, 2012, p. 81). She further shares that "it is the very question of justice-to-come, not the search for a final answer or final solution to that question, that motivates me. The point is to live the questions and to help them flourish" (p. 81). This article is an exploration of how living with the questions and helping them to flourish, or, in Haraway's (2012) terms, "staying with the trouble" (p. 311), might manifest in pedagogies of waste.

The questions that emerge through my wanderings are offered to the reader in three sections. In the first section, my aim is not to try and tell the origins of the pedagogical work that produced the moments drawn on in this article but rather to bring the reader into our inquiries and the emerging (ongoing) wonderings that they produce. In the second section I explore further the settings where these inquires take place and, leaning on Hird's research that challenges waste as simply a technical and individual problem, (re)consider the (settling/sedimenting) practices related to waste that our inquires (inadvertently) touch. Finally, I engage our emerging inquiry wonderings with some of Barad and Haraway's imaginings to interfere with the ubiquitous 3Rs (reduce, reuse, recycle) approach to tackling issues of waste with children, and offer the reader less of a conclusion than an invitation for more actions, inquiries, wonderings, and questions.

\section{Beginnings}

Over the past four years, I have had the good fortune to work as a pedagogical facilitator and researcher with many early years educators in a large, multicentred childcare setting for children aged 6 months to 5 years. Together we ${ }^{13}$ have engaged in several inquiries and professional development series that critically reflect on and theorize about the implementation of pedagogy and curriculum in the centres. This is challenging, never complete, and invigorating work. The article's opening narrative describes a moment during one of our current inquiries that we have named "thinking with textiles." In this inquiry (at the time of writing), we have brought in fabrics, knitted yarns, thread, sewing needles and scissors, natural dyes, and deer-shaped forms for the children and us (educators and researchers) to explore. For several months we have sewed, cut, scrunched, draped, twisted, knotted, rolled, looped, stretched, hung, tied, pulled, dyed, ripped, and layered (among other things!) these materials. We have plenty of materials - and ideas, questions, challenges - to think with. As described in the opening narrative, we store the materials of our thinking with textiles inquiry each week among many other material options for children at this centre, and I often wonder about all this stuff. This is not a new wonder (nor one that I alone have, as the following section shows). After one morning during our early efforts to challenge our pedagogical practices and the boundaries that we knowingly and unknowingly draw through our words and actions (e.g., "that's not safe," "stop," "that cannot go there/here"), I found myself on my hands and knees mopping up puddles and puddles of paint, wondering about abundance and the notion of "more."

The children have left to go back to their centre and I am cleaning up. The paper on the floor is sopping wet with paint, torn from the sliding. I do not save that paper but recycle it. The

${ }^{13}$ There are times in this article when I refer to "we." My use of the pronoun we is to acknowledge that I did not think, act, and question alone. These are my perceptions of our work together. 
paper that had been on the wall was not very wet so I roll and save it to be used another time. As I wash the floor, I find myself thinking a lot about the word "more." More paint. More paper. More floor and wall space to use. In the last few weeks we have spoken about whether the creative process needs "more." Is there a relationship between an abundance of materials and creativity? I think about this question as I mop up paint and scrape wet painted paper off of the floor. How is this kind of exploration sustainable in terms of time, money, material, and energy? As I pour the paint water down the drain, I have no idea where it goes or the damage it may do. The floor now has a slight blue tinge to it. The children's painted clothes will not completely wash clean. Their skin will take days (and much work) before it is no longer tinted. Safe? Impermanent? I feel a strong (irresolvable?) tension between my questions and my memories of the children engaging with the paint: excited faces as they feel the paint thick on their feet, pour paint onto their brushes and bodies, see the paint traces all over the floorpaper and wall-paper.

The tensions that emerged for me, as well as many of the other educators, in our early inquiries raised many questions about who and what we attend to (care for) in our practices: children's development, children's safety, parents' wishes, the materials, the spaces, educators' desires and concerns, the legacy of colonization, our environmental impact. (For more on some of these questions that have emerged in our collective research inquiries, see Clark \& Nelson, 2014; Clark, Pacini-Ketchabaw, \& Hodgins, 2014; Elliott \& Yazbeck, 2013; Hodgins \& Foreland, 2013; Yazbeck, 2013.) We have not smoothed out these tensions, and our questions have not brought about easy (any?) answers. I think that with every inquiry our questions simply grow. As we become a little more comfortable with stretching boundaries and experimentation with when (and in what) to intervene, when (and what) to pause, when (and what) to halt, new questions and tensions (or old ones that we have managed to avoid) bubble to the surface. Our current inquiry with textiles returns me to, or makes visible again, questions about waste/wasting and how in our pedagogical practices we are to be accountable, and to whom and what. With Harawayian curiosity, an active, enacting effort to know more and play well (see Haraway, 1994, 2008, 2012), I turn my attention to several threads of wasteconnection that our inquiry moments touch.

\section{Sett(l)ings}

Our inquiries together take place on a university campus that is envisioning and working toward being a zero-waste institution. Zero waste is a philosophy that focuses on minimizing the resources we consume and the amount of products that end up in the landfill (see University of Victoria, n.d.). Producing zero waste is of course impossible, but it is a catchy phrase, and certainly looks good on signage! Our own bodies are constantly producing waste as we breathe out carbon dioxide and excrete that which our bodies deem dangerous or unnecessary. However, waste for us may be fuel for others, as "one organism's waste is another's treasure" (Hird, 2013, p. 110). And, as Myra Hird, Queen's University sociologist and lead researcher of the Canada's Waste Flow research program points out, "waste, of course, doesn't really go away" (Hird, 2013, p. 107), it just moves elsewhere, often to landfills.

Drawing on data from Statistics Canada, Canadians lead the world in municipal solid waste production per capita (Hird, 2012, 2013, 2014; Hird et al., 2014; Ross, 2013), so in many ways 
the university's strategy can be seen as an important effort to combat their contribution to this production problem. So too can the efforts of the regional district that the university exists within to divert compostable materials from the local landfill through their Regional Kitchen Scraps Strategy (RKSS; see Capital Regional District, 2015). Municipal collection of separated garbage and kitchen scraps began in 2013, and as of January 1, 2015, kitchen scraps are banned at the local landfill (Capital Regional District, 2014a, 2014b, 2015). This work toward "cutting the carbon" (the logo on our city compost and garbage bins) has not been without its challenges as a local solution for processing the compostable waste struggles to find its footing. Currently the kitchen scraps that are collected are taken to the local landfill and then transferred to a processing plant that is over 100 kilometres away via land and water (Capital Regional District, 2014a). Cutting the carbon indeed. What Hird's research program makes clear is that "managing" all this waste is not only a technical and engineering problem, but a very material, social, cultural, economic, political and ethical one as well. Perhaps, as Hird suggests, rather than focusing on the management of waste, we should be focusing on why we produce and consume so much stuff to begin with (Hird, 2014). How will we in the field of early childhood be involved in such conversations and practices?

Rethinking our purchasing and consumption is actually the first "rule" of the waste reduction strategy on the campus where we work (University of Victoria, n.d.). But are we really ready to confront the "politics and economics of consumption" and our role in "our 'waste-maker' society" (Canada's Waste Flow, n.d., para. 9) in a way that might inch us toward breaking this production-consumption-waste-making never-ending cycle? Stepping out of this neoliberal machine will, at the very least, not be easy. Is it impossible? Our provincial government stresses that "trade is a critical component" of our economy (Government of British Columbia, 2015a, para. 1). In Canada, in 2013, British Columbia was the fourth-largest importer of goods from other countries after Ontario, Quebec, and Alberta (Government of British Columbia, 2015b). Port Metro Vancouver in BC is

Canada's largest port and the fourth largest tonnage port in North America, responsible for Canada's trade with more than 160 world economies.... Enabling the trade of approximately $\$ 184$ billion in goods annually, the port generates an estimated 100,000 jobs, $\$ 6.1$ billion in wages, and $\$ 9.7$ billion in GDP across Canada. (Port Metro Vancouver, 2015, para. 6)

What does reducing consumption (and in turn production and trade) look like and do in a society where consuming is often portrayed as an act of good citizenship ${ }^{14}$ (Tsai, 2010)? The capitalist drive to buy, buy, buy is little disrupted by dominant waste "management" solutions (e.g., recycling). Hird and colleagues (2014) argue that "privatization and individual responsibilization" (p. 443) of waste management operates "within a capitalist rationale to manage waste in ways that do not disturb circuits of mass production and mass consumption (and industry profit)" (p. 444). How do we begin to interfere with this governmentality?

\footnotetext{
${ }^{14}$ It is beyond the scope of this paper to explore the complex history of the construction of the citizen-consumer, where the role of the good consumer and responsible citizen have, over time and in varying ways, become intertwined. For more on this see Kroen (2004) and Schudson (2006).
} 
One of the dominant sociomaterial lines of involvement in ECE concerns engaging children through projects and play-based inquiries to learn more about recycling and waste disposal. Underlying many such initiatives is the assumption that instilling values and attitudes about sustainability early is the necessary foundation for ensuring future efforts in sustainable development (see, e.g., Engdahl \& Ärlemalm-Hagsér, 2002; Samuelson \& Kaga, 2008; SirajBlatchford, Smith, \& Samuelson, 2010). While the least effective, recycling is the most promoted waste management strategy (Hird, 2014), one that significantly generates its own waste (Hird et al., 2014), and one into which we have thoroughly integrated children and schools, as a quick Google search of "children recycling activities" will demonstrate. Hird (2014) raises questions as to whether we are actually burdening children, our little recycling champions, rather than involving them in the mundaneness (and mendacity), muck, and movement of waste(ing), and whether this focus is the most valuable expenditure of our (precious) resources. Focusing solely on individual consumer usage and responsibility also diverts needed attention and questions regarding industrial and governmental accountability as to what (and how) things get stored, recycled, burned, and buried, and about that which we are simply bequeathing to future generations for them to deal with (Hird, 2012; Hird et al., 2014). Individual responsibility and "the presumption that the world can be contained and controlled by human forces" (p. 120) drives a stewardship approach to environmental issues where humans are positioned as the heroic saviours of the earth. Yet, as Hird's (2013) research puts forward, from a geo-biological perspective, humans are ultimately (actually) vulnerable to earth processes. We were not the first organism to arrive here on earth and we will not be the last organism standing.

Another dominant sociomaterial line of involvement in ECE is reusing/repurposing "waste materials" for explorations, particularly for art (Samuelson \& Kaga, 2008; Siraj-Blatchford et al., 2010; Uyank, Inal, Çalışandemir, Akif, Can-Yaşar, \& Kandır, 2011), which has been promoted for some time (see Karns, 1979; O'Neill, 1976). This is certainly an aspect of our thinking with textiles inquiry and a regular practice in the centres we work with. Yet, even things that are reused or repurposed will "sooner or later ... be considered 'waste' and be disposed of" (Ross, 2013, p. 7). I think of this often as wine-cork-picture-frames go home for Mother's Day, and CDs-turned-sparkling-ornaments are tucked carefully into backpacks at Christmas. How long exactly have we diverted these materials from the landfill? Is diverted for some time better than not diverted at all? Hird and colleagues (2014) point out that "diversion practices are presented as a societal and environmental 'good,' but the reality of the diversion is more complicated, and certainly not a complete solution to waste issues" (p. 445). While I wonder about the utility of these diversions, I also practice (and, dare I add, believe in) this kind of reusing/repurposing. And it is so very easy to collect used/waste materials for such repurposing inquiries and projects; we are swimming (drowning?) in stuff. For our current textile inquiry, some of the fabrics we have been using came from my own home, from drawers of fabric stacks that had been sitting and waiting to be used for years! I was very pleased to see the material move from my home to be engaged with in our inquiry.

All this repurposing-hurray! And yet I went out and bought brand new small fabric scissors. At the beginning of the inquiry I was not convinced that we should introduce scissors with the fabric. Would the cutting be purposeful (as I defined it)? Would it disrupt our intentions with the fabrics, needles, and threads? Would we be wasting fabric by cutting, cutting, cutting it?

Volume 40 Number 22015

www.cayc.ca 
But scissors arrived on the first day of the inquiry (one pair brought out by an educator to cut threads for sewing, another pair brought out by one of the children) and they were quickly taken to the fabric by some of the children. Cindy worked with the kid-sized paper-craft scissors and a fabric piece, trying and trying to cut through it. The fabric would NOT give in to these dull metal blades (can they actually be called blades?), so I held the ends of the fabric taut and said, "Try cutting now." If the scissors angled just so on the pulled fabric she could get a rip going into it. Aaaah. Smile. Again and again and again and again, I held, she cut. I decided that if we are going to create space for exploring textiles with scissors then they have to work. We needed fabric scissors. Sharp, real. This produced some worry. The following week Cindy seemed well surprised and impressed with the new fabric scissors and what her hands-with-scissors could now do: slide through the fabric with ease. What a privileged position: I get to feel good about myself for "reusing" all these fabric scraps, diverting them from the landfill (and freeing up space in my drawers!), and I am able to buy new materials because I deem them a necessary element for the children's engagement.

\section{Imaginings}

My work with the educators and children is deeply influenced by the writings of Haraway and Barad. Their metaphoric and image-conjuring use of words like strings, threads, and knots (Haraway, 1994, 2008, 2012), entanglements and connections (Barad, 2007, 2010) are particularly vibrant as I engage and think with/in our textile inquiry. As hands tie knots in yarns and ribbons, stretch and weave these materials into new patterns (and possibilities), I cannot help but think that these hands-fabric-touches are so much more than children practicing fine motor skills, learning to share, and/or being creative. This work (like most relation-encounterings, as Barad and Haraway's writings suggest) is not easy and seamless work. Scissor-fingers struggle to cut through the thickness of fabric. Needles that powerfully stitch together can also suddenly, sharply, painfully poke fingers. Yarns that took so long and such care to tie together can break, come loose, and fall apart in a matter of seconds. And yet we go on, trying, encountering.

Barad and Haraway also help me remember to question and wonder about the multiple other knots, weavings, and connections that these material-moments touch. Where and how were these materials produced? Whose/which bodies enacted, and suffer(ed) from, their production? Why and how will I care about these multiple past-present-futures of production that our inquiries touch? These are questions that we have only begun to trace in our thinking with textiles inquiry, questions that take us out of the classroom to fields where plants are harvested for textiles, factories where fibres are treated and transformed into fabrics, and road, rail, and water ways that transport goods in various stages of production. They also take us to places of unequal relations, where certain human and nonhuman bodies bear the weight of (and benefit from) production more than others. With Hird's challenge to refigure waste as an imperative issue in our communities (Hird, 2012, 2014; Hird et al., 2014), I am now called to trace our inquiry connections to waste, in terms of both production and disposal, for, as Haraway (2008) reminds us, "once we know, we cannot not know" (p. 287). How do we illuminate the complexities of waste diversions, resist the neoliberal recycling champion subject, and begin to deliberately ask questions about the "association between economic growth and waste" (Hird 
et al., 2014, p. 446)? What challenges and possibilities we unfold in our future collective tracings I cannot know, but with inspiration from Haraway, I am certain of the need to do so.

Each time I trace a tangle and add a few threads that first seemed whimsical but turned out to be essential to the fabric, I get a bit straighter that staying with the trouble of complex worlding is the name of the game of living and dying well together on terra. (Haraway, 2012, p. 313)

By this point, it is unlikely that readers will be surprised that I conclude my diffractive wanderings with an assertion that they have not led me to any solid conclusions or a set of definitive answers that illuminate a pathway to best practices for pedagogies of waste. Some of the questions I am left with include these: How do I bring the complexities of waste into the classroom? What traces can I make visible with/to/for the children? How can I include children in these complicated conversations, not to set them up as tomorrow's fixers of the mess we bequeath them and they inherit, but because they are here, with me and all this mess, now? Can pedagogies of waste make space for and attend to the technological, social, material, economic, political, and ethical matters of our relentless production-consumption cycle? What might a more-than-human ethics of vulnerability bring? Where do my choices lie within these pedagogies? Is it (simply/only) a matter of resisting the temptation (obligation) to buy more, because (I think) the children need it? There are no straightforward answers to these questions, no simple smoothing out of the various knots and waste-connections that our inquiries touch. But as Barad (2007) puts forward, perhaps the responsibility of early childhood education in ecological justice-to-come lies in our everyday actions to live the questions and to help them flourish, not because we are transcendent super-humans that can save the world, but because we are of the world: "Only in this ongoing responsibility to the entangled other, without dismissal (without 'enough already!'), is there the possibility of justice-to-come" (Barad, 2010, p. 265).

As I pick up the fabric pieces from the morning's exploration, I wonder about the utility of keeping the ones that are getting rather small (due to cutting, tearing, ripping). Just how small is too small to keep? How small is too small to worry or bother about? It seems a little too easy to toss these small ones into the waste bin. Out of sight, out of mind. I wonder what would happen if I actually, routinely, resisted this tossing aside, this rendering invisible?

\section{References}

Barad, K. (2007). Meeting the universe halfway: Quantum physics and the entanglement of matter and meaning. Durham, NC: Duke University Press. 
Barad, K. (2010). Quantum entanglements and hauntological relations of inheritance: Dis/continuities, spacetime enfoldings, and justice-to-come. Derrida Today, 3(2), 240-268. doi: 10.3366/E1754850010000813

Canada's Waste Flow. (n.d.). About Canada's Waste Flow research program. Retrieved from: http://www.wasteflow.ca/\#!about/c1y13

Capital Regional District. (2014a). 2015 kitchen scraps landfill ban and longer processing plans. Retrieved from: https://www.crd.bc.ca/about/news/2014/10/08/2015-kitchenscraps-landfill-ban-and-long-term-processing-plans

Capital Regional District. (2014b). Backgrounder: Regional kitchen scraps strategy key dates and decisions. Retrieved from: https://www.crd.bc.ca/docs/default-source/newspdf/2014/2014-04-09-kitchen-scraps-processing-backgrounder-final.pdf?sfvrsn=0

Capital Regional District. (2015). Regional kitchen scraps strategy. Retrieved from: https://www.crd.bc.ca/service/waste-recycling/kitchen-scraps/regional-kitchen-scrapsstrategy

Clark, V., \& Nelson, N. (2014). Thinking with paint and water: An interview with Terry Wilson, Deanna Elliott, Diana Foreland, and Teresa Dixon. International Journal of Child, Youth, and Family Studies, 5(4.2), 854-864.

Clark, V., Pacini-Ketchabaw, V., \& Hodgins, B.D. (2014). Thinking with paint: Troubling settler colonialisms through early childhood art pedagogies. International Journal of Child, Youth, and Family Studies, 5(4.2), 751-781.

Elliott, D., \& Yazbeck, S. (2013). Navigating change through wonder and dialogue. In R. Langford \& A. Di Santo (Eds.), Leading the way: Recognizing the role of early 
learning lab schools in Canadian universities and colleges (pp. 34-41). Retrieved from: http://www.ryerson.ca/ecs/

Engdahl, I., \& Ärlemalm-Hagsér, E. (2014). Education for sustainability in Swedish preschools: Stepping forward or out of step? In R. Davis \& S. Elliott (Eds.), Research in early childhood education for sustainability: International perspectives and provocations (pp. 208-224). New York, NY: Routledge.

Government of British Columbia. (2015a). Exports and imports. Retrieved from: http://www.bcstats.gov.bc.ca/StatisticsBySubject/ExportsImports.aspx

Government of British Columbia. (2015b). Imports of goods and services from other countries, by province/territory [Excel document]. In Exports and imports: Data. Retrieved from:

http://www.bcstats.gov.bc.ca/StatisticsBySubject/ExportsImports/Data.aspx

Haraway, D. (1992). The promises of monsters: A regenerative politics for inappropriate/d others. In L. Grossberg, C. Nelson, P. A. Treichler (Eds.), Cultural studies (pp. 295-337). New York, NY: Routledge.

Haraway, D. (1994). A game of cat's cradle: Science studies, feminist theory, cultural studies. Configurations, 2(1), 59-71.

Haraway, D. (1997).Modest_witness@second_millennium. Femaleman (C_meets_oncomouse ${ }^{T M}$. Feminism and technoscience. New York, NY: Routledge. 
Haraway, D. (2008). When species meet. Minneapolis, MN: University of Minnesota Press.

Haraway, D. (2012). Awash in urine: DES and Premarin $®$ in multispecies response-ability. Women's Studies Quarterly, 40(1 \& 2), 301-316.

Hird, M. (2012). Knowing waste: Towards an inhuman epistemology. Social Epistemology: A Journal of Knowledge, Culture and Policy, 26(3-4), 453-469. doi: $10.1080 / 02691728.2012 .727195$

Hird, M. (2013). Waste, landfills, and an environmental ethic of vulnerability. Ethics \& the Environment, 18(1), 105-124.

Hird, M. (2014). Waste(Ed): Colonial legacies in the Anthropocene. Paper presented at the "Learning How to Inherit in Colonized and Ecologically Challenged Lifeworlds" symposium, University of Victoria, Canada, September 26-28, 2014. Retrieved from: https://www.youtube.com/watch?v=hksHLkMvjpw

Hird, M., Lougheed, S., Rowe, R. K., \& Kuyvenhoven, C. (2014). Making waste management public (or falling back to sleep). Social Studies of Science, 44(3), 441-465. doi: $10.1177 / 0306312713518835$

Hodgins, B. D., \& Foreland, D. (2014, March 8). Caring complexities: Thinking gender-care with and through pedagogical narrations. Paper presented at "Leading the Way: Recognizing the Role of Lab Schools in Canadian Universities," North Vancouver, BC, Canada, March 8, 2014.

Karns, M. (1979). Recycling into Easter baskets. Day Care and Early Education, 6(3), 55-57. 
Kleinman, A. (2012). Intra-actions: Interview with Karen Barad. Mousse, 34(June), 76-81.

Kroen, S. (2004). A political history of the consumer. Historical Journal, 47, 709-736.

O'Neill, J. (1976). Don't throw them out! Day Care and Early Education, 3(3), 34-35.

Port Metro Vancouver. (2015). About us: Canada's largest and busiest port. Retrieved from: http://www.portmetrovancouver.com/about.aspx

Ross, A. (2013). Canada's waste flow. (e)Affect, 4(Fall), 6-9. Retrieved from: http://www.queensu.ca/vpr/sites/webpublish.queensu.ca.vprwww/files/files/eAFFECT/ eAFFECT4Fall2013.pdf

Samuelson, I. P., \& Kaga, Y. (Eds.). (2008). The contribution of early childhood education to a sustainable society. Paris, France: UNESCO.

Schudson, M. (2006). The troubling equivalence of citizen and consumer. Annals of the American Academy of Political and Social Science, 608 (1), 193-204.

Siraj-Blatchford, J., Smith, K. C., \& Samuelson, I. P. (2010). Education for sustainable development in the early years. World Organization for Early Childhood Education. Retrieved from: http://www.327matters.org/Docs/ESD\%20Book\%20Master.pdf

Steffen, W., Crutzen, P. J., \& McNeill, J. R. (2007). The Anthropocene: Are humans now overwhelming the great forces of nature? Ambio, 36(8), 614-621.

Tsai, W. S. (2010). Patriotic advertising and the creation of the citizen-consumer. Journal Media and Communication Studies, 2(3), 76-84.

University of Victoria. (n.d.). Waste reduction. Retrieved from: http://web.uvic.ca:8080/sustainability/operations/waste.php 
Uyank, O., Inal, G., Çalışandemir, F., Akif, M., Can-Yaşar, M., \& Kandır, A. (2011). New explorations with waste materials in early childhood education. US-China Education Review, A1, 111-118.

Yazbeck, S. (2013). Movement and clay. Canadian Children, 38(1), 47. 